Marco Aurélio Palos Franco

\title{
Uma abordagem baseada em atividades para gestão e determinação de custos do processo na engenharia de requisitos
}

Dissertação apresentada à Escola Politécnica da Universidade de São Paulo para obtenção do Título de Mestre em Engenharia. 


\title{
Uma abordagem baseada em atividades para gestão e determinação de custos do processo na engenharia de requisitos
}

\author{
Dissertação apresentada à Escola Po- \\ litécnica da Universidade de São Paulo \\ para obtenção do Título de Mestre em \\ Engenharia. \\ Área de concentração: \\ Engenharia de Controle e Automação \\ Mecânica \\ Orientador: \\ Prof. Dr. José Reinaldo Silva
}


À minha esposa Evelin, exemplo de dedicação, persistência, amor, carinho e apoio incondicionais. 


\section{Agradecimentos}

Agradeço ao Prof. Dr. José Reinaldo Silva por orientar este trabalho, pela confiança e pelas idéias e sugestões para que este trabalho fosse concretizado.

Agradeço à Estratege Assessoria Empresarial, seus sócios Guiomede Guilardi Filho e Rogério Orsolini por oferecer todo o suporte para o desenvolvimento deste trabalho, agradeço ao colaborador Rubem Marcus Paschoarelli por todo o suporte em relação ao levantamento realizado para o estudo de caso e o fornecimento de alguns materiais de referência para o desenvolvimento deste trabalho e agradeço também ao colaborador Francisco Antonio Bezerra pelo suporte a respeito do uso do sistema ABC.

Agradeço ao colega Heitor Honda Federico por toda a ajuda relacionada ao uso do $\mathrm{HT}_{\mathrm{E}} \mathrm{X}$, no qual foi possível desenvolver esta dissertação.

E finalmente, agradeço a todos, não citados aqui, que direta ou indiretamente contribuiram para a realização deste trabalho. 


\section{Resumo}

No desenvolvimento de um sistema que envolve Software e Hardware, muitas vezes, o que se tem é uma idéia muito vaga sobre o que será feito. Neste sentido, a Engenharia de Requisitos (ER) foi criada para fazer a ligação entre o que o cliente deseja e o que será implantado. O processo de ER sempre foi destacado na literatura por fornecer uma decomposição não linear em relação a ER que cobre desde a concepção inicial do projeto até a especificação dos requisitos. Apesar de estudos sobre o uso da ER indicarem um grande ganho em relação ao desenvolvimento de projetos em termos de prazo de entrega do projeto e qualidade dos produtos finais, muito pouco foi feito a respeito de justificar ao cliente o esforço gasto até a especificação. Nesse sentido, uma análise do custo do processo de ER torna-se importante. Mas, para determinar o custo do processo de ER, deve-se lançar mão de um sistema de custeio em que as atividades são os principais fatores para se fazer uma análise mais adequada. Dessa forma, o sistema de custeio baseado em atividades (ou Activity Based Costing (ABC)) é uma maneira de chegar ao objetivo de fornecer um sistema de custeio adequado ao processo de ER. Assim, este trabalho visa aplicar os conceitos do sistema ABC para todo o processo de ER. Este estudo sugere que o uso do ABC para um processo de ER bem estruturado pode direcionar a uma estimativa de custo mais realística.

Palavras-chave: Engenharia de Requisitos. Custeio Baseado em Atividades. 


\section{Abstract}

During a software and hardware system development, in many times, there is a very opaque idea about what it will be done. In this case, the concept of Requirements Engineering (RE) was created in order to bridge the gap between what the client wishes and what will be implemented. The RE process is always highlighted on the literature as a mean to provide a non-linear decomposition of the $\mathrm{RE}$ which cover from an initial conception of the project to the requirements especification. Despite of studies related to the using of the RE have shown reduction of delivery time of projects and quality gain in the final products, very few have been done to justify to the client all effort until the system specification has finished. In this sense, a cost analysis of the RE process become important. However, in order to estimate a cost of the RE process, it is necessary to use an accounting system which activities are the main factor to provide an accurate analysis from them. In this case, an activity-based costing (ABC) system can provide a way to give an accounting system which is suited to the RE process. Therefore, the goal of the present work is to apply the ABC concepts to the whole RE process. The present work suggests that a well structured RE process can indicate a best actual cost estimation.

Keywords: Requirements Engineering. Activity based costing. 


\title{
Sumário
}

\section{Lista de Figuras}

\author{
Lista de Tabelas
}

\section{Lista de Abreviaturas}

1 Introdução

2 A Engenharia de Requisitos no Ciclo de Vida do Projeto

2.1 Ciclo de Vida de um Projeto . . . . . . . . . . . . . . . . . . 18

2.1.1 Cascata (ou Waterfall) . . . . . . . . . . . . 21

2.1.2 Prototipagem . . . . . . . . . . . . . . . 23

2.1 .3 Incremental . . . . . . . . . . . . . . . . . . . . . . 24

2.1.4 Espiral . . . . . . . . . . . . . . . . . 26

2.1.5 Métodos de desenvolvimento ágil . . . . . . . . . . . . . 26

2.2 Requisitos . . . . . . . . . . . . . . . . . . . . . . 29

2.3 Engenharia de Requisitos . . . . . . . . . . . . . . . . . . . . . . . 34

2.4 O Processo de Engenharia de Requisitos . . . . . . . . . . . . . 35

2.5 Modelos para o processo de Engenharia de Requisitos . . . . . . . 38

2.5.1 Os modelos baseados em pontos de vistas e o Preview . . . 38

2.5.2 Método Volere . . . . . . . . . . . . . . . . . . . . . . . 40

2.5.3 Modelo de Processo de Engenharia de Requisitos . . . . . 41

2.5.4 Process Framework . . . . . . . . . . . . . . . . . . 42

2.5.5 Triagem de Requisitos . . . . . . . . . . . . . 43

2.5 .6 RGM . . . . . . . . . . . . . . . . 44 
2.5 .7 x-RGM $\ldots \ldots \ldots \ldots \ldots$

2.6 As etapas do processo de Engenharia de Requisitos . . . . . . . . 46

2.6.1 Desenvolvimento de requisitos . . . . . . . . . . 47

2.6.2 Gerenciamento de Requisitos . . . . . . . . . . . . 51

2.7 Aspectos práticos do problema do processo de Engenharia de Requisitos ............................... 52

2.7.1 A escolha do método de Engenharia de Requisitos . . . . . 52

2.7 .2 O problema da quantificação . . . . . . . . . . . 53

2.7.3 Dicotomia entre custo e tempo . . . . . . . . . . 55

2.8 Proposta . . . . . . . . . . . . . . . . . 55

2.9 Justificativa . . . . . . . . . . . . . . . . . 56

$\begin{array}{lll}3 & \mathrm{O} \text { sistema } \mathrm{ABC} \text { de Custeio } & 58\end{array}$

3.1 A Contabilidade de Custos e a Abordagem Baseada em Atividades 58

3.2 O uso do ABC no gerenciamento de Projetos . . . . . . . . . . 59

3.3 Definição do ABC . . . . . . . . . . . . . . . . . . 62

3.4 Comparação do ABC com os sistemas tradicionais de Custeio . . 63

3.5 O Funcionamento do sistema $\mathrm{ABC} \ldots \ldots . \ldots 64$

3.6 Componentes do método $\mathrm{ABC} \ldots \ldots . \ldots 66$

3.6.1 Recursos ................... 66

3.6.2 Atividades ..................... 67

3.6.3 Direcionadores de Custos . . . . . . . . . . . 67

3.6.4 Objetos de custeio . . . . . . . . . . . . . 69

3.7 Exemplo didático . . . . . . . . . . . . . . . . . . 69

4 Modelagem do Processo de Engenharia de Requisitos $\quad 75$

4.1 Introdução . . . . . . . . . . . . . . . . . . 75

4.2 Avaliação pela qualidade . . . . . . . . . . . . . . . 76

4.3 Avaliação pela estruturação das atividades . . . . . . . . . . . . 76 
4.4 Método escolhido . . . . . . . . . . . . . . . . . . . . 80

$\begin{array}{llr}5 & \text { Desenvolvimento do Modelo } & 81\end{array}$

5.1 O método Volere do processo de Engenharia de Requisitos . . . . 81

$5.1 .1 \quad$ Blastoff ....................... 82

5.1 .2 Investigação . . . . . . . . . . . . . . . . . . 84

5.1 .3 Especificação . . . . . . . . . . . . . . . 86

5.1 .4 Portal da Qualidade . . . . . . . . . . . . . 86

5.1 .5 Prototipagem .................... 87

5.1.6 Repensar os Requisitos . . . . . . . . . . . . . . . . 88

5.1.7 Post Mortem . . . . . . . . . . . . . . . . . . . . . 89

$\begin{array}{lll}6 & \text { Estudo de Caso } & 91\end{array}$

6.1 Introdução . . . . . . . . . . . . . . . . . . . . . . 91

6.2 Materiais e Métodos . . . . . . . . . . . . . . . . . . . 91

6.2.1 Busca de Informações sobre o projeto . . . . . . . . . . . . 92

6.2.2 Busca de Informações em sistema específico . . . . . . . . 92

6.2.3 Tratamento dos dados levantados . . . . . . . . . . . . 93

6.3 Sobre a Empresa a ser estudada . . . . . . . . . . . . . . . . . 93

6.4 Sobre o processo de contratação de um projeto . . . . . . . . . . . 94

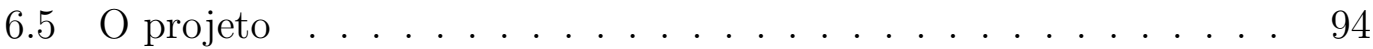

6.6 Informações obtidas . . . . . . . . . . . . . . . . . . . . . . 96

6.6.1 Recursos ..................... 96

6.6.2 Atividades e Horas . . . . . . . . . . . . . . . . . . . . 97

6.6.3 Recursos e Atividades . . . . . . . . . . . . . . . . . . 99

6.7 Ferramenta de Cálculo de custo . . . . . . . . . . . . . . . 103

$\begin{array}{lll}7 & \text { Resultados e Discussão } & 108\end{array}$

7.1 Análise do custo da etapa de requisitos . . . . . . . . . . . . 108 
7.2 Custos implícitos ao projeto . . . . . . . . . . . . 110

7.3 Análise do impacto da fase de requisitos . . . . . . . . . . . 111

7.4 Novo projeto . . . . . . . . . . . . . . . . 112

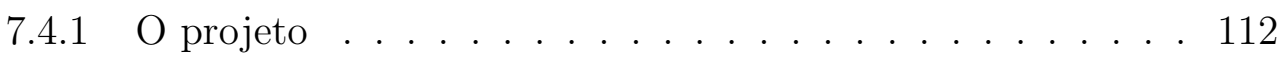

7.4.2 Estimativas ...................... 112

7.5 Considerações sobre o estudo de caso . . . . . . . . . . . . . 113

7.5.1 Critérios ......................... 113

7.5 .2 Busca de Informações . . . . . . . . . . . . . . . . . . 115

7.6 Limitações da abordagem deste trabalho . . . . . . . . . . . . 115

7.6.1 Aplicabilidade . . . . . . . . . . . . . 115

7.6.2 Estimativa de Tempo . . . . . . . . . . . . . 115

8 Conclusões e trabalhos futuros $\quad 117$

8.1 conclusões . . . . . . . . . . . . . . . . . . 117

8.2 Trabalhos Futuros . . . . . . . . . . . . . . . 118

$\begin{array}{lr}\text { Referências } & 119\end{array}$

Apêndice A - Levantamento dos parâmetros do ABC das atividades $\begin{array}{lr}\text { do Volere (Realizado) } & 128\end{array}$

Apêndice B - Levantamento dos parâmetros do ABC das atividades do Volere (Planejado) 135

Apêndice C - Levantamento dos parâmetros do ABC das atividades $\begin{array}{ll}\text { do Volere (Novo projeto) } & 143\end{array}$ 


\section{Lista de Figuras}

2.1 Custo relativo para correção de erros . . . . . . . . . . . . . 20

2.2 Distribuição de esforços durante o ciclo de vida do projeto . . . . 20

2.3 Modelo em cascata proposto por Royce (1970) . . . . . . . . . . 22

2.4 Representação simplificada do modelo "V" . . . . . . . . . . . . . 22

2.5 Representação do modelo de prototipagem . . . . . . . . . . . . 23

2.6 Representação do modelo tipo dente-de-serra . . . . . . . . . . . . 24

2.7 Representação do modelo incremental . . . . . . . . . . . . . . . . 25

2.8 Representação do RUP . . . . . . . . . . . . . . . . . . . . . . . . 26

2.9 Representação do modelo espiral . . . . . . . . . . . . . . . . . . . 27

2.10 Representação do Extreme Programming . . . . . . . . . . . . . . 28

2.11 Representação do modelo scrum . . . . . . . . . . . . . . . . . . . 28

2.12 Estudo da performance de projetos . . . . . . . . . . . . . . 31

2.13 O efeito cumulativo de Erros . . . . . . . . . . . . . . 33

2.14 Estruturação do modelo tridimensional . . . . . . . . . . . . . . . 35

2.15 Processo Preview . . . . . . . . . . . . . . . . . . . 39

2.16 Estruturação do Processo Volere . . . . . . . . . . . . . . . . . . . 41

2.17 Estruturação do modelo proposto por Richards (2000) . . . . . . . 41

2.18 Estruturação do Process Framework . . . . . . . . . . . . . . . . . 43

2.19 Estruturação do Processo de triagem . . . . . . . . . . . . . . . . 44

2.20 Estruturação do Processo RGM . . . . . . . . . . . . . . . . 45

2.21 Estruturação do Processo x-RGM . . . . . . . . . . . . . . . . 46

2.22 Estruturação do processo de Engenharia de Requisitos . . . . . . 47

3.1 Hierarquia de alocação de custos . . . . . . . . . . . . . . . . 62 
3.2 Modelo ABC . . . . . . . . . . . . . . . . . 65

3.3 Representação dos direcionadores de custo no ABC . . . . . . . . 68

4.1 Visão Custo $\times$ Processo . . . . . . . . . . . . . . . . . 78

5.1 Processos do método Volere . . . . . . . . . . . . . . . . . . . . 82

5.2 Subprocessos do método Volere . . . . . . . . . . . . . . . . . . 82

5.3 Estrutura das atividades do processo de Blastoff . . . . . . . . . 84

5.4 Estrutura das atividades do processo de Investigação $\quad$. . . . . . 85

5.5 Estrutura das atividades do processo de Especificação . . . . . . . 86

5.6 Estrutura das atividades do processo Portal da Qualidade . . . . . 87

5.7 Estrutura das atividades do processo de Prototipagem . . . . . . . 88

5.8 Estrutura das atividades do processo de Repensar os Requisitos . 89

5.9 Estrutura das atividades do processo de Post mortem . . . . . . . 89

6.1 Proposta de solução do projeto . . . . . . . . . . . . . . . 95

6.2 Planilha de Recursos . . . . . . . . . . . . . . . . . . . . . . . . 104

6.3 Planilha de direcionadores . . . . . . . . . . . . . . . . . . . . 104

6.4 Planilha de Atividades . . . . . . . . . . . . . . . . . . . . 105

6.5 Janela de inclusão/ exclusão de recursos. . . . . . . . . . . . . . 106

6.6 Janela de inclusão de direcionadores. . . . . . . . . . . . . . . 106

6.7 Planilha de detalhamento de recursos . . . . . . . . . . . . 107 


\section{Lista de Tabelas}

2.1 Projetos Bem sucedidos: Causas Principais . . . . . . . . . . 31

2.2 Projetos Contestados: Causas Principais . . . . . . . . . . . . 32

2.3 Projetos Cancelados: Causas Principais . . . . . . . . . . . 32

3.1 Exemplo de apropriação de custos . . . . . . . . . . . . . . 66

3.2 Atividades, tempo de execução e direcionadores . . . . . . . . . . 70

3.3 Recursos - Custos Fixos Mensais . . . . . . . . . . . . . . 70

3.4 Recursos - Custos Variáveis . . . . . . . . . . . . . . . 71

3.5 Cálculo dos custos unitários para cada atividade em relação aos serviços. . . . . . . . . . . . . . . . . 73

3.6 Cálculo dos custos mensais para cada atividade em relação ao serviço A e B. . . . . . . . . . . . . . . . . . . . . . . . 74

4.1 Relações entre os conceitos de avaliação do processo de Engenharia de Requisitos . . . . . . . . . . . . . . . . . . . . . . 77

4.2 Relações entre os modelos do processo de Engenharia de Requisitos 80

6.1 Informações de Recursos obtidos no sistema GePro . . . . . . . 97

6.2 Informações de custo de Recursos . . . . . . . . . . . . . . . . . . 97

6.3 Informações de Atividades obtidas no sistema GePro . . . . . . . 98

6.4 Informações de Atividades referentes aos requisitos e especificações 98

6.5 Distribuição das atividades do método Volere . . . . . . . . . . . 99

6.6 Distribuição dos recursos em cada atividades referente aos requisi-

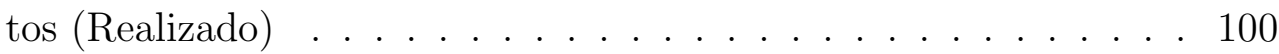

6.7 Distribuição de cada recurso nas atividades referente aos requisitos 101

6.8 Distribuição dos recursos em cada atividades referente aos requisitos (Planejado) . . . . . . . . . . . . . . . . . 102 
7.1 Resultado do cálculo do custo realizado das atividades usando o método Volere . . . . . . . . . . . . . . . . . . . . . . . . . 109

7.2 Resultado do cálculo do custo planejado das atividades usando o método Volere . . . . . . . . . . . . . . . . . . . . . . . . . . . 110

7.3 Resultado do cálculo do custo do novo projeto das atividades usando o método Volere . . . . . . . . . . . . . . . . . . . . . . . . 114 


\title{
Lista de Abreviaturas
}

\author{
ABC Activity Based Costing \\ BOM Bill Of Materials \\ CORE COncern of Requirement Engineering \\ CMM Capability Maturity Model \\ ER Engenharia de Requisitos \\ ICR Índice de Custeio de Recursos \\ Preview Process and requirements engineering viewpoints \\ RGM Requirements Generation Model \\ ROI Return On Investment \\ RUP Rational Unified Process \\ SADT Structured Analysis and Design Technique \\ UML Unified Modeling Language \\ VORD Viewpoint-Oriented Requirements Definition \\ VOSE Viewpoint-Oriented System Engineering \\ x-RGM expanded Requirements Generation Model \\ XP Extreme Programming
}




\section{Introdução}

Para um projeto de sistemas automáticos, incluindo software e hardware, é importante se criar métodos para que o desenvolvimento do projeto seja feito de maneira eficaz e dentro do orçamento previsto (WILLIAMS; HALL; KENNEDY, 1999; WILLIAMS; KENNEDY, 2000). A criação de métodos tem como objetivo saber com precisão o tempo necessário para o desenvolvimento do projeto e também evitar problemas entre o que foi especificado e o que realmente foi implementado. Por esse motivo, o conceito de ciclo de vida é amplamente divulgado em todas as pesquisas relacionada ao gerenciamento de projetos.

Entretanto, antes de focar no objetivo final do sistema, devemos nos preocupar em como a especificação deve ser elaborada mesmo tendo algumas exigências na maioria das vezes ambíguas, imprecisas, incompletas e inconsistentes, já que as especificações sempre partem de uma linguagem mais informal e devem ser "traduzidas" para uma linguagem mais formal para resolver estes problemas (BUBENKO et al., 1994).

Algumas práticas de Gestão de Requisitos tem sido estudada para resolver muitos dos problemas que os Requisitos podem gerar, principalmente nas etapas iniciais. O resultado dessas práticas é demostrado em pesquisas através do ganho em prazo, eficácia e custo que um projeto com requisitos bem definidos possui (MOORTHY, 2005).

Apesar de estudos sustentarem a hipótese de que um modelo de processo de ER mais completo é essencial para fazer uma especificação mais eficaz (MOORTHY, 2005), empresas não seguem estas práticas (MORRIS; MASERA; WILIKENS, 1998; MEAD, 2000; DAVIS; HICKEY, 2002; KAINDL et al., 2002). Um dos motivos é que as empresas não possuem meios práticos de quantificar o esforço desenvolvido para se fazer os requisitos do sistema e dessa maneira, elas preferem já começar a projetar o sistema, mesmo que isso possa causar desperdício de tempo e dinheiro e assim, projetos ainda falham por estar além do orçamento e com pouquíssimas funcionalidades que de fato era o que o cliente desejava. 
O objetivo deste trabalho é propor um método para se estimar o custo referente a etapa de requisitos de um projeto. O custo terá como base o levantamento das atividades necessárias, seguindo um método bem estruturado do processo de ER, neste caso o método a ser seguido é o Volere (ROBERTSON; ROBERTSON, 1999). Com as atividades, a análise de custos será feita usando o sistema de Custeio Baseado em Atividades (ABC).

Além disso, para ilustrar a eficácia do método em relação ao levantamento de custos, um estudo de caso será apresentado. Esse estudo de caso consistirá em um exemplo de um projeto real de uma empresa destacando a etapa de ER. A partir desse estudo de caso, será feito um comparativo entre o que a empresa estimou de custo para cumprir esta etapa e o que o método apresentado nos dirá, de uma forma mais apurada, sobre o custo.

O trabalho seguirá a seguinte ordem. Primeiro será destacado a importância dos requisitos durante o ciclo de vida do projeto, evidenciando os principais problemas enfrentados tanto pela indústria quanto pelos meios acadêmicos, até onde este problema foi resolvido e qual será a contribuição deste trabalho para preencher as lacunas que os métodos existentes não resolveram. Depois, será apresentado como é determinado o custo de um projeto, destacando o sistema ABC, suas vantagens em relação ao ponto de vista de custos e de processos, seus componentes e finalmente com o objetivo de proporcionar um melhor entendimento do sistema $\mathrm{ABC}$, um pequeno exemplo didático será mostrado. A seguir, serão discutidos os métodos existentes para o processo de ER em relação ao ponto de vista de qualidade do método e estruturação de suas atividades, destacando o método Volere e evidenciando o motivo da escolha. Conseqüentemente, o método Volere será detalhado com uma visão de processos/atividades e como serão calculados os parâmetros para o ABC. A seguir será apresentado o estudo de caso, como foram obtidos os dados do projeto estudado e seus resultados. Depois será feito uma discussão sobre os resultados obtidos e o método empregado para a obtenção destes resultados. Finalmente, o trabalho será encerrado com uma conclusão e algumas idéias para estudos futuros. 


\section{A Engenharia de Requisitos no Ciclo de Vida do Projeto}

O foco deste capítulo é apresentar todo o panorama relativo à pesquisa desenvolvida nesta dissertação. Mais especificamente o conteúdo deste capítulo está estruturado para cumprir os seguintes objetivos:

1. Prover uma descrição sobre os mais importantes modelos de ciclo de vida de um projeto, destacando a fase de requisitos;

2. Evidenciar o impacto da etapa de requisitos em um projeto, citando suas causas;

3. Introduzir o conceito de ER e seus objetivos;

4. Introduzir o conceito de processo de ER, sumarizando os problemas enfrentados tanto na indústria quanto no meio acadêmico em relação à adoção de métodos para esse processo;

5. Descrever as etapas do processo de ER e seus problemas específicos de gestão;

6. Apresentar alguns modelos para o processo de ER;

7. Descrever os problemas enfrentados na prática em relação ao processo de ER e onde é necessário focalizar para obter uma solução.

8. Propor uma solução para resolver os problemas relatados no item anterior.

\subsection{Ciclo de Vida de um Projeto}

Com o objetivo de manter a competitividade no mercado atual, indústrias necessitam de sistemas que são capazes de se adaptar rapidamente às mudanças, enquanto mantém suas operações estáveis. A principal barreira para o sucesso 
desta área, entretanto, é resultado das exigências relacionadas com os desejos do cliente para o desenvolvimento de um projeto (ou seja, alta qualidade, personalizável, produtos de baixo custo e que possam ser entregues rapidamente) com a crescente complexidade do projeto (isto é, se estes sistemas são por sua natureza, distribuídos, concorrentes ou estocásticos). Para atender estes requisitos, o conceito de ciclo de vida ${ }^{1}$ de um projeto é amplamente divulgado.

Devido à crescente complexidade de sistemas, os problemas organizacionais aumentam proporcionalmante. Para lidar com os vários componentes de um produto em um ambiente multidisciplinar, a criação deste produtos devem ser divididas em porções gerenciáveis. Tipicamente, este processo é feito através de projetos feitos de forma separada e na maioria das vezes, de maneira concorrente. Exemplos são os componentes de hardware ou software, subsistemas, aplicativos, infraestruturas e prataformas. Com isso, o uso de um modelo simples do ciclo de vida de um projeto torna-se questionável. Portanto, o ciclo de vida sendo a identificação, especificação e a composição estruturada de fases, pontos de alcance, produtos entregues e atividades, define um fluxo lógico para a criação de um produto (MOLL et al., 2002). De um modo geral, com algumas diferenças na estruturação, as etapas são compreendidas por:

- Requisitos

- Desenvolvimento

- Implementação

- Testes

- Manutenção

Das etapas citadas acima, muita atenção tem sido dada para os requisitos, pois é a etapa que influencia todas as posteriores. Requisitos constituem uma das primeiras fases do ciclo de vida de um projeto. Eles são direcionados às necessidades e aos resultados esperados de um projeto, independentemente de sua realização (KOTONYA; SOMMERVILLE, 1996). Os gráficos a seguir mostram o custo relativo de cada etapa em comparação com a etapa de requisitos (figura 2.1) e a distribuição dos esforços durante o ciclo de vida para o desenvolvimento de um software(figura 2.2).

\footnotetext{
${ }^{1}$ No contexto deste trabalho, o termo 'Ciclo de Vida' se refere somente a fase de criação de um produto.
} 


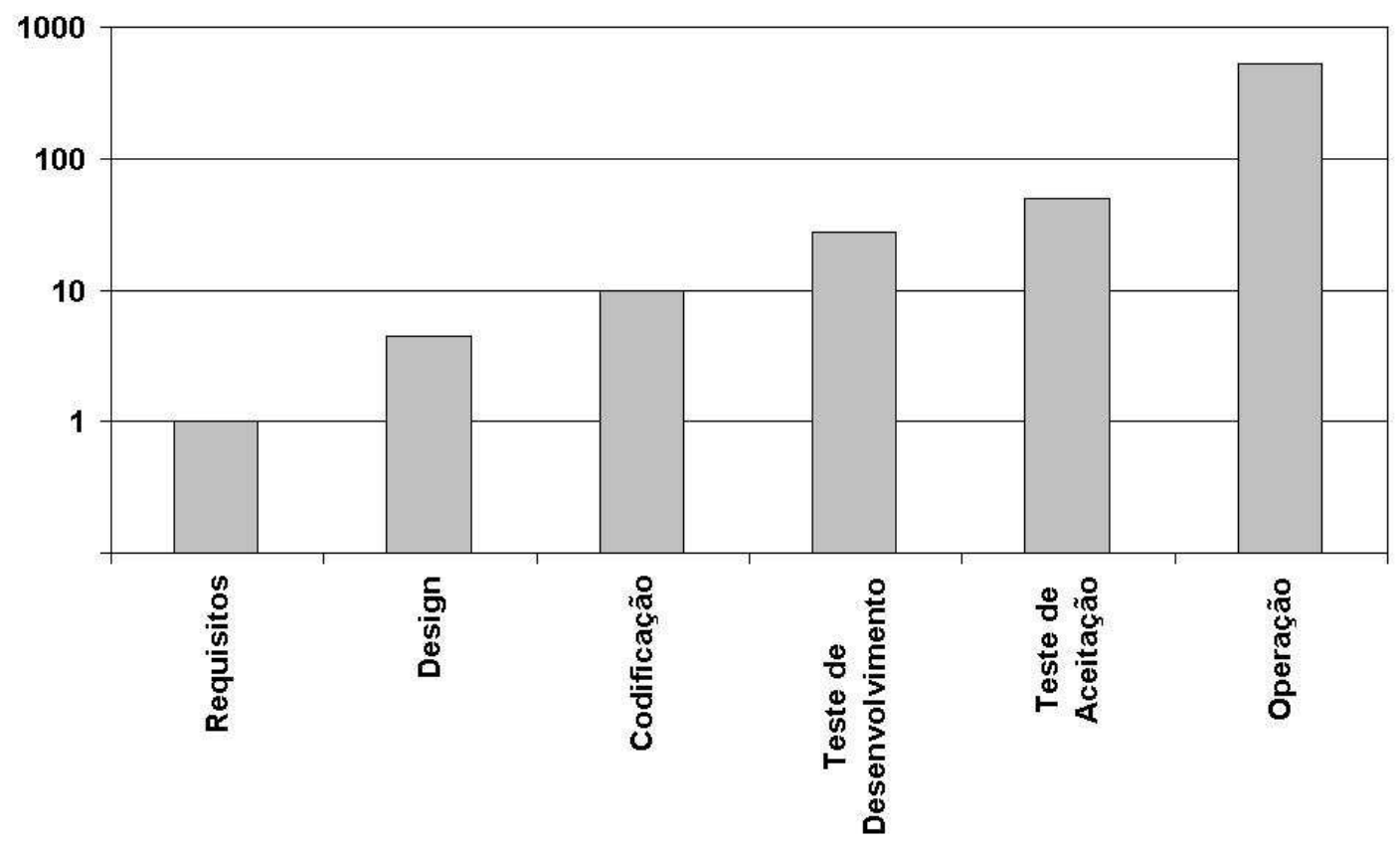

Figura 2.1: Custo relativo para correção de erros. O eixo vertical representa o custo relativo tomando como base a etapa de requisitos (BOEHM, 1981)

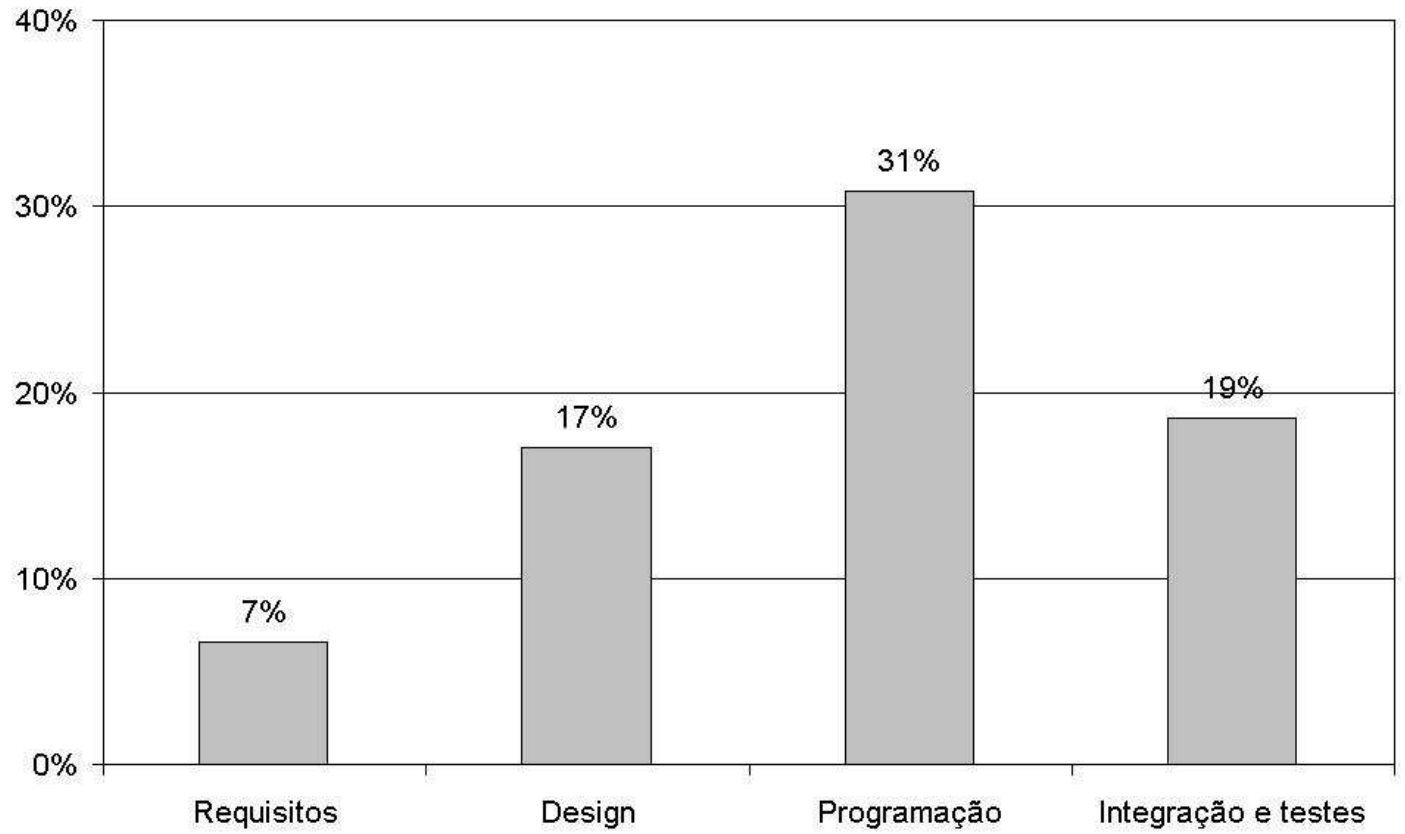

Figura 2.2: Distribuição de esforços durante o ciclo de vida do projeto. O eixo vertical representa a percentagem da distribuição dos esforços em relação a todo o projeto (BOEHM, 1981)

A figura 2.1 mostra que quando o sistema já está em operação, o custo para corrigir o erro chega a ser cerca de 1000 vezes maior comparando-se com a etapa de requisitos. A etapa à qual se dá maior atenção é durante codificação, enquanto o levantamento de requisitos é a etapa menos importante (de acordo com a figura 
2.2). A experiência nas empresas evidencia que a fase de codificação demanda mais esforço por causa do grande volume de trabalho e que mostra resultados mais visíveis. Tradicionalmente, a etapa de requisitos recebe relativamente pouca percentagem dos recursos do projeto durante o ciclo de vida de um sistema, segundo Boehm (1981), a etapa de requisitos recebe $6 \%$ do custo do projeto e de $9 \%$ a $12 \%$ da duração do projeto. Esta tendência foi confirmada por Chatzoglou e Macaulay (1996) que mostraram através de um estudo empírico envolvendo 107 projetos que o custo da etapa de requisitos está aproximadamente entre $5 \%$ e $15 \%$ assim como $15 \%$ da duração do projeto está alocada na etapa de requisitos.

Nos itens abaixo, serão apresentados e examinados alguns modelos de ciclo de vida usado na indústria, algumas variações destes modelos e o papel da fase de requisitos nestes. Devido ao grande número de modelos existentes, serão descritos apenas os modelos mais conhecidos.

\subsubsection{Cascata (ou Waterfall)}

O modelo mais antigo de ciclo de vida de um projeto foi conhecido como stagewise (BENNINGTON, 1956 apud BOEHM, 1986). Este modelo consiste na recomendação de que um software deva ser desenvolvido em estágios sucessivos (plano operacional, especificação operacional, especificação de codificação, codificação, testes paramétricos, testes de integração, organização e avaliação de sistemas).

O tratamento original do modelo em cascata sugere uma abordagem linear, sistemática e seqüencial para o desenvolvimento de sistemas, acrescentando ao modelo stagewise, entre outras coisas, a possibilidade de voltar para a etapa precedente no caso de sistemas complexos (ROYCE, 1970). Muitos problemas da engenharia foram resolvidos através deste modelo, por esse fornecer uma solução racional. A figura 2.3 mostra o modelo em cascata proposto.

O Vorgehensmodell (ou modelo "V") (BROEHL; DROESCHEL, 1995) é uma variação do modelo em cascata no qual a dependência entre as atividades de desenvolvimento e as atividades de verificação são mostradas explicitamente (figura 2.4). A diferença entre o modelo em cascata e o modelo "V", é a noção de níveis de abstração. Todas as atividades desde os requisitos até a implementação consiste em ter uma representação cada vez mais detalhada do sistema, enquanto isso, paralelemente, cada nível de detalhe é verificado.

Analisando estes modelos em cascata, verifica-se que a etapa de requisitos

\footnotetext{
${ }^{2}$ Vorgehensmodell vem do alemão e significa 'Modelo Procedural'
} 


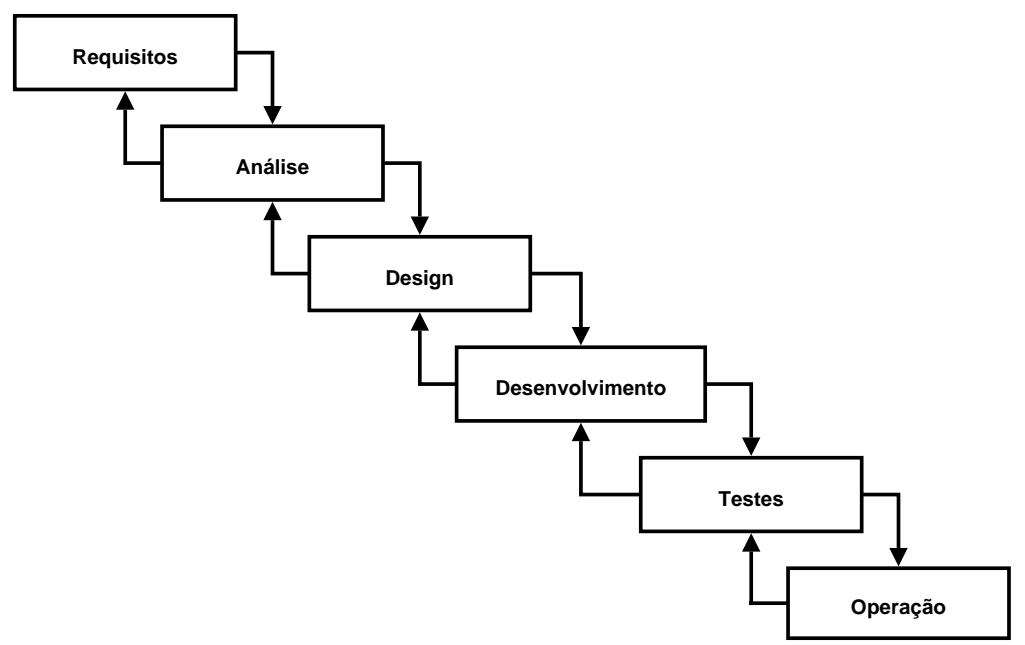

Figura 2.3: Modelo em cascata proposto por Royce (1970)

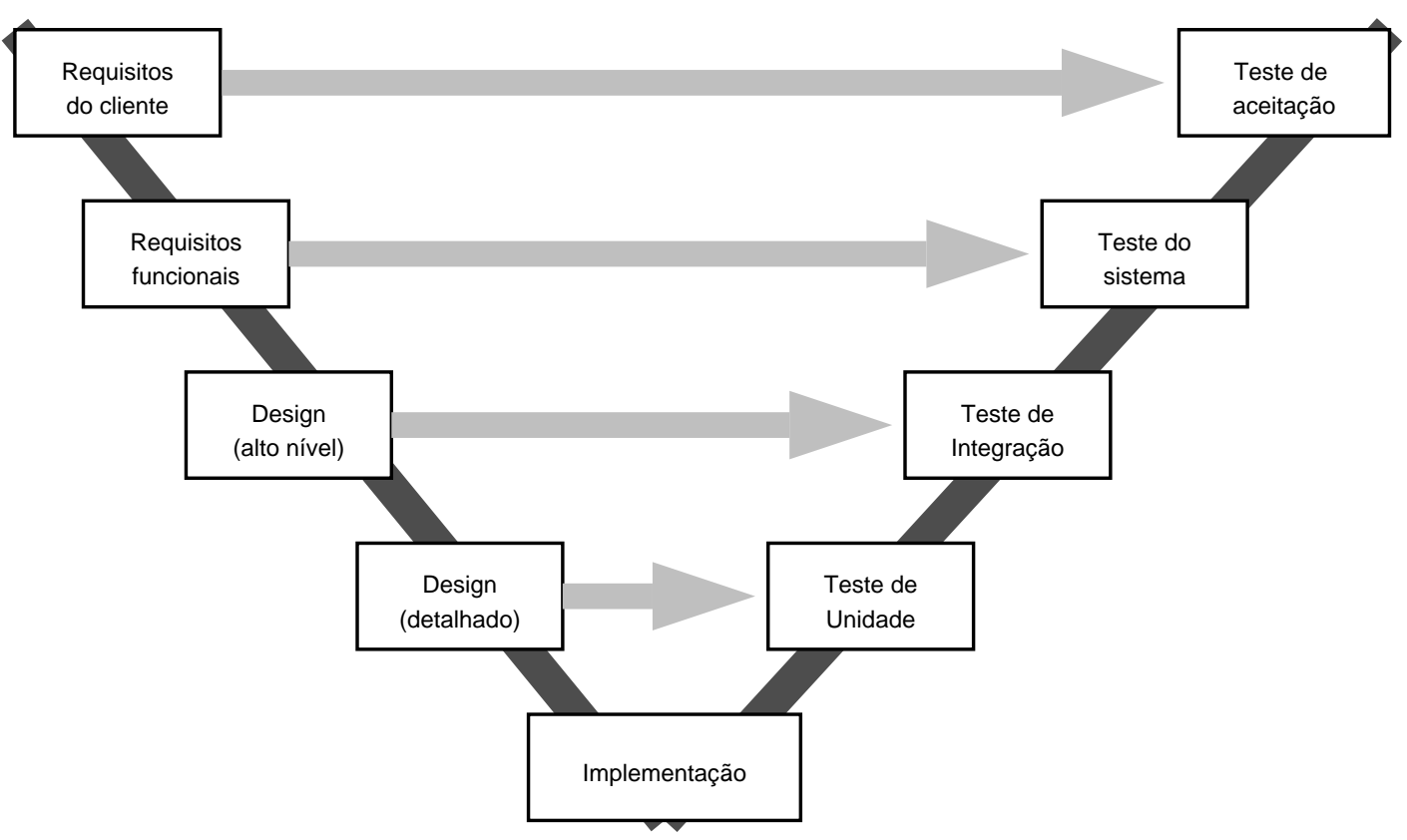

Figura 2.4: Representação simplificada do modelo "V"

aparece no início do processo e que, uma vez definida, não se pode alterar. Dessa forma, este modelo é muito criticado por não oferecer uma representação realística no desenvolvimento de sistemas, principalmente softwares pois é difícil para as partes interessadas do projeto especificar tudo e assim não precisar voltar etapas.

Portanto, estes modelos só são válidos para projetos onde os requisitos já estão bem definidos e não haverá mudanças. 


\subsubsection{Prototipagem}

Para obter uma especificação condizente com os desejos do cliente, o modelo de prototipagem incorpora a iteratividade na etapa de requisitos do modelo em cascata (GOMAA; SCOTT, 1981; HOOPER; HSIA, 1982). A figura 2.5 descreve o processo de prototipagem.

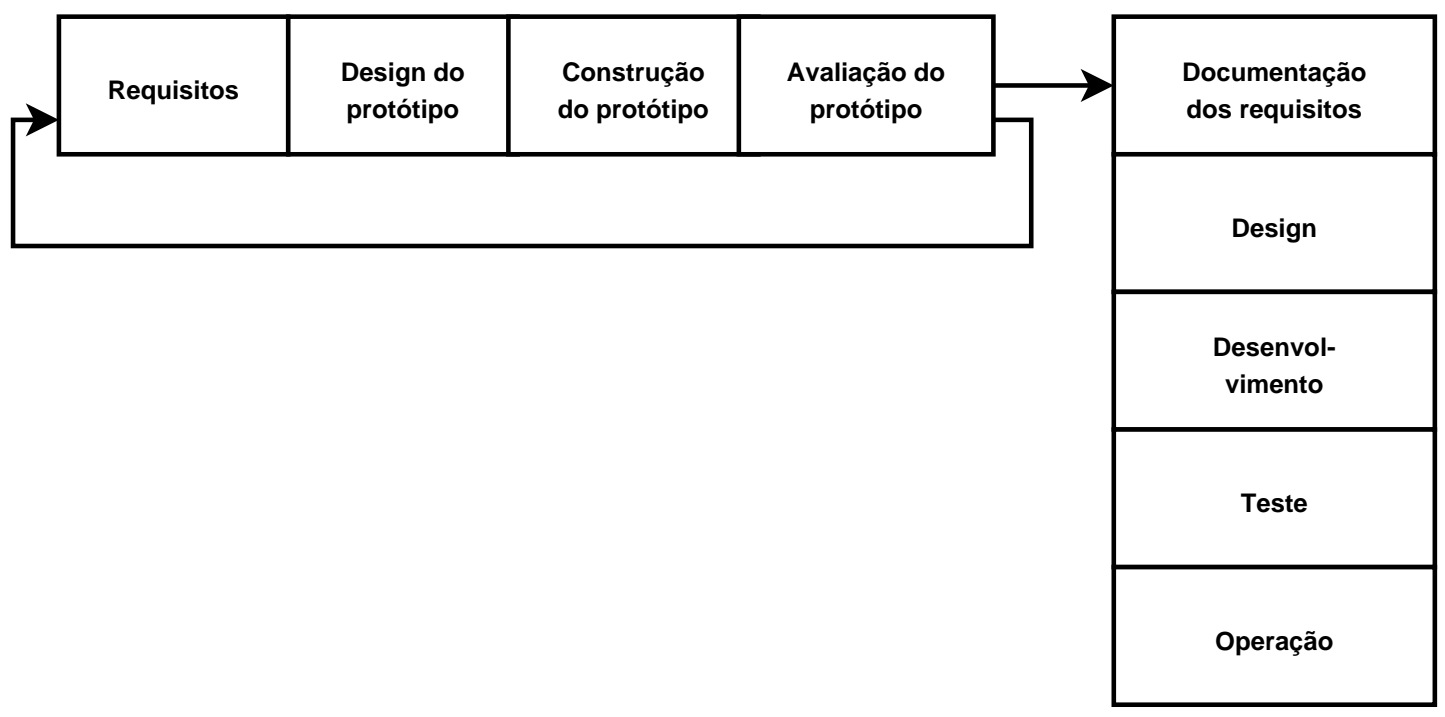

Figura 2.5: Representação do modelo de prototipagem. Este modelo evidencia que a etapa de requisitos deve ser feita de forma iterativa, ao contrário do modelo em cascata em que os requisitos já devem estar definidos no início do projeto.

Esse processo começa com a coleta de requisitos, seguido pela concepção, construção e avaliação do protótipo. Após a avaliação do protótipo, outro protótipo deve ser construído, baseando-se na opinião do usuário. Após a etapa de requisitos, os protótipos são destruídos, pois ele é só uma representação do sistema real. Este modelo não introduz idéias novas em relação ao modelo em cascata, apenas evidencia que a etapa de requisitos deve ser feita de forma iterativa.

Um outro modelo que evidencia os conceitos de prototipagem, mantendo também os conceitos do modelo em cascata é o modelo sawtooth (ou dente-deserra) (ROWEN, 1990). Este modelo, é uma variação do modelo "V" incluindo níveis de abstração dos clientes e desenvolvedores de acordo com cada etapa a ser desenvolvida do ciclo de vida. A figura 2.6 mostra uma representação desse modelo:

O modelo dente-de-serra, provê dois protótipos: Revolucionário e Evolucionário. O protótipo Revolucionário geralmente é ilustrativo, pois esse deve ser construido rapidamente para demostração das funcionalidades do sistema. O protótipo Evolucionário é mostrado em estágios avançados do desenvolvimento do 


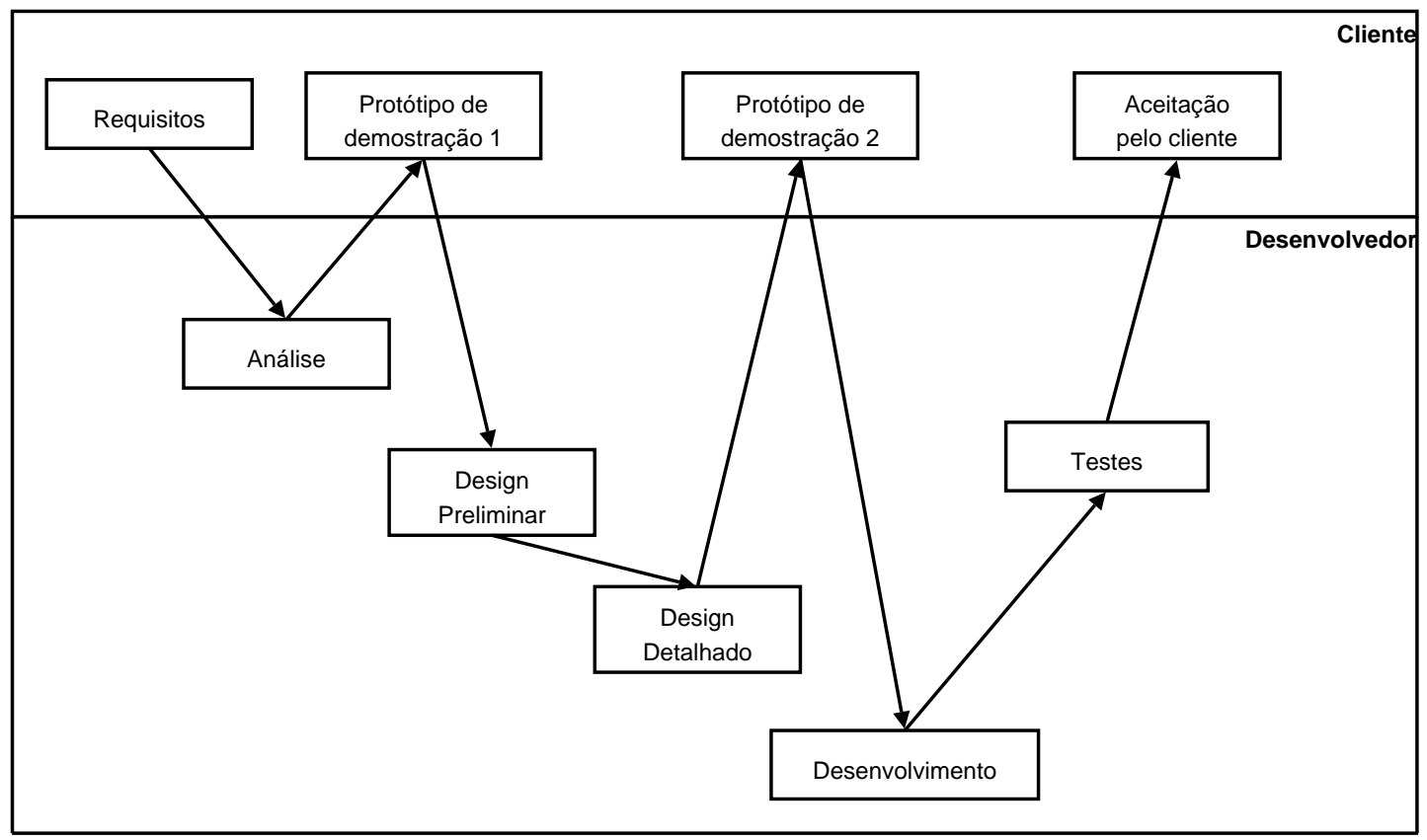

Figura 2.6: Representação do modelo tipo dente-de-serra. Este modelo estrutura as etapas levando em consideração dois pontos de vistas: Cliente e Desenvolvedor.

sistema em que algumas funcionalidades já estão implementadas, este protótipo pode ser incrementado para identificação de possíveis requisitos perdidos ou desconhecidos (CARTER et al., 2001). A distinção principal destes dois protótipos é que o Revolucionário não precisa de um design ${ }^{3}$ completo enquanto o Evolucionário, precisa.

\subsubsection{Incremental}

O modelo incremental combina o processo iterativo de prototipagem com o modelo em cascata (BASILI; TURNER, 1975; LARMAN; BASILI, 2003). A idéia básica é que o sistema deve ser desenvolvido em incrementos e que para cada incremento, são adicionadas algumas funcionalidades para o produto até o sistema ser completamente desenvolvido. A figura 2.7 mostra uma representação do modelo incremental.

O primeiro incremento é o elemento principal do produto no qual está indicado os requisitos básicos. Funcionalidades suplementares são incluídas nos incrementos subseqüentes. Cada vez que as novas funcionalidades são entregues, elas são verificadas pelo cliente e servirão de base para novos incrementos. Este

\footnotetext{
${ }^{3}$ Design vem do inglês e pode ser traduzido como projeto. Mas para não causar confusão entre o projeto em si (que seria a criação de um artefato) no qual é o enfoque deste trabalho, este termo será utilizado para a estruturação de uma solução de um problema.
} 


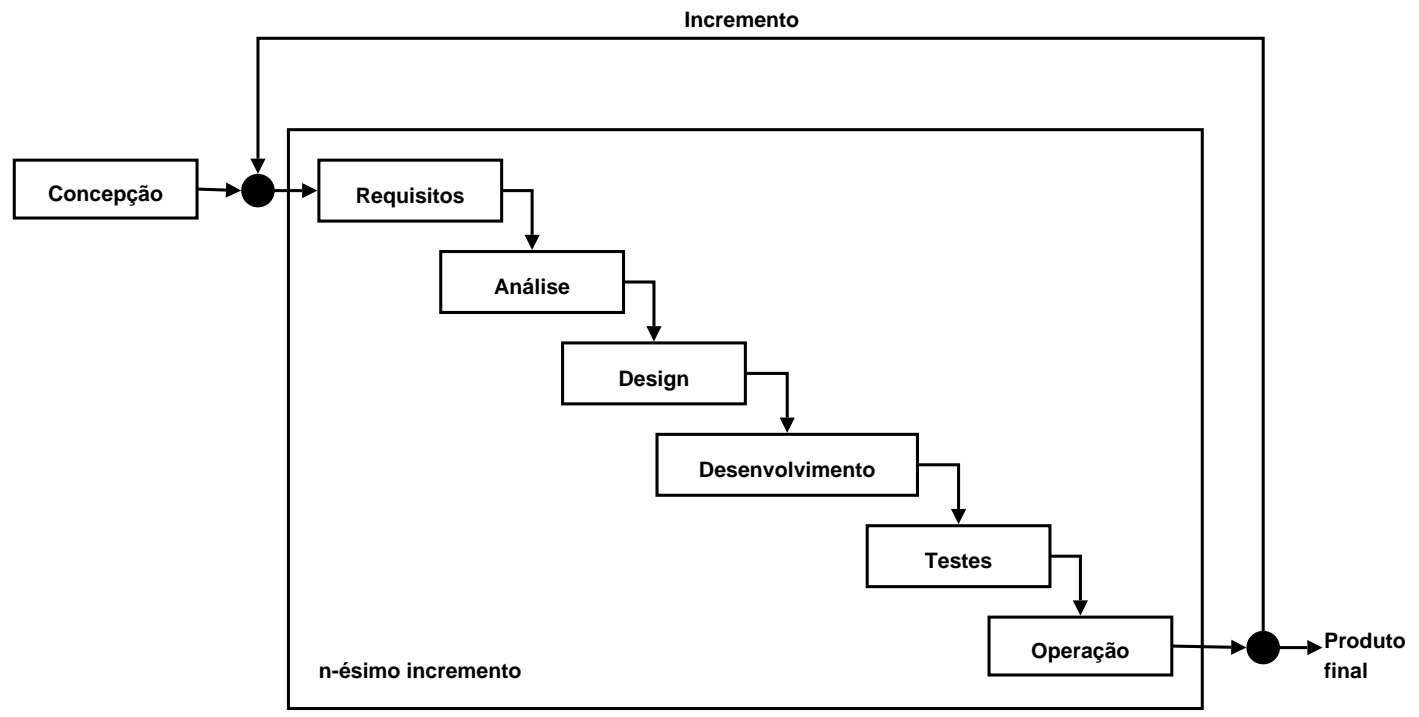

Figura 2.7: Representação do modelo incremental. Este modelo inicia com uma concepção inicial do projeto, seguido pelos incrementos a cada nova inclusão de funcionalidades.

modelo é similar ao modelo de prototipagem com exceção que o incremento é parte do produto final, não sendo descartado.

Diferente do modelo em cascata, o modelo incremental não produz uma especificação completa. Conforme dito anteriormente, o primeiro incremento ainda não possui todos os requisitos, e esses vão surgindo a cada iteração. A especificação completa somente aparece no final do desenvolvimento do produto.

Entretanto, o processo incremental levanta algumas questões como por exemplo, o que definir em cada incremento e como convergir os incrementos para um produto e com que base será feita uma nova iteração (KRUCHTEN, 2003).

Para resolver estas questões, o Rational Unified Process (RUP) (KRUCHTEN, 2003) estrutura o processo incremental. O RUP tenta avaliar o progresso do desenvolvimento do sistema para assegurar que o incremento de fato converge para um produto. O RUP é composto pelas seguintes etapas:

- Início: Especifica a visão final do produto e possíveis extensões do projeto;

- Elaboração: Planejar as atividades necessárias e os recursos exigidos; especificar as funcionalidades e projetar a arquitetura;

- Construção: Construir o produto, estando pronto para entrega aos usuários;

- Transição: Entregar o produto aos usuários, treinar e fazer a manutenção do produto até a satisfação dos usuários. 
Sendo que em cada etapa, são feitos os devidos incrementos de acordo com o produto final da mesma e seguindo um padrão parecido com o representado na figura 2.7. Uma representação do RUP está na figura 2.8. Neste modelo, a etapa de requisitos pode perdurar durante o ciclo de vida do projeto, da mesma forma que o modelo incremental da figura 2.7.

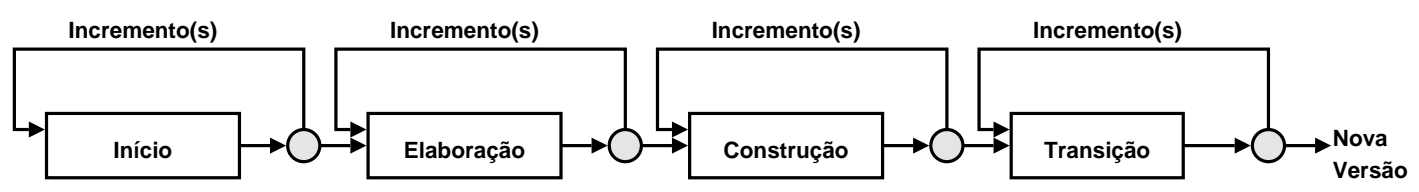

Figura 2.8: Representação do RUP. Este modelo prevê quatro etapas para desevolvimento do produto, e para cada etapa, tem-se seus incrementos (a estrutura dos incrementos são da mesma forma que está sendo representada pela figura 2.7).

\subsubsection{Espiral}

O modelo espiral (BOEHM, 1986) é centralizado nas atividades que atacam a origem da falha do modelo em cascata, ou seja, resolve o problema de mudanças constantes do sistema. Este modelo é baseado nas mesmas atividades do modelo em cascata e nos conceitos do modelo de prototipagem, incluindo, algumas atividades como análise de riscos, reutilização e prototipagem em cada atividade. Estas atividades extendidas são chamadas ciclos. A representação deste modelo está na figura 2.9.

A fase de requisitos no modelo espiral é diferente de outros modelos de ciclo de vida, pois em cada fase, as atividades são identificadas explicitamente em alto nível. Estas fases incluem a comunicação com o cliente, o planejamento, a análise e a avaliação pelo cliente (verificação e validação). Um ponto positivo deste modelo é que na fase de requisitos, está evideciada a iteratividade com o cliente durante todo o desenvolvimento do projeto e o artefato só será construído depois que foram feitas todas as análises possíveis (é claro que neste caso, o custo tende a aumentar). Este é o modelo mais robusto e adequado para sistemas em larga escala e inspirou a criação dos modelos de desenvolvimento ágeis.

\subsubsection{Métodos de desenvolvimento ágil}

Os métodos de desenvolvimento ágil visam reduzir mais ainda o tempo de mudanças de requisitos, em relação ao modelo em cascata e incremental. Nesta 


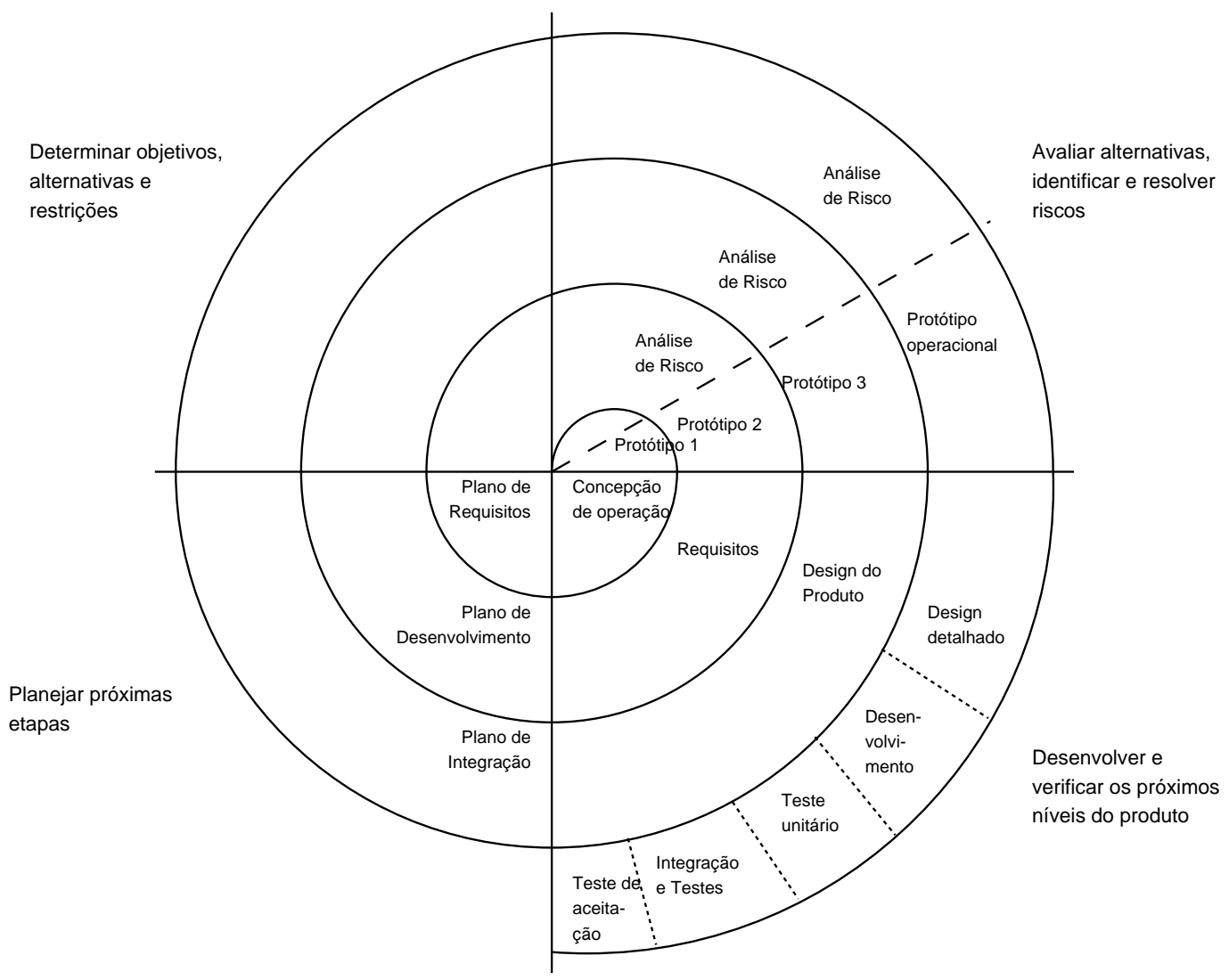

Figura 2.9: Representação do modelo espiral. Cada quadrante do modelo é uma fase a ser executada. Esta notação permite facilmente determinar a situação do projeto no tempo. A distância da origem é o custo acumulado pelo projeto, enquanto as coordenadas angulares indicam o progresso alcançado em cada fase (quadrantes)(BOEHM, 1986).

categoria, destacam-se os modelos Extreme Programming (XP) (BECK, 1999) e o Scrum (SCHWABER, 1995; RISING; JANOFF, 2000).

Também conhecido como "Programação extrema", o XP é composto por várias práticas, entre elas, o cliente participando intensamente no projeto, não há protótipos, inclusão de pequenos incrementos no desenvolvimento do projeto, ausência de documentação, etc, tornando assim o desenvolvimento do sistema mais ágil.

Para a fase de requisitos, esta está implícita do desenvolvimento do projeto. O levantamento de requisitos é feito pelo cliente para obter suas necessidades na forma de cenários/histórias. O desenvolvedor e o cliente, em conjunto, analisam estas histórias e determinam a prioridade destas. Uma vez terminada a priorização, são determinados os casos de testes para cada história e estas histórias são fragmentadas em pequenas tarefas e assim, faz-se o design e o desenvolvimento do sistema. Assim, a fase de requisitos é iterativa, enfatizando no envolvimento contínuo do usuário por todo o processo. 


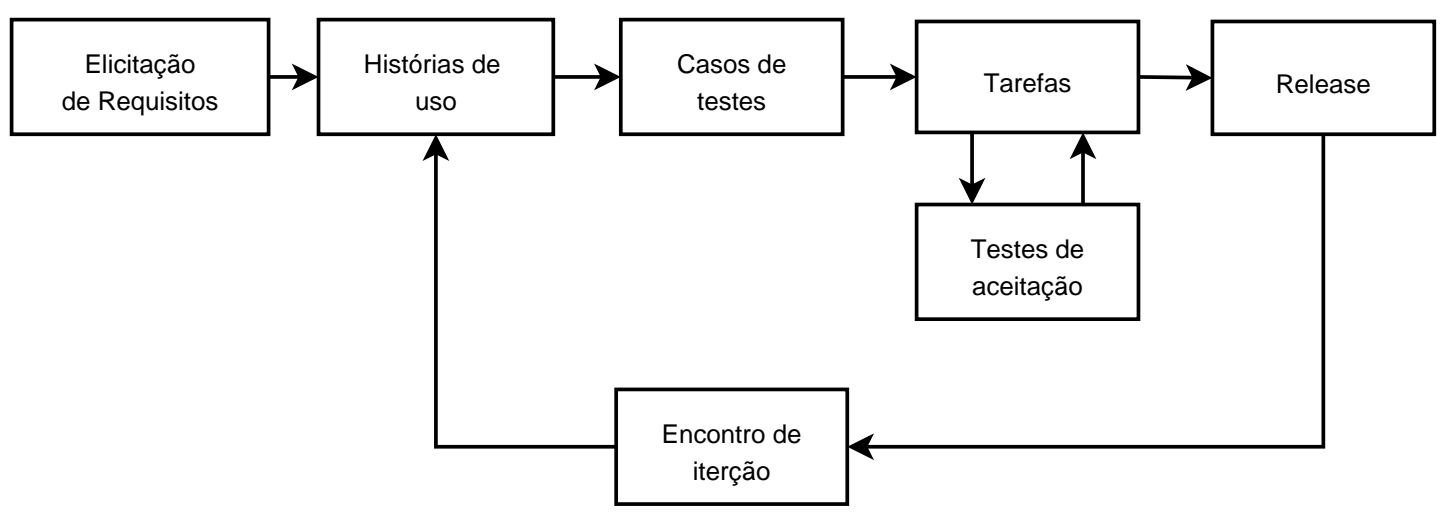

Figura 2.10: Representação do XP

Devido à falta de alguns componentes principais para o desenvolvimento de grandes projetos (como por exemplo, a falta de documentação), o XP é aplicado somente a pequenos e médios projetos.

O modelo Scrum fornece um processo conveniente para o projeto e o desenvolvimento de sistemas orientados a objetos. Assim como o XP, a idéia principal do modelo scrum é obter flexibilidade, adaptabilidade e produtividade no desenvolvimento de sistemas. Uma representação do modelo está na figura 2.11.

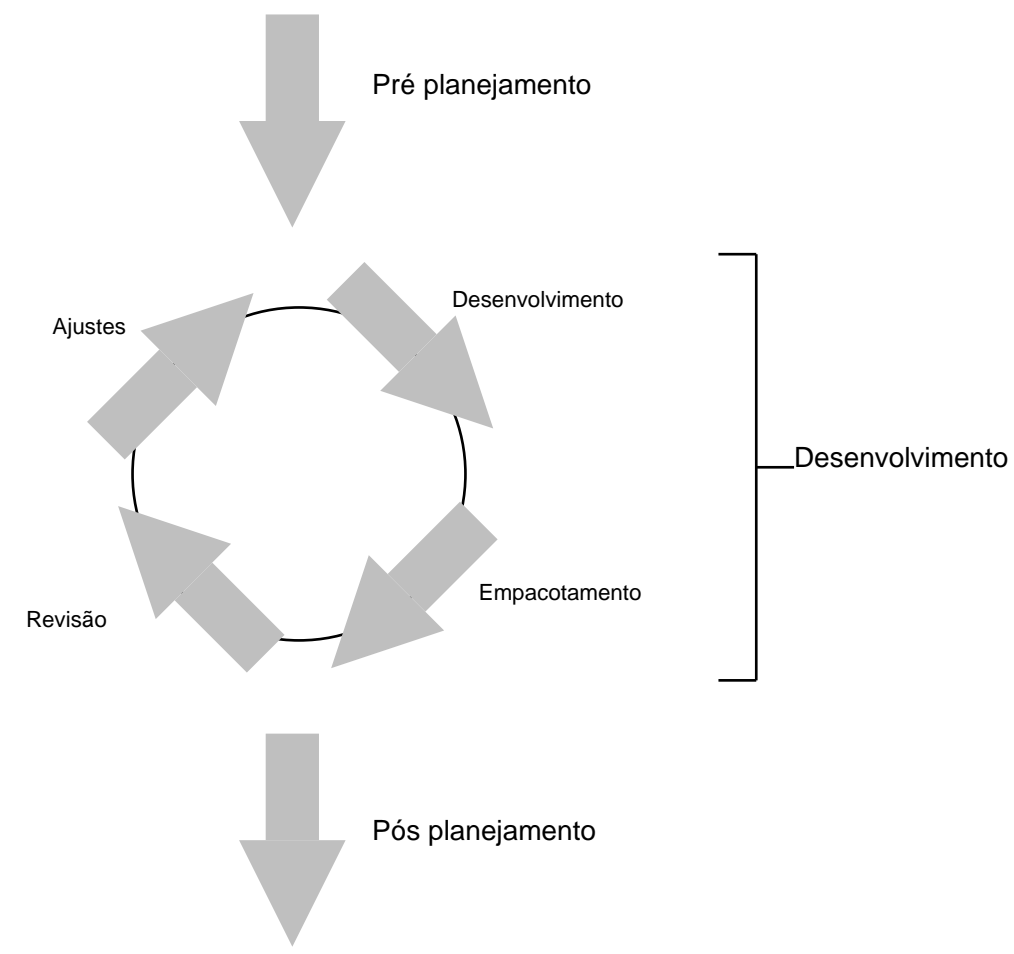

Figura 2.11: Representação do modelo scrum. Esta figura mostra o ciclo de vida de um sprint

Este modelo divide o desenvolvimento em ciclos iterativos (chamados sprints) 
no qual os requisitos estão temporariamente "congelados". Na etapa de préplanejamento, os requisitos são descritos em um documento, priorizados e assim, são feitas estimativas de esforços para o desenvolvimento de cada requisito. Eventuais mudanças nos requisitos descritos na documentação são identificadas, assim como seus riscos.

No desenvolvimento do sistema são criados os sprints e para cada sprint, as variáveis técnicas e do ambiente são identificadas, observadas e controladas. A partir daí, o ciclo é feito de forma tradicional (análise, projeto, implementação e testes).

No pós-planejamento, são feitas reuniões para analisar o progresso do projeto e demonstrar o sistema para o cliente. Além disso, são feitos integrações, testes finais e documentação.

\subsection{Requisitos}

Nos itens anteriores, foram destacadas a etapa de requisitos, sendo evidenciadas em alguns ciclos de vida do desenvolvimento de um projeto. O objetivo desta secção é fornecer uma definição do que são requisitos e sua grande importância para o desenvolvimento de um projeto.

Os requisitos são as descrições de propriedades, atributos, serviços, funções e ou comportamentos necessários em um produto para chegar a um objetivo e a uma proposta de um sistema (CARR, 2000).

Os requisitos do sistema são um fator crucial para que as próximas etapas no desenvolvimento do projeto sejam feitas de maneira eficaz.

Os requisitos estão divididos em dois tipos principais (RZEPKA; OHNO, 1985):

- Funcional: É tudo que o sistema pode fazer (CARR, 2000). Ele captura a natureza da interação entre o componente e o ambiente (KOTONYA; SOMMERVILLE, 1996).

- Não funcional: São as restrições do sistema que devem ser consideradas. (KOTONYA; SOMMERVILLE, 1996; CARR, 2000)

Como o desenvolvimento de sistemas é muito caro, requisitos mal definidos ou incompletos (PARSONS-HANN; LIU, 2005) causam falha no projeto pela programação de atividades e pelo estouro do orçamento. Para um desenvolvimento 
de sistemas ser mais eficaz, deve haver uma visão técnica mais global entre projetistas e programadores e os clientes. Assim, os requisitos devem estar direcionados às necessidades e não devem especificar uma solução de design (CARR, 2000).

O maior problema gerador de falhas no projetos é devido a falta de especificação e também especificações incompletas (PARSONS-HANN; LIU, 2005), já que a etapa de requisitos é considerada nebulosa pois envolve uma idéia vaga sobre o que o sistema faz e por isso, há muitas incertezas (MOYNIHAN, 2000). Além disso, requisitos instáveis afetam negativamente a performance de um projeto (PFAHL; LEBSANFT, 2000). Estudos mostraram que o ponto mais importante que faz um projeto falhar é 'Requisitos pobremente formulados' (KASSER; WILLIAMS, 1998).

Standish Group (1994) realizou um estudo para avaliar a performance de vários projetos. O estudo procurou ser o mais completo possível. Os resultados foram baseados no que foi considerado como "Achados chaves" a partir de pesquisas e diversas entrevistas pessoais. Os entrevistados foram gerentes executivos de TI. A amostra inclui empresas de pequeno, médio e grande porte como bancos, empresas de segurança, seguradoras, empresas de manufatura, empresas de varejo e atacado, serviços e empresas do serviço de saúde. A amostra consistia em 365 entrevistados, representando 8.380 aplicações. Além disso foram destacados quatro grupos de foco e foram incluídas numerosas entrevistas pessoais com o objetivo de fornecer o contexto qualitativo para os resultados do estudo. Segundo critérios como o comparativo entre o prazo de término previsto e o realizado, a diferença entre o orçamento previsto e o realizado e a quantidade de funcionalidades implementadas em relação às especificadas, os projetos foram classificados em três grupos:

- Projetos bem sucedidos: Projetos que foram feitos dentro do prazo e do orçamento e com todas as funcionalidades previamente especificadas;

- Projetos Contestados: Projetos completos e em operação mas concluídos acima do orçamento (o estudo mostrou que o custo médio desses projetos foram de $189 \%$ do custo originalmente determinado) e com menos funcionalidades originalmente determinadas;

- Projetos Cancelados: O projeto foi cancelado em alguma etapa do ciclo de vida durante o desenvolvimento;

Foi encontrado que apenas 16,2\% dos projetos foram bem sucedidos enquanto $52,7 \%$ foram contestados e os projetos cancelados tiveram um índice de 31,1\% (Figura 2.12). 


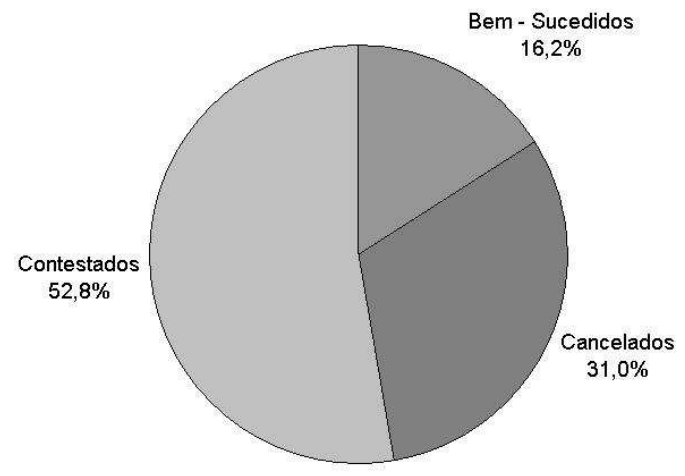

Figura 2.12: Estudo da performance de projetos. O gráfico mostra, segundo entrevistas com diversos gerentes de projetos, a distribuição de tipos de projetos:

Bem sucedidos, Contestados e Cancelados (STANDISH GROUP, 1994)

As Tabelas 2.1, 2.2 e 2.3 mostram respectivamente as causas para os projetos serem Bem Sucedidos, Contestados e Cancelados. Em relação dos projetos bem sucedidos, 'requisitos bem definidos' são a terceira maior causa de sucesso (13,0\% das respostas). No que diz respeito aos projetos contestados, 'requisitos incompletos' constituem a segunda maior causa de falhas $(12,3 \%)$ e 'constantes mudanças de requisitos são a terceira maior causa (11,8\%). 'Requisitos incompletos' são a maior causa de falhas $(13,1 \%)$ e 'mudanças de requisitos' constituem a sexta maior causa de cancelamento de projetos. A soma das causas de falhas relativas a requisitos tanto no caso dos projetos contestados $(24,1 \%)$ como cancelados $(21,8 \%)$ sugerem que problemas durante a fase de requisitos são a principal causa de projetos mal sucedidos. Isto permite especular que o impacto potencial de um requisito pobremente formulado sobre um projeto é substancial (WILLIAMS; KENNEDY, 2000).

Tabela 2.1: Projetos Bem sucedidos: Causas Principais

\begin{tabular}{lll}
\hline & Causas & $\%$ das Respostas \\
\hline 1 & Envolvimento com o Usuário & $15,9 \%$ \\
2 & Apoio Gerencial Executivo & $13,9 \%$ \\
3 & Requisitos claramente definidos & $13,0 \%$ \\
4 & Planejamento Adequado & $9,6 \%$ \\
5 & Expectativas Realísticas & $8,2 \%$ \\
6 & Poucos Pontos Críticos & $7,7 \%$ \\
7 & Equipe Competente & $7,2 \%$ \\
8 & Visões e Objetivos Claros & $2,9 \%$ \\
9 & Equipe Empenhada & $2,4 \%$ \\
& Outros & $19,2 \%$ \\
\hline
\end{tabular}

Um projeto com problemas de requisitos são identificados pelos seguintes 
Tabela 2.2: Projetos Contestados: Causas Principais

\begin{tabular}{lll}
\hline & Causas & $\%$ das Respostas \\
\hline 1 & Falta de Entrada Pelo Usuário & $12,80 \%$ \\
2 & Requisitos e Especificações Incompletas & $12,30 \%$ \\
3 & Mudanças de Requisitos & $11,80 \%$ \\
4 & Falta de Suporte Executivo & $7,50 \%$ \\
5 & Incompetência Tecnológica & $7,00 \%$ \\
6 & Falta de Recursos & $6,40 \%$ \\
7 & Expectativas não realísticas & $5,90 \%$ \\
8 & Objetivos não claros & $5,30 \%$ \\
9 & Tempo Estimado não Realístico & $4,30 \%$ \\
10 & Novas Tecnologias & $3,70 \%$ \\
& Outros & $23,00 \%$ \\
\hline
\end{tabular}

Tabela 2.3: Projetos Cancelados: Causas Principais

\begin{tabular}{lll}
\hline & Causas & $\%$ das Respostas \\
\hline 1 & Requisitos Incompletos & $13,10 \%$ \\
2 & Falta de Envolvimento do Usuário & $12,40 \%$ \\
3 & Falta de Recursos & $10,60 \%$ \\
4 & Expectativas não realísticas & $9,90 \%$ \\
5 & Falta de Suporte Executivo & $9,30 \%$ \\
6 & Mudanças de Requisitos e Especificações & $8,70 \%$ \\
7 & Falta de Planejamento & $8,10 \%$ \\
8 & Não precisarão do produto no momento & $7,50 \%$ \\
9 & Falta de Gerenciamento da TI & $6,20 \%$ \\
10 & Falta de conhecimento tecnológico & $4,30 \%$ \\
& Outros & $9,90 \%$ \\
\hline
\end{tabular}

sintomas (CARR, 2000):

- O sistema falha no teste de aceitação, mesmo se passou no teste de desenvolvimento.

- O projeto passa do prazo,

- O custo do projeto passa do orçamento consideravelmente,

- O volume de retrabalho pelos desenvolvedores é muito alto devido à requisitos vagos, ambíguos, incorreto, inconsistente ou conflitantes,

- Há uma grande quantidade de propostas de mudanças, identificação de problemas e falhas e requisições de novas funcionalidades logo após o sistema estar em produção, 
- O usuário final não consegue entender nem usar todas as funcionalidades do sistema causando um sentimento de rejeição de todo o sistema.

- Muito tempo é necessário para que o desenvolvedor aceite as mudanças do sistema depois de recebido os novos requisitos.

O problema é a dificuldade com a especificação de requisitos. Especificações simplificadas visando o desenvolvimento de um projeto da maneira mais barata possível gera ambigüidades, o que na maioria das vezes, não reflete o que o cliente deseja, de modo que o sistema provavelmente terá que ser retrabalhado (KOTONYA; SOMMERVILLE, 1996).

Alguns problemas não são detectados durante a fase de desenvolvimento, mas na fase de testes e validações. O resultado é um custo muito alto nas últimas etapas do desenvolvimento do projeto. Uma detecção de erros nas primeiras fases do projeto reduz muito o custo do mesmo devido a retrabalhos (KOTONYA; SOMMERVILLE, 1996). A figura 2.13 mostra como um erro nos requisitos pode impactar nas fases seguintes no ciclo de vida do projeto.

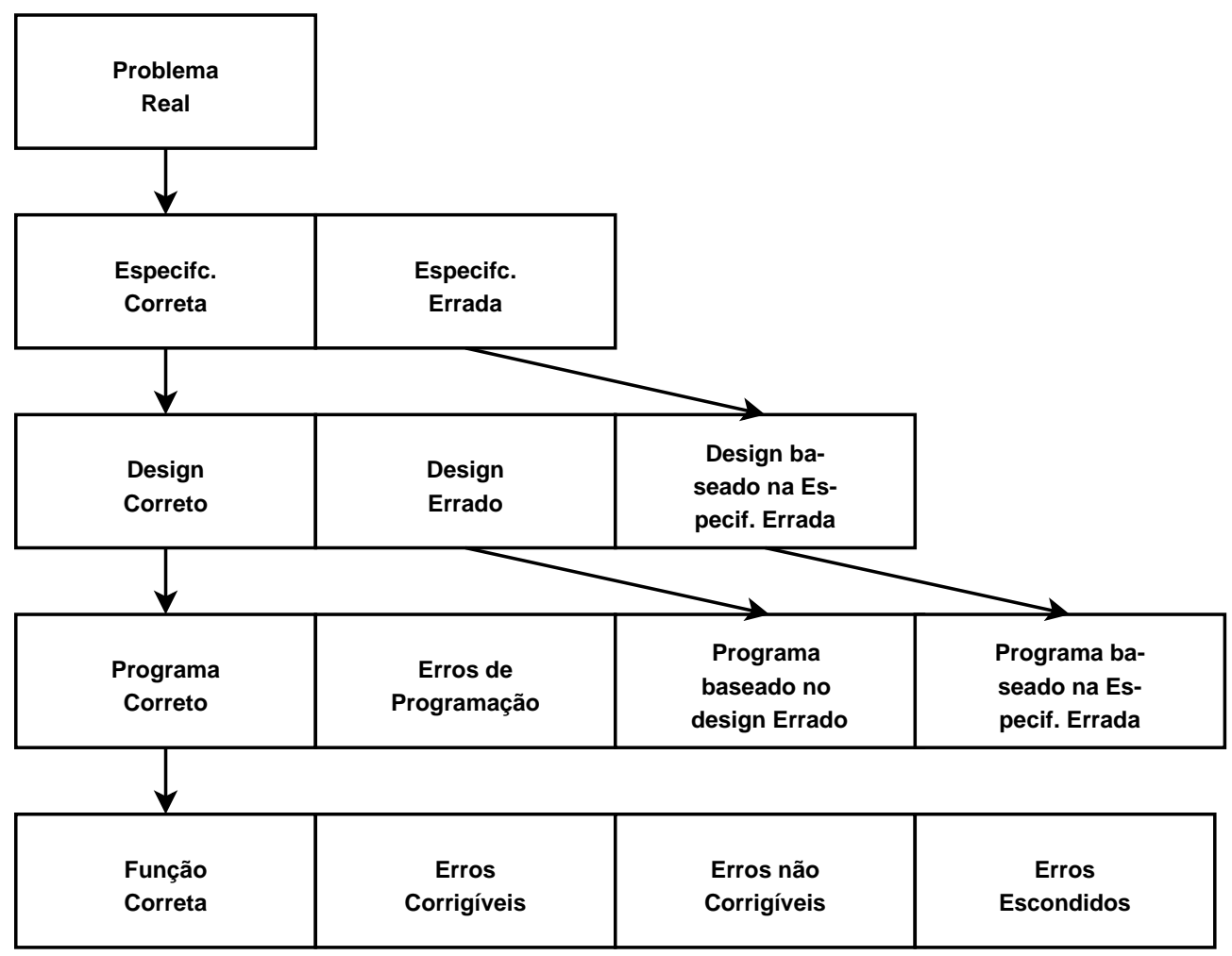

Figura 2.13: O efeito cumulativo de Erros.

Na figura 2.13, quando se inicia uma especificação, esta pode seguir dois caminhos: a especificação pode estar correta, ou seja, era exatamente o que o cliente desejava para o sistema, ou a especificação pode estar errada. Assim, a 
especificação correta pode ser a base para um design correto, mas também a especificação correta pode ser a base para um design errado e um terceiro problema, se a especificação errada não for corrigida, é fazer a etapa de design tendo como base esta especificação incorreta. Após o design, faz-se a programação, nesta ocasião, tendo como base o design correto, ainda pode-se ter uma programação correta ou errada, pode-se ter uma programação que teve como base o design errado e por fim, poderia ocorrer uma programação baseada na especificação errada. Como resultado final a função poderia estar correta, errada (em que o custo de corrigir é baixo), poderia ter uma função baseada no design errado (no qual o custo para corrigir aumenta) e por fim poderia ter uma função baseada na especificação errada (em que o custo para correção aumentaria consideravelmante). Assim, este diagrama mostra que uma especificação errada é muito difícil de ser identificada até a fase de programação pois os erros se mantém escondidos e somente na fase de testes é que estes erros aparecem, causando retrabalho e assim, perda de tempo.

\subsection{Engenharia de Requisitos}

Devido à grande importância que é dada atualmente à etapa de requisitos no ciclo de vida do projeto, foi criado o termo 'Engenharia de Requisitos', onde o termo 'engenharia' envolve gerenciamento, custo, planejamento, modelagem, análise, implementação, teste e manutenção dos requisitos do sistema (WILLIAMS; KENNEDY, 2000).

O objetivo da ER é criar etapas para resolver os problemas relacionados aos requisitos. A figura 2.14 mostra uma representação do modelo tridimensional da ER proposto por Pohl (1994).

$\mathrm{Na}$ "entrada", inicialmente, o conhecimento do sistema a ser construído é grosseiro. Algumas funcionalidedes do sistema são óbvias, enquanto outras existem vagamente na imaginação das pessoas envolvidas no projeto, ou seja estão opacas. Como as pessoas envolvidas no projeto possuem vários papéis, a visão do sistema é diferente para cada envolvido no processo e assim a visão pessoal da existência do sistema é a que prevalece. Além disso, no início dos requisitos, há somente anotações em diagramas, gráficos e/ou escritas em linguagem natural, caracterizando representações informais.

A "saída desejada" prevê que à medida que os requisitos vão sendo feitos, o sistema vai se tornando mais claro, fazendo com que a especificação fique mais completa. A linguagem natural, que inicialmente faz com que as pessoas enten- 


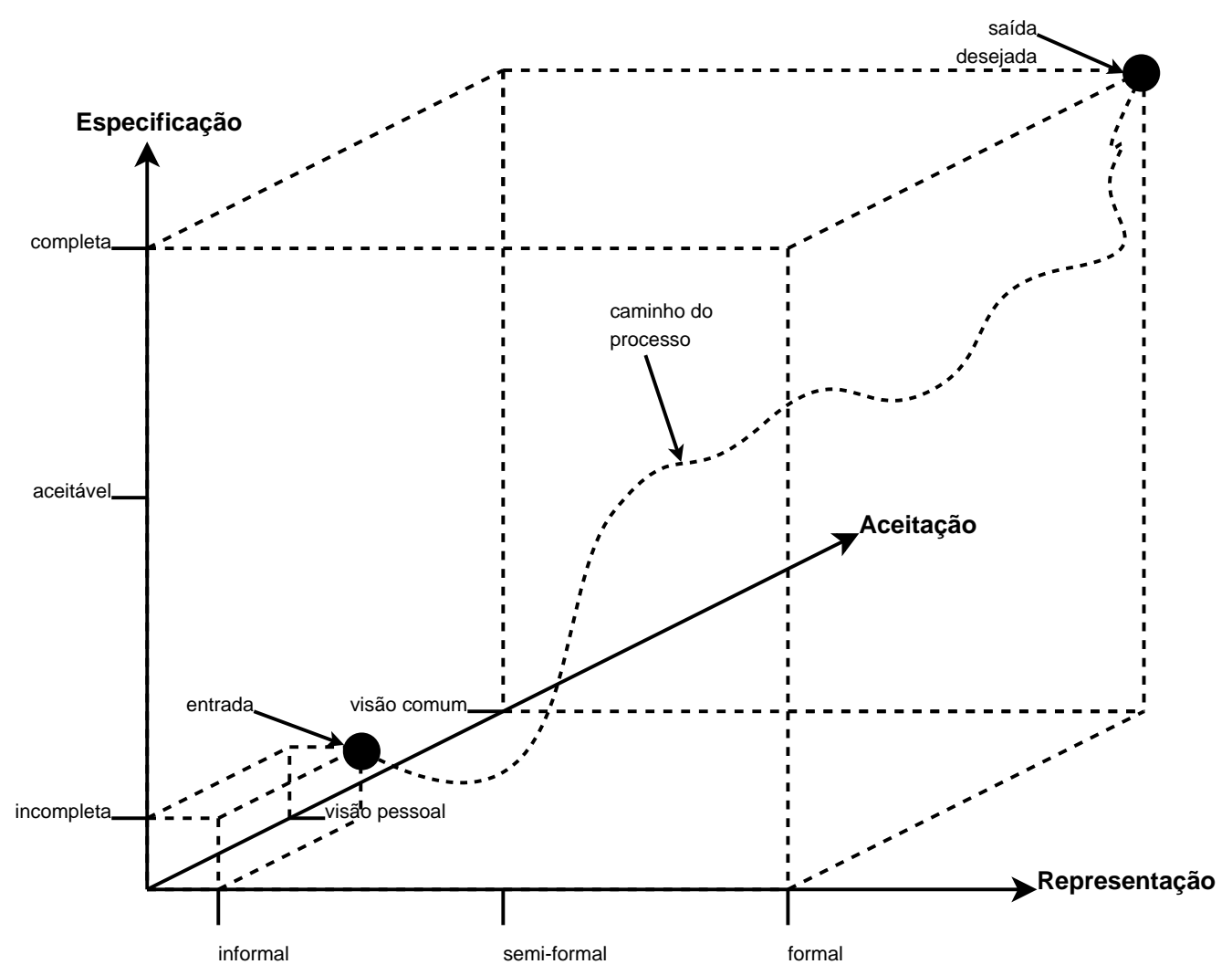

Figura 2.14: Estruturação do modelo tridimensional. O modelo tridimensional prevê três objetivos: 1.Incrementar a compreensão do sistema de maneira opaca para uma especificação completa; 2. Transformar o conhecimento informal em uma representação formal; 3.Adquirir um acordo em comum na especificação ao invés de visões pessoais (POHL, 1994).

dam a mesma especificação de maneira diferente (podendo gerar designs inesperados do sistema), dá lugar a uma linguagem formal que é de comum entendimento das pessoas envolvidas no projeto. E finalmente, a visão pessoal que, devido à conhecimentos específicos do domínio de cada parte envolvida no projeto (gerando inicialmente desacordo entre as partes envolvidas), se transforma em uma visão em que todos concordam com a especificação.

\subsection{O Processo de Engenharia de Requisitos}

O Processo de Engenharia de Requisitos é um termo usado para decomposição da ER em atividades não lineares. O principal objetivo é fornecer um modelo de necessidades de forma clara, consistente, precisa e não ambígua do problema a ser resolvido (KOTONYA; SOMMERVILLE, 1996).

Porém, atingir este objetivo não é uma tarefa fácil, pois em uma organização de relações humanas, para agrupar e conciliar as diferentes considerações, necessidades, exigências e informações, diversos profissionais devem estar envolvidos no 
projeto, tanto no lado do cliente quanto no lado do desenvolvedor, cada um com uma visão diferente do sistema mas todos demandando o mesmo produto. Estes profissionais são a parte interessada no projeto e são denominados Stakeholders. Como um projeto pode envolver diversos Stakeholders, cada um com maior conhecimento de sua área e na maioria das vezes, pouco conhecimento de outras áreas, o processo se torna muito complexo uma vez que é necessário "traduzir" tudo que os Stakeholders desejam.

Em uma avaliação inicial do processo de ER foi encontrado que a maioria das especificações de requisitos ainda eram escritas em linguagem natural (HSIA; DAVIS; KUNG, 1993) já que o desenvolvimento de técnicas, conceitos e ferramentas estavam sendo conduzidos especificamente para requisitos muito complexos de sistemas em larga escala. Com o surgimento da Unified Modeling Language (UML) (RUMBAUGH; JACOBSON; BOOCH, 1999) houve um reconhecimento da importância de uma linguagem padrão de modelagem. Mas isso ainda não foi o suficiente, pois a UML é uma ferramenta de visão de desenvolvimento orientado a objetos que conseqüentemente pode não resolver o problema de ambigüidade (ROBERTSON; ROBERTSON, 2000). Além disso, muitas ferramentas de documentação de requisitos facilitaram o gerenciamento de requisitos e implementaram políticas de rastreabilidade de requisitos. Apesar de haver algumas evidências sobre os benefícios dos resultados do uso da ER em projetos industriais (GREENSPAN; MYLOPOULOS; BORGIDA, 1982; KAINDL, 1997; SOMMERVILLE; SAWYER, 1997b; SOMMERVILLE; SAWYER; VILLER, 1998), a grande maioria das práticas industriais de ER ainda vem de processadores de textos (para compor a descrição dos requisitos em linguagem natural) e ferramentas de desenhos ao invés do uso dos resultados das pesquisas de ER (KAINDL et al., 2002).

Os esforços de pesquisas atuais em muitas vezes têm falhado em fazer os clientes/usuários (e até desenvolvedores) entenderem a real importância técnica, sobretudo na gestão do projeto como um todo. Melhorar a pesquisa para se atingir a eficácia do processo de ER é a peça chave para entender os problemas que vão de encontro com a expectativa do Stakeholder do sistema, a qual espera que o sistema seja feito dentro do prazo, do orçamento e com a qualidade adequada (WILLIAMS; HALL; KENNEDY, 1999; WILLIAMS; KENNEDY, 2000).

Kaindl et al. (2002) identificaram diversos obstáculos em relação à transferência de práticas, técnicas, conceitos, métodos e ferramentas para o processo de ER. Esses foram classificados em dois lados: do lado dos provedores de tecnologia (Academia) e do lado dos usuários de tecnologia (Indústria): 
- Provedores de tecnologia

- Por sua natureza, ferramentas de modelagem e análise desenvolvidas no meio acadêmico não são imediatamente absorvidas pela indústrias, pois as universidades não possuem recursos nem habilidades para lidar com grandes projetos, apesar delas terem papel fundamental na transferência de tecnologia para a indústria;

- Falta de cursos de ER como parte do currículo, fazendo com que os treinamentos relacionados à ER tenham que ser aprendidos na indústria, focando em alguma ferramenta especifica.

- Não há linguagem padrão para especificação de requisitos. No meio acadêmico, é prática comum inventar uma nova linguagem ao invés contribuir diretamente pelo trabalho dos outros, além de pesquisadores limitarem sua atenção para pequenos exemplos acadêmicos para a validação de seus métodos;

- Falta de ferramentas de suporte para novas linguagens e métodos. Mesmo se algumas ferramentas estão disponíveis como protótipos, elas são raramentes robustas, documentadas e escalonadas.

- Grande pressão para transferir tudo que foi pesquisado à prática com o objetivo de justificar o investimento em pesquisa, resultando em ferramentas pouco conceituadas e que não foram testadas, causando um sentimento de desilusão na indústria.

- Usuário de Tecnologia

- Com o ambiente competitivo e prazos apertados, cria-se um sentimento de que não há tempo para testar algo novo, fazendo com que o processo de ER, por sua natureza complexa, deixe de receber a devida atenção.

- Inércia de engenheiros e seus gerentes por possuirem preferência de usar ferramentas já testadas e aprovadas, pois o orçamento de um projeto é direcionado às atividades do ciclo de vida do projeto e esse deve incluir também os novos métodos de ER.

- Falta de suporte técnico, deixando o desenvolvedor perdido e isolado.

- Falta de aproximação do analista de sistema com os conceitos do negócio, aumentando o tempo do ciclo de vida entre a (re)formulação dos objetivos do negócio e a (re)especificação dos requisitos. 
- Dificuldade de lidar com a natureza evolvente dos requisitos, fazendo com que os engenheiros e seus gerentes na indústria sintam que o processo de ER nunca acaba.

- A dificuldade de entender as notações formais e as técnicas de análise faz com que os benefícios do processo de ER não sejam claros de modo que o processo requer muito esforço e muito detalhamento em fases preliminares durante o desenvolvimento.

Nos casos citados acima, é importante ter-se um gerencimento. Mas o gerenciamento geralmente não está consciente do papel estratégico da ER. O envolvimento gerencial e o compromisso com o trabalho de ER é geralmente baixo. Isto implica que o trabalho da ER normalmente não está relacionado com a visão e os objetivos do negócio, com a reengenharia dos processos de negócio e nem com as mudanças organizacionais (BUBENKO, 1995).

Assim, é necessário um processo de gestão especial para os requisitos, com o objetivo de dar a devida atenção à ER. Atualmente, muitos clientes, na sua contratação, já estão separando a fase de requisitos do restante do projeto. Dessa forma, eles garantem que o projeto seja feito dentro das especificações.

\subsection{Modelos para o processo de Engenharia de Requisitos}

Devido a existência de vários modelos para o processo de ER e como neste trabalho, o foco é a análise das atividades deste processo, nos próximos items, serão apresentados alguns modelos orientados por atividade.

\subsubsection{Os modelos baseados em pontos de vistas e o Pre- view}

Os modelos baseado em ponto de vista sempre foram desenhados para que cada Stakeholder entenda o problema a ser resolvido de acordo com suas atribuições e experiência. Estes modelos começaram implicitamente com a Structured Analysis and Design Technique (SADT) (ROSS; SCHOMAN, 1977) e o primeiro método explícito mas ainda fraco, foi a Controlled Requirements Expression (CORE) (MULLERY, 1979). Métodos como o Viewpoint-Oriented System Engineering (VOSE) (FINKELSTEIN et al., 1992) e o proposto por Leite (1989) possuíam uma notação mais definidas de pontos de vistas. 
Os modelos citados acima consideravam os pontos de vistas como processos de subsistemas ou perspectivas internas. O modelo Viewpoint-Oriented Requirements Definition (VORD) (KOTONYA; SOMMERVILLE, 1996) é baseado em entidades onde os requisitos são responsáveis ou pode restringir o desenvolvimento do sistema proposto.

A grande desvantagem é a pouca aplicação prática destes métodos, somente o método CORE é usado efetivamente na prática e mesmo assim o uso deste método é limitado ao departamento de defesa do Reino Unido (SOMMERVILLE; SAWYER, 1997b).

O método Process and requirements engineering viewpoints (Preview) (SOMMERVILLE; SAWYER; VILLER, 1998) visa complementar os problemas existentes nos processos de ER em relação aos pontos de vistas (figura 2.15). O modelos modernos de pontos de vistas costumam ter seus pontos de vistas mais rígidos, fazendo com que a empresa não consiga aplicá-los na fase de requisitos de seu sistema. O Preview ao invés de impor algum tipo particular de ponto de vista ou notação, ele propõe uma abordagem mais flexível no qual acomoda diversos pontos de vistas e permite o usuário definir os pontos de vista de acordo com sua aplicação. (SOMMERVILLE; SAWYER; VILLER, 1998).

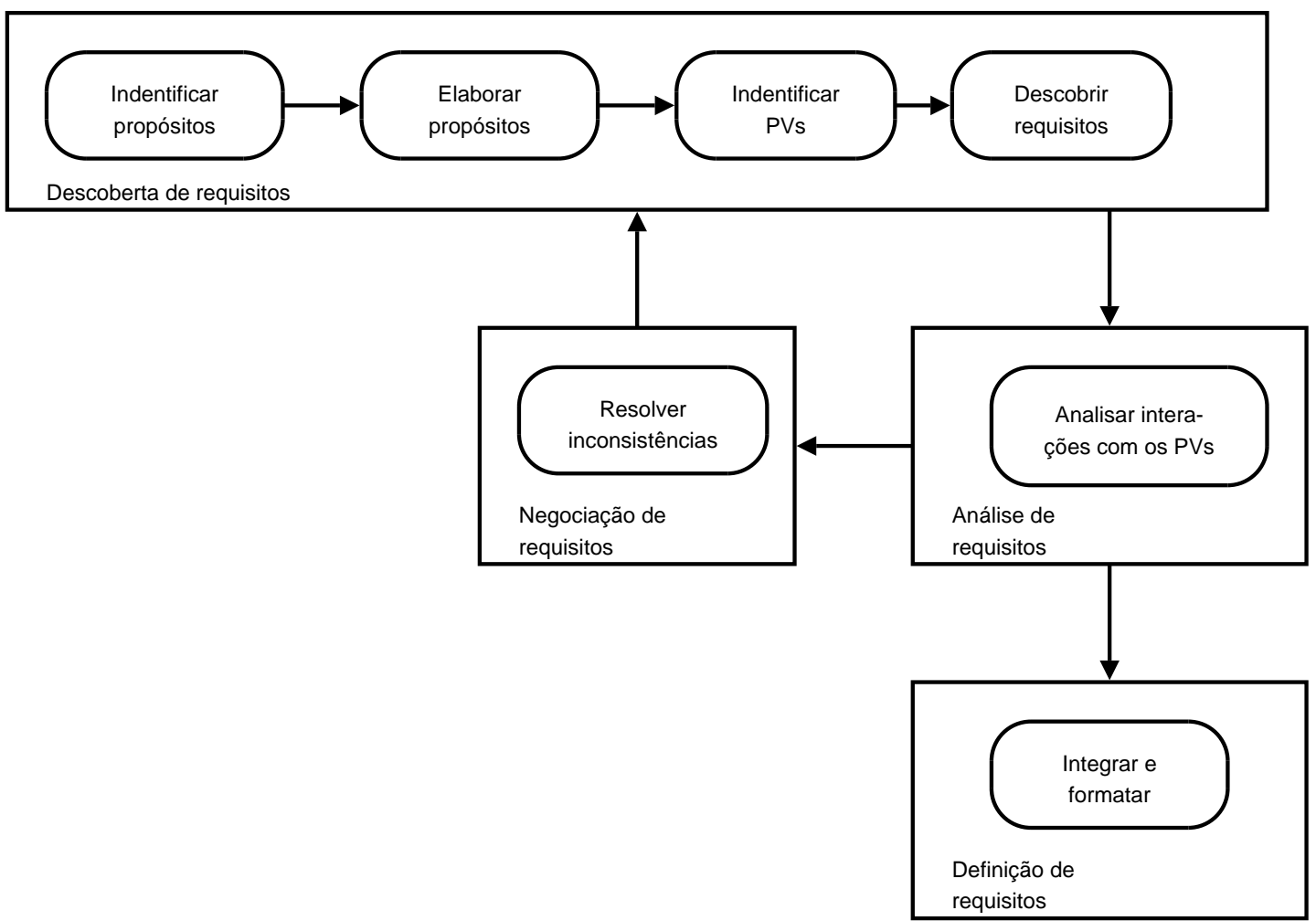

Figura 2.15: Estruturação do Processo Preview.

Além disso, enquanto no VORD, as fronteiras entre as atividades de desco- 
berta, análise, negociação e especificação de requisitos não estão muito claras (SOMMERVILLE; SAWYER, 1997b), o Preview define atividades mais estruturadas dentro dos processos apresentados.

\subsubsection{Método Volere}

O Volere é um modelo completo do processo de ER, com um guia passo a passo para reunir os requisitos de um sistema (ROBERTSON; ROBERTSON, 1999). Este modelo fornece um guia rigoroso para identificar e refinar requisitos, tanto funcionais quanto não funcionais (figura 2.16). O modelo Volere possui os seguintes macro processos:

- Blastoff: consiste em definir Stakeholders, arranjo físico, participação, algumas restrições prévias do projeto e restringir domínio;

- Investigação: é responsável por determinar os requisitos essenciais, levantamento de mais requisitos através de brainstorm ${ }^{4}$ ou entrevista, estudar os sistemas adjacentes;

- Especificação: consiste em escrever os diversos tipos de requisitos e critérios;

- Portal da Qualidade: consiste em filtrar os requisitos previamente levantados, verificando com os stakeholders a qualidade dos requisitos um a um.

- Prototipagem: é responsável por construir um protótipo para verificação e validação quando as informações levantadas não forem o suficiente para o entendimento do trabalho;

- Repensar os Requisitos: possui o objetivo de revisar, unir, identificar requisitos perdidos e interação;

- Post mortem: é responsável por fazer um balanço do processo, pontos a ser melhorados e requisitos que podem ser reaproveitados;

Além disso, este modelo prevê a reutilização de requisitos levantados em projetos anteriores.

Este modelo é muito rico em detalhes e em definições de produtos gerados e o nível de detalhe chega a ser de tarefas.

\footnotetext{
${ }^{4}$ Brainstorm é uma técnica de reunião coletiva de criação. Consiste em reunir pessoas de diferentes especialidades, para a discussão livre e descontraída, onde os participantes podem expor qualquer idéia.
} 


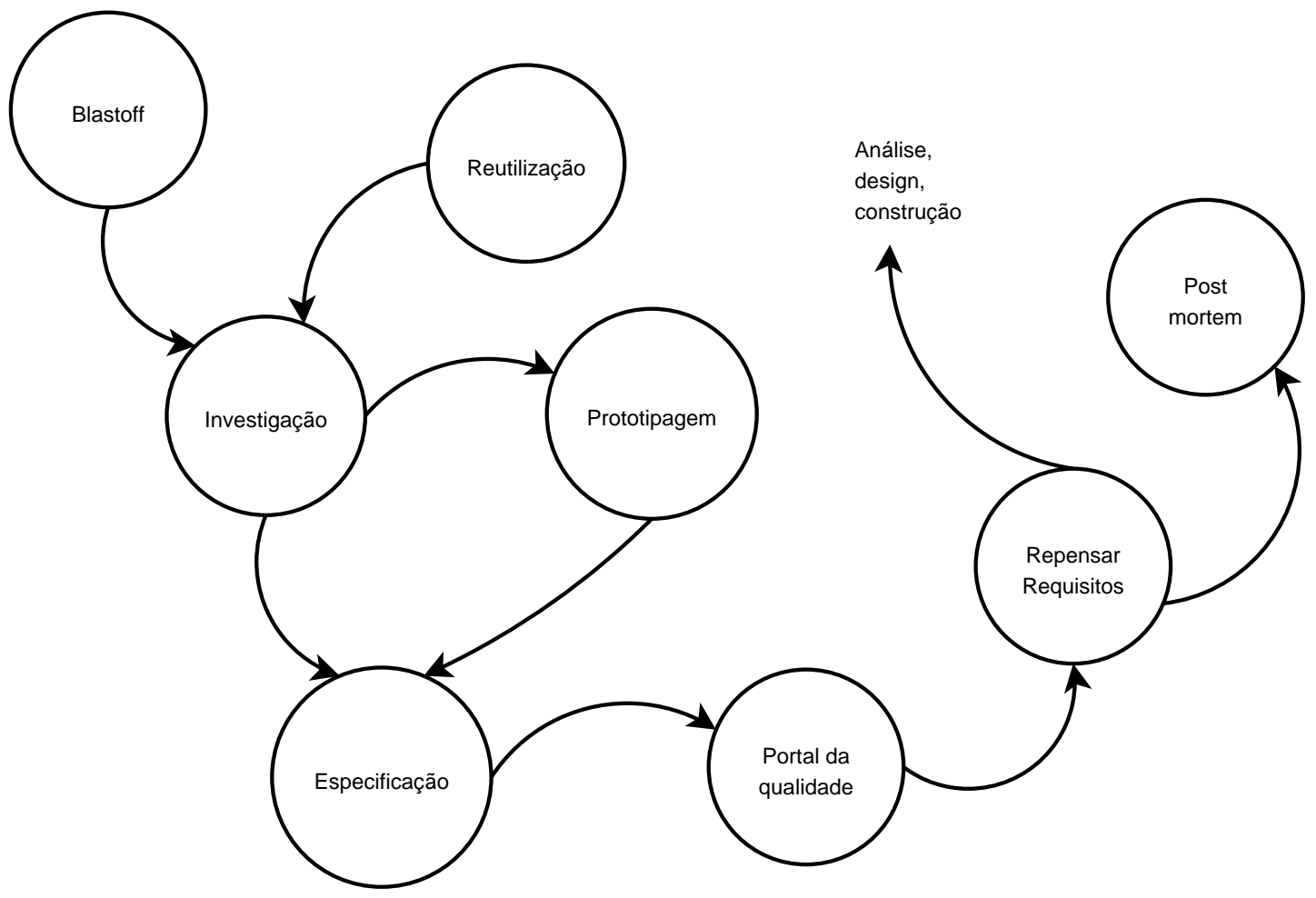

Figura 2.16: Estruturação do Processo Volere. Nesta figura estão representados somente os processos

\subsubsection{Modelo de Processo de Engenharia de Requisitos}

O modelo proposto por Richards (2000) é um meio iterativo que fornece um processo de ER de baixo nível, no qual pode ser expresso em formato de tabelas cruzadas. A figura 2.17 ilustra o processo.

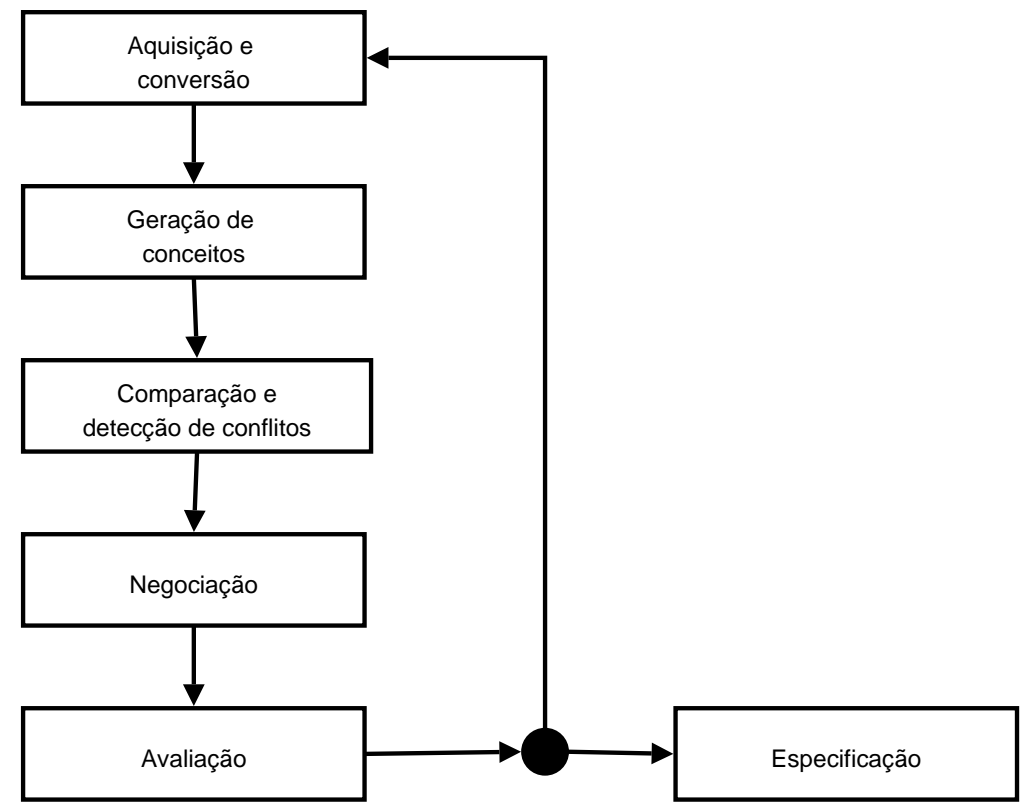

Figura 2.17: Estruturação do modelo proposto por Richards (2000). 
O modelo se concentra nas atividades de levantamento, modelagem e validação de requisitos e é composto pelos seguintes estágios:

1. Aquisição e Conversão: Captura cada ponto de vista individualmente, usando técnicas como descrições de casos de uso ou transcrições de entrevistas. Estas informações ficarão dispostas em uma tabela cruzada;

2. Geração de conceito: As tabelas cruzadas são interpretadas e formalizadas para entendimento de cada ponto de vista;

3. Comparação de conceitos e detecção de conflitos: Comparação em pares entre as diferentes visões para detectar conflitos;

4. Negociação: Resolução de conflitos e transformação dos requisitos para uma visão comum;

5. Avaliação: Determina os níveis de conflito para verificar se os pontos de vistas estão convergindo, identificando a necessidade de uma nova iteração;

O primeiro estágio corresponde a atividade de levantamento no qual está direcionado à aquisição dos requisitos vindo dos modelos das partes envolvidas no projeto, isto inclui comparação de modelos, identificação e reconciliação de conflitos. Os estágios 2 a 5 apóiam a modelagem e validação feitas por cada parte envolvida. O ciclo continua até que uma das partes estiverem satisfeitas com a especificação combinada.

\subsubsection{Process Framework}

O framework ${ }^{5}$ proposto por Alcázar e Monzón (2000) visa resolver a dificuldade de levantar requisitos do usuário e gerenciar o domínio do problema enfrentados na fase de especificação dos requisitos. O Process Framework está estruturado pelas as seguintes atividades (figura 2.18):

- Capturar Requisitos de Usuário: coletar todos os itens de informações (stakeholders, dados);

- Analisar requisitos: criar um entendimento comum entre requisitos, domínio do problema, vocabulário e outras informações relevantes entre os stakeholders;

\footnotetext{
${ }^{5}$ Framework é uma estrutura de suporte definida em que outros projetos podem ser organizados e desenvolvidos.
} 
- Fazer a especificação da solução: expressar o que o sistema deve alcançar de tal forma que o engenheiro de requisitos e o cliente tenham uma visão mais clara do problema a ser resolvido e que este sistema, posteriormente, possa ser aceito por todos;

- Verificar especificação: permite o engenheiro de requisitos confirmar tudo que foi capturado e gravado.

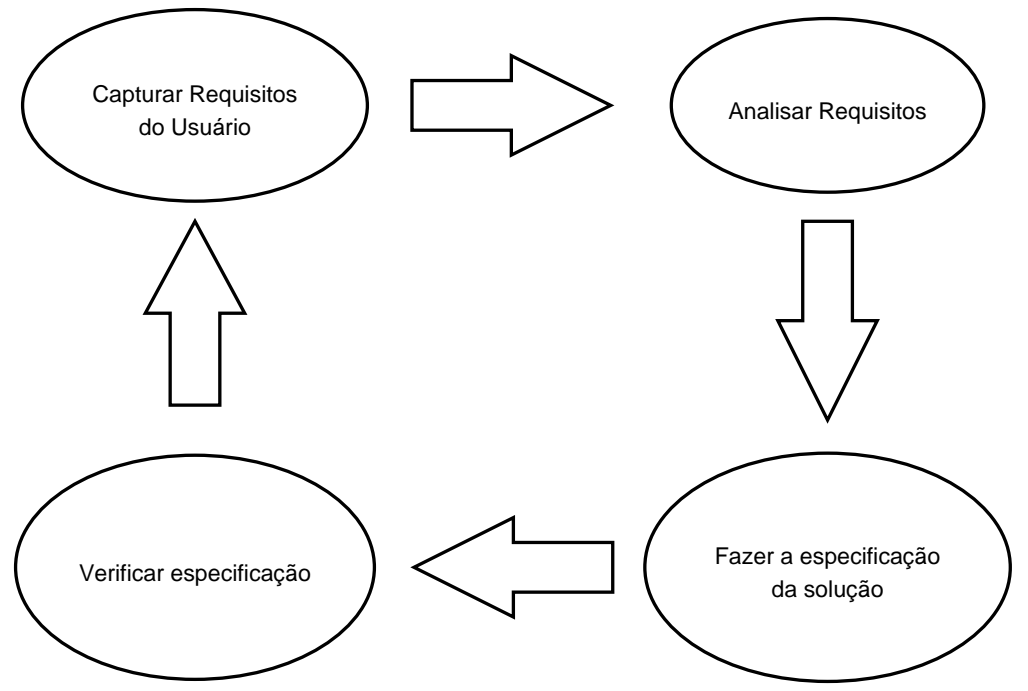

Figura 2.18: Estruturação do Process Framework.

O objetivo deste Framework é construir um modelo de domínio do problema e situar os requisitos de usuários neste contexto, analisando e construindo um entendimento em comum dos problemas do usuário. Além disso, este modelo sugere algumas técnicas para fazer estas atividades de maneira mais eficaz.

\subsubsection{Triagem de Requisitos}

Triagem é o processo de determinar quais requisitos o produto tem que satisfazer dado tempo e recursos disponíveis para executar o projeto (DAVIS, 2003). Este processo visa satisfazer as necessidades do cliente sem comprometer o projeto e suas funcionalidades. O processo consiste em três fases:

- Priorização: Estabiliza prioridades relativas para os requisitos, incluindo também interdependências referentes às prioridades;

- Estimativa de Recursos: Estimar os recursos necessários para satisfazer cada requisito bem como estabilizar interdependências referentes aos recursos; 
- Classificação de requisitos: Selecionar subgrupos de requisitos que otimiza a probabilidade de sucesso do produto no mercado.

A figura 2.19 ilustra o processo. O foco do processo de triagem é a análise de requisitos.

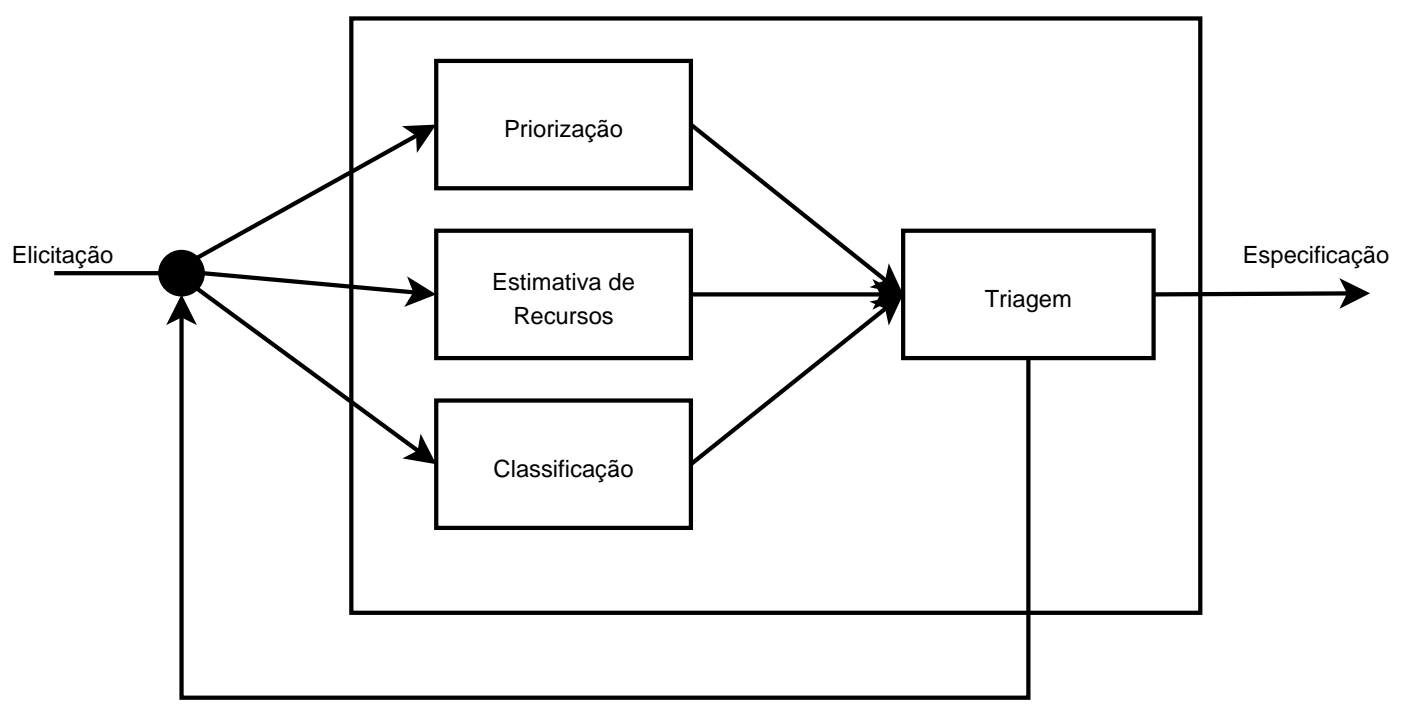

Figura 2.19: Estruturação do Processo de triagem.

A processo de triagem é pouco explorado pela dificuldade de fazê-lo. Outra grande desvantagem é o risco que este processo pode incorrer. Este risco pode expor tanto o lado político quanto o lado financeiro. Do ponto de vista político, a exposição ocorre devido a reivindicações de tarefas como parte da responsabilidade tanto do pessoal de marketing quanto do pessoal técnico e do ponto de vista financeiro um erro na triagem pode causar uma maior perda de dinheiro.

\subsubsection{RGM}

O modelo Requirements Generation Model (RGM) (ARTHUR; GRÖNER, 2005) fornece um framework estruturado para a fase de requisitos e identifica os componentes principais para o processo de requisitos. Este modelo visa corrigir erros provenientes do processo de geração de requistios. A figura 2.20 ilustra o processo.

O modelo RGM é composto pelas seguintes mini-fases:

- Setup: Determina responsabilidades iniciais de cada participante do projeto antes de capturar os requisitos;

- Captura de requisitos: Foca nas atividades que serão identificadas, gravadas e refinadas. Esta mini-fase é iterativa permitindo o refinamento dos requisitos, mas de uma forma não estruturada. 


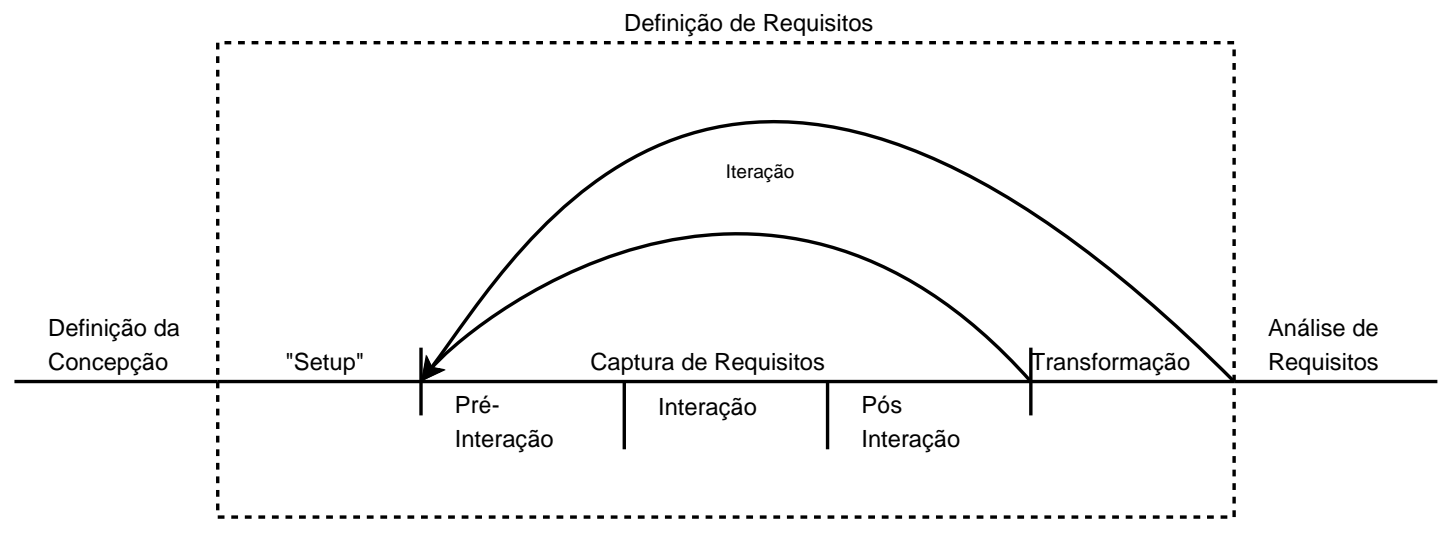

Figura 2.20: Estruturação do Processo RGM. O processo é composto por três mini fases: setup, captura de requisitos e transformação (ARTHUR; GRÖNER, 2005).

- Transformação: Transforma a captura de requisitos na especificação. Os requisitos são examinados pela sua completude, precisão e inteligibilidade e então são classificados;

\subsection{7 x-RGM}

O modelo expanded Requirements Generation Model (x-RGM) (LOBO; ARTHUR, 2005b) visa adicionar uma análise mais apurada ao processo de geração de requisitos. Este modelo possui o objetivo de guiar o engenheiro de requisitos nas tarefas críticas de implementação de um modelo eficaz de geração de requisitos (da mesma forma que o RGM) e selecionar métodos para as várias atividades determinadas pelo modelo. Além disso, este modelo implementa dois tipos de análise durante a geração de requisitos:

- Análise Local: Esta fase iterativa é focada na elicitação ${ }^{6}$, análise, documentação e avaliação de incremento de conjuntos de requisitos;

- Análise Global: Complementa a análise local, concentrando-se na análise do processo de negócio em relação ao conjunto de requisitos;

Uma representação do modelo proposto está na figura 2.21 .

Na Análise Local, o cliente e o engenheiro de requisitos descobrem, revê, articula e avalia conjuntos de requisitos correspondentes à parte funcional do sistema. Isto é feito através de reuniões para elicitação, modelagem, racionalização, organização de requisitos e avaliação de cada requisito.

\footnotetext{
${ }^{6}$ Elicitação: (Do Inglês Elicitation) descobrir, obter informações de alguém sobre alguma coisa obscura
} 


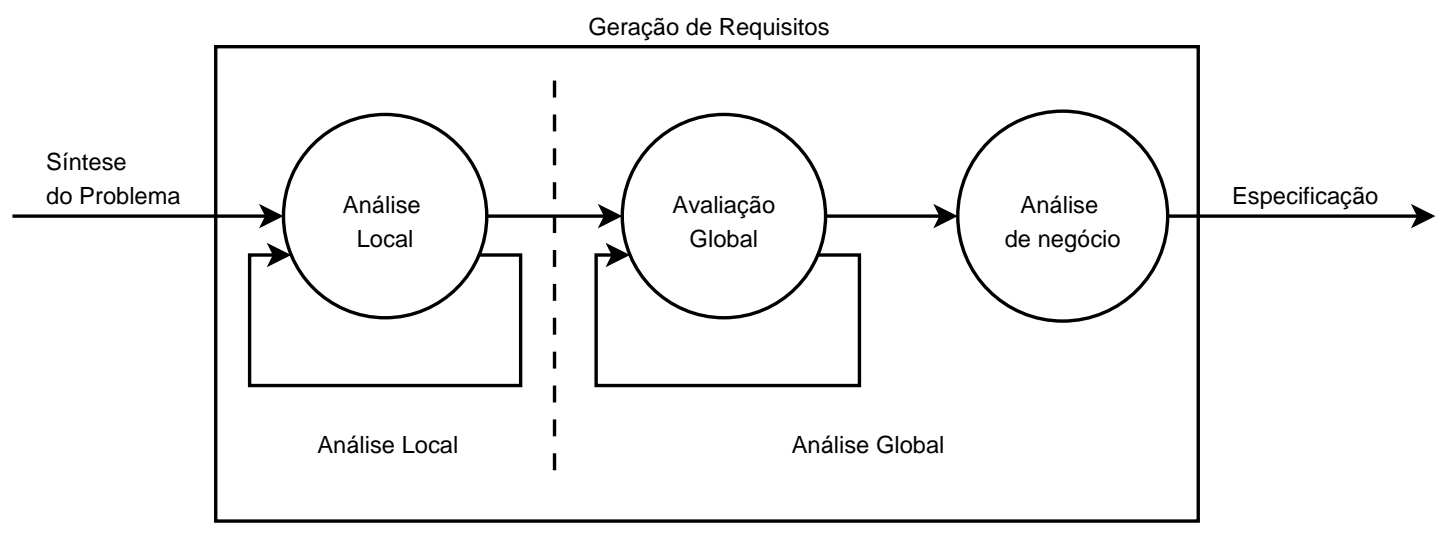

Figura 2.21: Estruturação do Processo x-RGM.

Enquanto na Análise Global, são determinados dois processos:

- Avaliação Global: verificar a qualidade e aderência do requisitos;

- Análise de Negócio: inclui análises de mercado, priorização de requisitos estimativa de cronograma e custos, análise de riscos e preço e avaliação do sistema.

Dessa forma, a verificação e validação são feitas em dois momentos distintos: Individualmente através da análise local (feita desde o início da geração de requisitos) e conjuntamente através da análise global (feita após o levantamento de todos os requisitos). Dessa forma, este processo é importante para que se tenha uma etapa de verificação e validação mais clara (LOBO; ARTHUR, 2005a).

\subsection{As etapas do processo de Engenharia de Re- quisitos}

Na secção anterior, foram discutidos alguns modelos do processo de ER. A partir de informações obtidas anteriormente, as principais etapas do processo de ER podem ser agrupadas em (PRESSMAN, 2005):

1. Desenvolvimento de requisitos

(a) Elicitação

(b) Análise

(c) Especificação

(d) Verificação e Validação 
2. Gerenciamento de Requisitos

Esquematicamente, a figura 2.22 mostra as etapas do processo de ER. O processo de ER consiste na divisão de dois subprocessos (Desenvolvimento e Gerenciamento). No Desenvolvimento, as etapas de elicitação, análise e especificação são de forma cíclica, sendo necessária a verificação e validação para estas etapas. O subprocesso de Gerenciamento dá suporte ao Desenvolvimento.

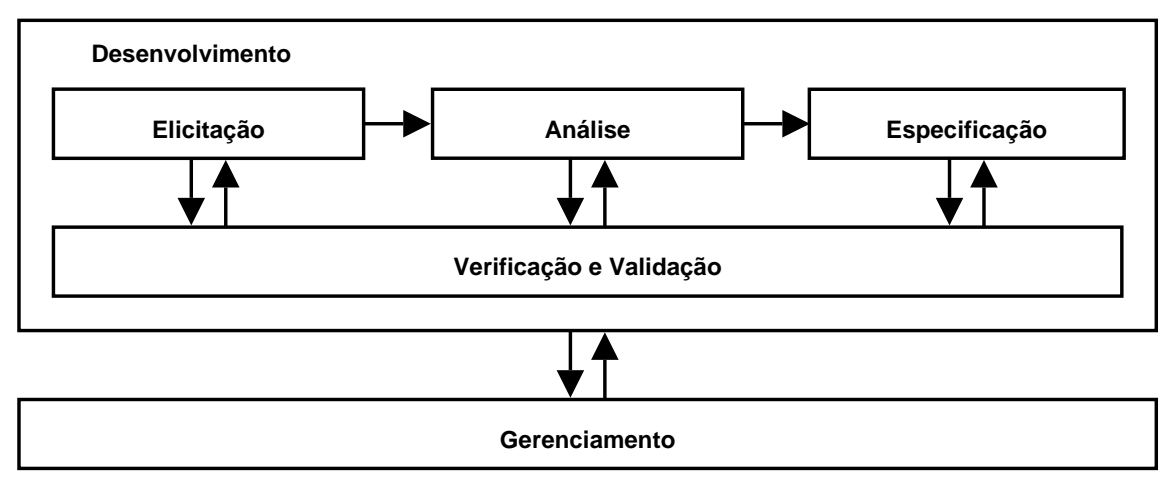

Figura 2.22: Estruturação do processo de Engenharia de Requisitos

A seguir, serão analizadas cada uma das fases e seus problemas específicos de gestão.

\subsubsection{Desenvolvimento de requisitos}

\subsubsection{Elicitação}

O processo de elicitação é um processo interativo onde o cliente lista tudo que precisa. O principal objetivo é fazer com que o engenheiro de requisitos extraia a perspectiva dos usuários finais e de todos o Stakeholders, e que o pessoal de desenvolvimento construa o sistema de acordo com os problemas a serem resolvidos e dentro de suas necessidades.

Os passos principais do processo de elicitação são:

- Identificar as fontes dos requisitos para o sistema como fatores ambientais (fronteiras), documentação organizacional, usuários finais.

- Obter uma "lista de desejos" de cada parte. Esta lista inicial provavelmente será ambígua, conflitante, incompleta, inconsistente e instável.

- Analisar e refinar esta lista inicial. O resultado é uma lista refinada que se poderia chamar de requisitos pois é precisa e não ambígua. 
Vários problemas vêm da elicitação. Estes problemas podem ser divididos em categorias, que são:

- Problema de escopo;

- Problema de entendimento;

- Problema de volatilidade.

O problema de erros durante a fase de elicitação pode-se ser resolvido com o alinhamento dos Stakeholders. Isto garante que todos os Stakeholders possuem um melhor entendimento do processo de requisitos e conseqüentemente, a tarefa de obter uma série de requisitos estáveis e completos se torna mais fácil.

O produto final desta etapa é uma prévia da especificação, mas sem estar formalizada. A etapa de análise justamente verifica tudo que já foi levantado para obter um modelo de especificação.

\subsubsection{Análise}

Análise de requisitos é o processo de analisar as necessidades dos usuários e dos clientes para obter uma definição consistente dos requisitos. Esta etapa inclui representar os requisitos em diferentes formas para facilitar sua análise em diferentes perspectivas. Assim, alguns autores se referem a esta etapa como sendo 'Modelo conceitual' ou 'Modelagem de Requisitos'. As etapas principais da análise de requisitos são: elaborar modelos alternativos para o sistema alvo e negociar o aspecto conflitante do modelo para que o modelo final seja aceitável para o Stakeholder.

A modelagem transforma idéias capturadas durante a elicitação para uma linguagem mais formal. A modelagem realça a comunicação entre o cliente e o engenheiro de requisitos, pois uma representação gráfica é mais compreensível pelo cliente. Assim, qualquer não entendimento dos requisitos serão identificados no início do ciclo de vida do processo de ER. A modelagem também auxilia o engenheiro de requisitos a entender melhor os requisitos e identificar o impacto de mudanças mais rapidamente.

Outro objetivo da análise de requisitos é analisar os requisitos em relação a diferentes perspectivas, as quais vêm da identificação dos atributos, que são:

- Fatores de risco; 
- Importância do requisito;

- Valor do requisito para o produto.

Estes fatores são importantes para avaliar os requisitos contra fatores como risco, custo, programação (NORD; SONI, 2003). Além disso, durante a fase de análise de requisitos, o engenheiro de requisitos deve decidir se o projeto é passível ou não de ser executado.

Outro ponto importante é a identificação de conflitos e a tentativa de resolvêlos. Assim, a participação de todos os Stakeholders é muito importante para se ter um entendimento em comum do que será o artefato.

\subsubsection{Especificação}

Juntamente com a elicitação e análise, é necessário que os requisitos sejam documentados. Durante a especificação, os requisitos estão precisamente e claramente gravados para servirem de base para um contrato entre o cliente e quem irá resolver ou desenvolver a solução do problema. Neste ponto também é importante possuir uma linguagem de especificação.

Uma linguagem de especificação deve aderir às características de qualidade listada abaixo (IEEE, 1998b):

- Precisão: Tudo que for listado nos requisitos é o que o sistema deverá fazer;

- Não ambigüidade: Tudo que estiver nos requisitos possui somente uma interpretação;

- Completude: Os requisitos capturam todos os aspectos do sistema;

- Consistência: Os requisitos listados não possuem conflitos;

- Verificável: As funções dos requisitos devem ser testadas pela performance em um dado tempo;

- Modificável: A estrutura e o estilo dos requisitos devem ser modificáveis tal que suas mudanças possam ser facilmante incorporadas;

- Rastreável: A origem de cada requisito deve ser rastreável. 


\subsubsection{Verificação e Validação}

A Verificação e Validação é uma fase que deve ser desenvolvida em paralelo com as demais fases no processo de ER, garantindo as seguintes vantagens (LOBO; ARTHUR, 2005a):

- Melhora o feedback, pois os Stakeholders possuem ainda claramente os requisitos em mente;

- Mais ágil já que não é necessário ter que revisitar todos os requisitos e analisá-los individualmente.

A verificação assegura a qualidade da especificação para posterior adequação dos requisitos para continuar com o design, construção e teste. A conformidade da especificação com os padrões de documentação é também verificada durante este processo. A verificação também examima os requisitos logo que os mesmos são gerados e determina se possuem os atributos de qualidade desejados.

A validação é o processo que garante que os requisitos capturaram exatamente as necessidades do cliente. O principal objetivo é achar algum desacordo entre o que o usuário deseja e o que os requisitos possuem. Conflitos são identificados para correção dos requisitos com a finalidade de minimizar a probrabilidade de mudanças feitas para a especificação no futuro.

A validação é conduzida depois da verificação em diferentes estágios durante a fase do processo de ER. Durante a elicitação, parte dos requisitos já é verificada e validada pelo usuário. Analogamente, quando se obtém um conjunto de requisitos, a validação é novamente feita. Finalmente, no final do ciclo de vida da ER, a validação é novamente feita na especificação dos requisitos quando são criados os padrões de documentação e os formatos (IEEE, 1998a).

O problema durante a Verificação e Validação vem da falta de alinhamento entre todos os Stakeholders envolvidos (ou seja, o alinhamento entre os pontos de vista). Para evitar problemas é essencial o desenvolvimento de um consenso com todos os requisitos para todos os Stakeholders (KUDIKYALA; ALLEN; VAUGHN, 2004). Além do consenso, a modelagem dos requisitos para validação garante o melhor entendimento do sistema por todos os pontos de vistas (SILVA; SANTOS, 2004). 


\subsubsection{Gerenciamento de Requisitos}

Gerenciamento de requisitos se refere a uma série de procedimentos que auxiliam o gerenciamento do processo de requisitos e o produto requisito, além de fazer a manutenção da evolução dos requisitos durante todo o ciclo de vida do desenvolvimento. A eficácia do gerenciamento é essencial para produzir uma boa especificação de requisitos e conseqüentemente, um produto de boa qualidade.

Projetos com gerenciamento pobre tendem a funcionar além de sua capacidade, fazendo com que sejam abandonadas todas as práticas e padrões para o gerenciamento em favor do ativismo e atitudes ansiosas, os quais tendem a ser um desperdício de recursos (MELI, 1999).

As atividades de gerenciamento incluem planejamento, priorização, rastreamento, tratamento do impacto da mudança do requisito, etc.

O gerenciamento de requisitos segue desde a fase de requisitos até a fase de teste do sistema.

As duas principais atribuições com as quais o gerenciamento de requisitos devem lidar são:

- Rastreabilidade dos requisitos: Um requisito é rastreável se é possível descobrir a origem desse requisito e a relação com outros requisitos e como os requisitos se relacionam com outros artefatos (SOMMERVILLE; SAWYER, 1997b). A rastreabilidade é útil para determinar o impacto da mudança de requisitos sobre o design e a implementação, e além disso, pode facilitar a identificação de inconsistências entre todos os requisitos e as necessidades do usuário.

- Gerenciamento de mudanças de escopo: Naturalmente, requisitos são voláteis, e um gerenciamento de mudança efetivo é necessário. Uma vez que a fase de ER está completa, o gerente de requisitos deve levar em consideração diversas mudanças que podem ocorrer durante o restante do ciclo de vida do projeto. Cabe ao gerente de requisitos identificar as mudanças, analisar o impacto, procurar caminhos alternativos para incorporar as mudanças requisitadas, atualizar as novas especificações de requisitos sem causar inconsistências e finalmente registrar as mudanças. 


\subsection{Aspectos práticos do problema do processo de Engenharia de Requisitos}

Vários estudos, conforme referido anteriormente, mostram falhas que podem ocorrer no projeto quando a etapa de requisitos não é feita adequadamente. No entanto, apesar de existirem diversos métodos que auxiliem o desenvolvimento do processo de ER, ainda há projetos que apresentam problemas. Isto acontece devido não somente ao abismo que ainda separa a pesquisa dos meios acadêmicos (teoria) do que se faz no meio industrial (prática), mas também a outros aspectos práticos, os quais podem ser divididos em três grupos:

- A escolha do método de ER

- A quantificação do Processo de ER

- Com o método escolhido, o que fazer para resolver o problema custo x tempo

A seguir, serão descritos os itens citados anteriormente.

\subsubsection{A escolha do método de Engenharia de Requisitos}

Às vezes, o problema da ER começa na escolha do melhor método para o processo. As causas podem ser a falta de conhecimento dos métodos e como aplicá-los, a falta de experiência por conhecer somente um método, ou achar que se um método funcionou da última vez, pode funcionar outra vez (HICKEY; DAVIS, 2003). Outra causa identificada é que o processo de ER produz somente papéis e não há progresso real até que o sistema esteja em desenvolvimento (CARR, 2000). Uma outra causa é o fato de projetos não atenderem aos reais conceitos do Stakeholders. Dessa forma, as necessidades mais importantes acabam sendo apenas mais um dos muitos requisitos levantados, sem ser dada a devida importância a elas (SAWYER; SOMMERVILLE; VILLER, 1996).

Resultados de estudos de práticas de ER anteriores mostraram que os modelos do processo de ER existentes na prática diferem do que é comumente aceito como processo de ER na literatura (HOUDEK; POHL, 2000; NGUYEN; SWATMAN, 1998). Os processos aplicados na indústria têm mostrado que os modelos de ER sistemáticos e incrementais não refletem em suas práticas, pois estes tendem a funcionar apenas até a chegada de pontos muito complexos durante o desenvolvimento do projeto e a partir daí, a prática torna-se oportunista, com algumas simplificações esporádicas e reestruturações do modelo (NGUYEN; SWATMAN, 1998). 
Hofmann e Lehner (2001) examinaram 15 processos de ER e encontraram que a maioria dos participantes disseram que a ER é um processo ad hoc (ou seja, um processo específico para a ER), enquanto somente alguns usam processos padrões de ER. Martin et al. (2002) mostraram que o uso dos métodos de ER depende da complexidade do projeto e algumas atividades tendem a ser implícitas, explícitas ou inexistentes, tendo como base, modelos de processo de ER já consolidados. Em oposição a esses achados, Emam e Madhavji (1995) concluíram que as organizações tendem a usar processos de ER padrões quando são questionados sobre melhores práticas.

A classificação por qualidade determina se o processo de ER possui todos os atributos necessários. Neste caso, os padrões, práticas, conceitos e níveis de capacidade tentam auxiliar o engenheiro de requisitos a verificar se o método escolhido cobre tudo que é importante no processo de ER (GAUSE; WEINBERG, 1989; SOMMERVILLE; SAWYER, 1997a; GASKA; GAUSE, 1998; JIANG; EBERLEIN; FAR, 2004a).

Além disso, o modelo x-RGM e o Process Framework tentam decompor o processo de ER em atividades, e para cada atividade, são sugeridos métodos para contemplá-las. Isto garante que o engenheiro de requisitos verifique através destes modelos, a adequação do processo para sua aplicação.

Outro modelo tem como objetivo analisar o processo de ER usando dinâmica de sistemas (WILLIAMS; HALL; KENNEDY, 1999). A dinâmica de sistemas permite através de indicadores como qualidade, custo, recursos e programação, saber as conseqüencias de uma diminuição ou aumento de um destes indicadores. Dessa forma há uma melhoria da eficácia do processo de ER.

\subsubsection{O problema da quantificação}

A falta de meios para medir os esforços do processo de ER e portando determinar uma maneira de "cobrar" do cliente este esforço, faz com que muitos gerentes de projetos ignorem a parte referente à especificação de requisitos. Muitas empresas que desenvolvem projetos consideram que o trabalho de levantamento de requisitos é um risco que a mesma assume e que isto pode ser diluído na fase de desenvolvimento.

Dessa maneira, só resta à empresa que desenvolve projetos estimar um custo para esta etapa utilizando o conhecimento prévio de outros projetos, ou usando como base a fase de desenvolvimento (em que os meios de quantificar esta etapa 
são mais tangíveis), fazendo um reajuste pela percentagem de esforços para cada etapa do ciclo de vida do projeto.

É muito comum na literatura analisar o processo de ER com o objetivo de verificar custos e/ ou qualidade de seus produtos finais.

O custo dos esforços e os esforços gastos na análise dos requisitos crescem desproporcionalmente à medida que aumenta o tamanho do projeto (BOEHM, 1981). Quando se avalia o processo visando a melhoria do produto final, a finalidade é gerar especificações que possam ser passíveis de desenvolver. Assim, a avaliação do processo, além de evitar a complexidade no desenvolvimento do sistema, evita os seguintes problemas (CORBIN, 1991):

- Levantamento trabalhoso de requisitos pela listagem de tudo que os entrevistados necessitam;

- O volume de requisitos carregados impacta no volume de mudanças solicitadas durante as etapas subseqüentes do ciclo de vida do projeto;

Para isso, a definição de atributos para uma boa qualidade da especificação (DAVIS et al., 1993), a definição de várias métricas para avaliar os requisitos (COSTELLO; LIU, 1995), a priorização de requisitos através da abordagem do valor-custo (KARLSSON; RYAN, 1997; SIVZATTIAN; NUSEIBEH, 2001), a análise do impacto de mudanças de requisitos com a determinação do custo de tais mudanças (LAVAZZA; VALETTO, 2000) e a medição da complexidade dos requisitos (PARSONS-HANN; LIU, 2005) podem ser úteis.

O termo 'Eficácia do Processo de ER' pode ser considerado um meio de quantificar processo. Esse termo é usado como medida da exatidão e completude de se atingir os objetivos do processo de ER. A dimensão da eficácia é capturada de tal maneira que pode ser traduzida para um conceito de qualidade, custo e programação do tempo de maneira quantitativa (WILLIAMS; HALL; KENNEDY, 1999; WILLIAMS; KENNEDY, 2000).

Mas os métodos citados acima apenas resolvem parcialmente o problema, traduzindo o impacto do processo de ER em termos dos resultados adquiridos com os produtos finais, não levando em consideração que para se fazer um estudo de impacto de mudanças, de complexidade e de custos extras de novos requisitos, é necessário algum esforço. 


\subsubsection{Dicotomia entre custo e tempo}

Devido à natureza evolvente do processo de ER, a grande questão diz respeito a qual ponto é considerado que os requisitos estão realmente corretos. Métodos mais completos tendem a possuir inúmeras atividades com alguma iteração que descrevem detalhadamente tudo o que é necessário para esse propósito. Entretanto, o processo se torna muito grande, não havendo meios para justificar para o cliente e/ou Stakeholders o tempo gasto. O refinamento e verificação de alta qualidade leva tempo (e portanto custa caro), tendo fases repetidas para obter maior qualidade. Mas, por outro lado, o processo deve terminar em algum ponto onde o custo/beneficio seja razoável. O cuidado com os requisitos devem ser proporcionais ao impacto financeiro do artefato e dessa maneira, teremos os requisitos de maneira correta.

Dessa forma, a busca de um ponto razoável em termos de custo/benefíco é onde se pode ter uma boa noção do restante do projeto para fazer um contrato com boa visão da alocação de recursos que serão empregados. Se não chegar a isto os requisitos definitivamente não estão prontos de forma aceitável.

Os processo de ER iterativos listados na secção 2.5 destacam a iteratividade como um meio de alcançar qualidade dos requisitos levantados, mas não evidenciam um ponto que a etapa de requisitos deve encerrar para que o design e o desenvolvimento do sistema possam ser feitos.

\subsection{Proposta}

Uma abordagem mais efetiva para se fazer tal quantificação consiste na análise de custos. O grande problema é que só se possuem modelos de custos de projetos depois que toda a especificação está pronta e validada.

Além disso, é necessário custear as atividades do processo de ER, pois o levantamento de atividades é feito depois de se ter a funcionalidade do sistema. Dessa forma, se faz necessário também levantar as atividades para desenvolver os requisitos do sistema. Alguns trabalhos descrevem atividades que serve como guia durante a etapa de desenvolvimento dos requisitos (ROBERTSON; ROBERTSON, 1999; JIANG; EBERLEIN; FAR, 2004b; ARTHUR; GRÖNER, 2005; LOBO; ARTHUR, 2005b). O desenvolvimento baseado em atividades fornece uma noção mais clara das atividades que agregam valor ou não durante a fase de requisitos.

A contribuição deste trabalho é resolver esses problemas práticos do processo 
de ER. Um meio bem tangível de quantificar o levantamento de requisitos até a especificação, em termos de custo do processo será feito tomando como base um método que possui boa qualidade em conjunto com uma quantificação do custo do processo e com uma análise de todas as atividades do processo de ER do referido método. Para a quantificação do custo, será utilizado o modelo ABC no método Volere de Requisitos. Assim, esta abordagem, fornece as seguintes vantagens:

- Determinar o real valor de um levantamento de requisitos, considerando a complexidade e os pontos de vista para a especificação

- Usar como ponto de apoio para identificacao de melhorias de processos;

- Poder estimar custos extras devido ao levantamento de novos requisitos ou a mudança de requisitos existentes, porém visando o custo referente às atividades desenvolvidas para fazer tal levantamento durante o desenvolvimento do projeto;

- Poder estabelecer um ponto em que o refinamento e a verificação são adequados para determinar os requisitos, levando em consideração o impacto financeiro do artefato.

Na literatura, a aplicação do modelo ABC para projetos contempla as etapas de Design (BEN-ARIEH; QIAN, 2003), Desenvolvimento (OOI; SOH; LEE, 1998; BENARIEH; QIAN, 2003) e Implementação (OOI; SOH; LEE, 1998) de projetos, não havendo, até o presente trabalho, a aplicação do modelo ABC para a etapa de requisitos.

As etapas posteriores dos requisitos são mais fáceis de quantificar, pois as atividades já estão bem definidas, já que esta etapa tem justamente um desses propósitos. Alguns trabalhos mostram a grande vantagem de usar o sistema ABC para projetos considerando que o artefato e sua interação com o ambiente já estão bem definidos (RAZ; ELNATHAN, 1999; MACHERIDIS, 2004).

\subsection{Justificativa}

Algumas empresas possuem dificuldade de estimar custos para o processo de ER em relação a todo o processo, então, para resolver esta dificuldade, as empresas fazem a estimativa levando em consideração uma pecentagem grosseira em relação a todo o projeto. Esta percentagem difere devido ao sucesso na cooperação com os stakeholders e pode variar de projeto em projeto. Pois empresas consideram 
que, incluindo todo o processo de ER (em sua aplicação ótima), no preço do projeto, o cliente acaba rejeitando todo o projeto devido aos altos custos. Assim, a importância de alcançar um balanço entre o custo do esforço da ER e a vontade do cliente em pagar por isso, é claramente conhecido nas empresas. Pois alguns clientes consideram que o processo de ER gera um custo desnecessário (AXELSSON et al., 2003).

Outras empresas percebem que uma estimativa bem apurada do custo do projeto deveria ser feita após o processo de ER, mas isto acontece raramente. Dessa forma, os custos geralmente são baseados em experiências anteriores. Em alguns casos, as empresas possuem um orçamento e elas sabem o que podem fazer com este orçamento, como resultado, o processo de ER pode ser priorizado ou cancelado dependendo dos limites do orçamento (ÅKERUD et al., 2003).

No próximo capítulo será abordada a questão de custos em projetos, mostrando as vantagens de usar o sistema $\mathrm{ABC}$ em relação ao modelo baseado em volume sob o ponto de vista do projeto e dos requisitos, além disso, no mesmo capítulo, o ABC e seus componentes serão conceituados. 


\section{O sistema ABC de Custeio}

No capítulo anterior, foi sugerida uma abordagem para resolver o problema da quantificação através do custo do processo de ER. O objetivo deste capítulo é mostrar como a abordagem por atividades pode ser útil para determinar o custo do levantamento dos requisitos de um projeto.

\subsection{A Contabilidade de Custos e a Abordagem Baseada em Atividades}

A contabilidade de custos é o processo que determina custos para produtos e serviços. Os princípios da contabilidade de custos originalmente eram aplicados somente na manufatura mas atualmente também estão sendo aplicados nas indústrias de serviços, pois muitas empresas estão oferecendo serviços e não produtos.

Custos diretos de trabalho e material geralmente não são suceptível a métodos de alocação arbitrariamente determinado. Entretanto, custos indiretos de overhead ${ }^{1}$ não são tão facilmente determinados pelos métodos que geralmente presumem uma relação direta entre trabalho e uso de equipamentos e o custo indireto de overhead. Mas este nem sempre é o caso (FREEMAN, 1998).

A abordagem Baseada em Atividades para o gerenciamento de custos dá ênfase à necessidade de obter um entendimento mais rigoroso de como os custos indiretos e de overhead se comportam e como eles se relacionam com o trabalho que realmente foi feito. Por exemplo, um orçamento de departamento de manutenção convencional poderia classificar gastos com o título de 'tipo de custos' (salários, viagem ao local, etc.). Um orçamento baseado em atividades poderia classificar gastos com o título de 'atividade' (manutenção, reparos). Outro exemplo de um sistema baseado em atividade busca atribuir despesas a produtos de maneira individual, usando uma análise das atividades que contribuem para a

\footnotetext{
${ }^{1}$ overhead: Relativo às funções administrativas, despesas referentes à contabilidade, preparação de orçamento etc.
} 
conclusão desses produtos, no lugar de usar taxas de absorção de overheads do sistema tradicional de custeio (SCARLETT, 2004).

Nas próximas secções será conceituado o sistema ABC, comparando com os métodos tradicionais de custeio. Por fim, para efeito de entendimento do ABC, um exemplo didático será abordado.

\subsection{O uso do ABC no gerenciamento de Proje- tos}

Um projeto possui várias características e por essas características, tem-se alguns requisitos em relação ao custeio. O custeio de projetos deve ser elaborado para suprir requisitos específicos nas seguintes orientações (MACHERIDIS, 2004):

- Objetivo definido: Orientação a Objetivos;

- Recursos definidos: Orientação pelo Custo;

- Duração: Orientação a Processos;

- Temporária e organização rápida: Orientação à Organização

É importante para o gerenciamento do projeto identificar e avaliar o seu custo para estimar a lucratividade e a agregação de valores de um projeto (MACHERIDIS, 2004).

Para projetos, temos os seguintes métodos de determinação de Custos (PMI, 2000):

- Estimativa Análogas: Também chamada estimativa top-down, significa usar o custo real de um projeto similar anterior como base para estimativa do custo do projeto atual. É usado freqüentemente para estimar o custo do projeto quando o mesmo está em fase inicial (ou quando não se sabe todos os detalhes do projeto). Este tipo de estimativa possui custo menor que outras técnicas, mas geralmente é pouco preciso, sendo mais confiável aplicar esta estimativa se o projeto anterior é realmente similar e se a pessoa que fizer a estimativa possuir experiência em projetos;

- Modelagem Paramétrica: A modelagem paramétrica envolve o uso das características (parâmetros) em um modelo matemático (simples ou complexo dependendo do projeto) para predizer o custo do projeto. Tanto o 
custo quanto a precisão variam muito e são mais confiáveis quando as informações para o desenvolvimento do modelo são precisas, os parâmetros usados podem ser quantificados ou o modelo é escalonável (funciona tanto para projetos pequenos quanto para projetos grandes);

- Estimativa Bottom-up: Esta técnica consiste em estimar o custo de atividades individuais ou "pacotes de trabalho" e que serão depois sumarizado para uma estimativa individual para ter o total do projeto. O custo e a precisão da estimativa Bottom-up são direcionados pelo tamanho e complexidade das atividades individuais: pequenas atividades aumentam o custo e a precisão do processo estimado. A equipe de gerenciamento de projeto deve ponderar precisões adicionais contra custos adicionais;

- Ferramentas computadorizadas: Ferramentas como softwares de gerenciamento de projetos ou ferramentas de simulação e estatística são amplamente utilizadas com a estimativa de custos. Tais produtos podem simplificar o uso de técnicas mencionadas acima.

O sistema $\mathrm{ABC}$ de custeio pode ser comparado com um tipo de modelagem paramétrica. A diferença é que modelos paramétricos baseiam-se em dados históricos enquanto o $\mathrm{ABC}$ se baseia em dados atuais de custo definidos através da estimativa de custo atual que leva em consideração a obtenção de custos e demanda de recursos (KINSELLA, 2002).

No caso da estimativa bottom-up, os custos são determinados usando os métodos tradicionais de custeio, que são descritos adiante. O ABC define custos de uma maneira que difere os métodos tradicionais, ao isolar e reavaliar os custos indiretos que depois são incorporados às atividades (KINSELLA, 2002).

Um bom caminho para controlar os custos do projeto é através do ciclo de vida que o projeto segue. O ABC nos dá uma boa oportunidade de considerarmos todos os custos envolvidos no ciclo de vida. É importante identificar o processo necessário no projeto para completá-lo e entender as relações com vários custos de projeto, o que significa que o $\mathrm{ABC}$ pode ser usado como ferramenta de relacionamento, pois atividades que não agregam valor podem ser removidas ou os custos podem ser conectados às outras atividades (MACHERIDIS, 2004).

O ABC associado ao projeto torna o mesmo fácil de controlar, direcionar e acompanhar a performance, pois as atividades são diretamente relacionadas com a estrutura organizacional do projeto (MACHERIDIS, 2004). 
O custo do projeto pertence à fase de definição, pois nos dá suporte à decisão de que o projeto será aceito ou não. Se for aceito, o papel do custeio de projetos é definir preços, alocação de custos, planejamento de atividades e tomada de decisão (MACHERIDIS, 2004).

Ao invés de alocar custos em diferentes tipos de unidades produzidas, o objetivo é calcular o custo total de todo o projeto como uma simples unidade de trabalho. Sendo assim, o custo total é a soma dos custos nos diferentes níveis, mais a distribuição dos custos indiretos incorridos pela organização. Os direcionadores de custo relacionam a atividade com o nível (RAZ; ELNATHAN, 1999).

Os tipos de custos podem ser classificados em (RAZ; ELNATHAN, 1999):

- Custo Direto

- Esforço medido;

- Custo indireto

- Esforço medido;

- Esforço Compatilhado: Custos que são alocados nas atividades de projeto, baseando-se no tempo de duração;

- Nível de esforço: Custos que são alocados nas atividades na sua proporção direta com o esforço de medição.

A hierarquia que pode servir como base da estimativa de custos através do $\mathrm{ABC}$ é a estrutura de produtos resultantes que são esperados no projeto. Essa é similar ao Bill Of Materials (BOM). O BOM é bem usado para capturar dados de custo direto mas não relacionam várias atividades de overhead (RAZ; ELNATHAN, 1999).

Como alternativa, para determinação de custo de um projeto, separa-se a estrutura de estimativa de custos, que apresenta as seguintes similaridades com a hierarquia do ABC para manufatura (RAZ; ELNATHAN, 1999; NAKAGAWA, 2001):

- Nível de Organização: Similar ao nível de sustentação de instalação, inclui atividades de gerenciamento que oferece suporte ao direcionamento estratégico da empresa e também à organização estrutural;

- Nível de Projeto: Similar ao nível de sustentação de produtos. Neste ponto, temos vários projetos na organização, cada um em diferentes estágios do ciclo de vida; 
- Nível de "Pacotes Entregues": Similar ao nível de lote, representa os produtos entregues após o término de um projeto;

- Nível de Unidade: Último nível, representa unidades de um mesmo lote (subprodutos de um lote).

Esta Hierarquia está esquematizada na figura 3.1.

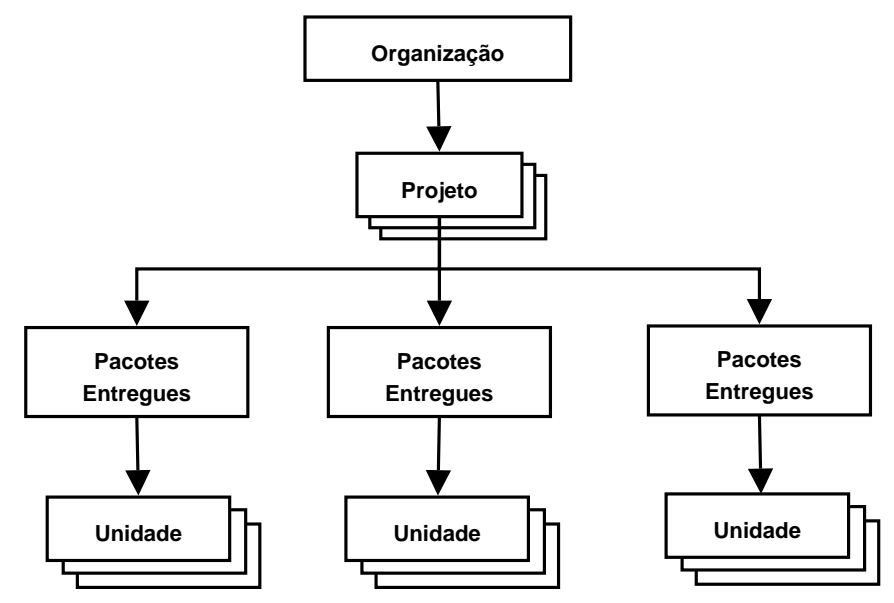

Figura 3.1: Hierarquia de alocação de custos. O diagrama mostra como os produtos/ subprodutos de um projeto são disponibilizados de acordo com o ABC

(RAZ; ELNATHAN, 1999).

Para cada atividade em nível de unidade, lote ou produto, um direcionador é identificado e o custo por unidade do direcionador é determinado. É esta informação que faz com que o ABC possa ser considerado uma poderosa ferramenta de determinação de preço (LERE, 2000).

\subsection{Definição do ABC}

A metodologia do ABC foi desenvolvida e criada pelos Profs. Cooper e Kaplan em meados da década de 80 como alternativa para as técnicas tradicionais de contabilidade. Atualmente, esse modelo é muito útil para calcular custos tanto no setor de manufatura, quanto no setor de negócios (BORDEN, 1990).

Os métodos de contabilidade tradicionais se concentram no sistema de Custeio Baseado em Volume. Os sistemas baseados em volume sempre foram desenhados para empresas que competiam no mercado com base em estratégias de redução de custos de produtos homogêneos e manufaturados em grande escala para estoques. Estes sistemas apropriavam os custos indiretos com base em algum atributo diretamente relacionado com o volume de produção, tais como horas de mão-deobra direta, horas-máquinas, valor do material consumido e outros. Entretanto, 
estes sistemas deixaram de ser exatos à medida que as empresas evoluíram para a produção de enorme variedade de produtos (NAKAGAWA, 1991; SPEDDING; SUN, 1999)

No método ABC, as atividades são o foco do processo de custeio. Os custos são investigados, relacionando-se as atividades ao produto com base na demanda por tais atividades pelo produto durante o processo de produção ou o serviço em questão. Portanto, as bases de alocação usadas no ABC são medições das atividades executadas, as quais podem incluir horas do tempo de ajuste da máquina ou o número de vezes que isto foi feito, ou demais maneiras de distribuição em função da atividade que está sendo analisada, seja industrial ou de serviços.

\subsection{Comparação do ABC com os sistemas tra- dicionais de Custeio}

Os sistemas tradicionais de custeio são caracterizados por:

- Absorção do overhead da produção nos custos do produto com o propósito de determinar o valor do que foi produzido;

- Uso de horas ou custos de mão-de-obra como uma base "conveniente" de recuperação do overhead, não relacionando com a proporção do real do custo total do trabalho;

- O uso de um custo de overhead único por simplificação.

Em relação a tomada de decisão, este sistema possui alguns problemas básicos. A alocação de overheads para a produção com o objetivo de determinação do valor de produção é direcionado somente pelo processo financeiro externo. Alguns custos de venda e administração são obviamente relacionados ao produto, mas não podem ser alocados dessa forma por causa de suas restrições. O aumento do custo de mão-de-obra está sendo levado em conta por uma proporção cada vez menor do custo total da empresa, já que as empresas estão se tornando mais eficientes e estão fazendo uso de novas tecnologias. O custo de overhead único não leva em consideração a utilização real tanto do departamento quanto dos produtos. Assim, alguns departamentos da emprersa podem ser considerados como geradores de despesas (como por exemplo, Marketing) e o custo de alguns processos é considerado como sorvedor de custos (como por exemplo, custos de Pesquisa e Desenvolvimento). No ABC, a tentativa feita é direcionar os overheads 
para unidade de custo (i.e., a unidade que gera o custo de overhead o mais exato possível) (LETZA; GADD, 1994).

Um meio mais exato de alocação de overhead para os produtos significa que o custo do produto pode ser conhecido exatamente. A análise do ABC geralmente indica que baixo volume de produtos é substancialmente subcusteado, e assim, leva a uma mudança da estratégia do produto. Freqüentemente, companhias que adotam o ABC encontram produtos que não dão lucros e podem ser eliminados e paralelamente, encontram alguns produtos lucrativos que não foram explorados adequadamente, pois não se sabia o custo corretos desse produtos (LETZA; GADD, 1994). Dessa forma, o sistema ABC é útil não só para alocar os custos de overhead, mas também para indicar áreas de desperdício (HELBERG; GALLETLY; BICHENO, 1994).

O ABC oferece vantagens sobre os métodos tradicionais de custeio por duas dimensões: Processo e Custo (TURNEY; STRATTON, 1992). Na determinação pelo custo, temos impacto positivo no Return On Investment (ROI) (CAGWIN; BOUWMAN, 2002) e na determinação de preços (LERE, 2000) e assim, temos um design de produtos com custo eficaz (TORNBERG; JAMSEN; PARANKO, 2002). No ponto de vista de processos, temos a melhoria contínua de processo (TURNEY; STRATTON, 1992; DRIVER, 2001) e assim, podemos assegurar a qualidade do processo (LETZA; GADD, 1994; MOTTA; PAMPLONA, 1999).

O ABC é um método de custeio completo, pois tem como objetivo alocar todos os custos, recursos e o que provoca os custos. A grande força do ABC está no suporte à tomada de decisões em relação a preço e investimento o qual é adequado a diferentes setores da indústria (MACHERIDIS, 2004).

A medição do sucesso do uso do ABC, pode ser quantificada pelo uso para tomada de decisão (KRUMWIEDE, 1998; GUPTA; GALLOWAY, 2003), por trazer algum benefício financeiro (SHIELDS, 1995; KRUMWIEDE, 1998), a satisfação com o sistema de custeio (SHIELDS, 1995; SWENSON, 1995; MCGOWAN; KLAMMER, 1997) ou ainda outros benefícios (MCGOWAN, 1998).

\subsection{O Funcionamento do sistema ABC}

O ABC foca nas atividades necessárias para produzir um produto ou serviço. As atividades são as causadoras de custos. Portanto, uma determinação precisa de custos tem que examinar as atividades necessárias para produzir o produto. Custeando as atividades, é possível obter uma medida mais precisa de recursos 
consumidos para produzir um produto. Este método de medição pode ser usado para avaliação de performance de gerenciamento, pois estabelece uma relação de causa-efeito entre as atividades controladas e o custo gerado em cada atividade (FREEMAN, 1998).

O método ABC demonstra a relação entre Recursos consumidos (o que foi gasto), Atividades executadas (onde foi gasto) e Objeto de Custo (para que foi gasto) (NAKAGAWA, 2001). Uma representação esquemática está na figura 3.2.

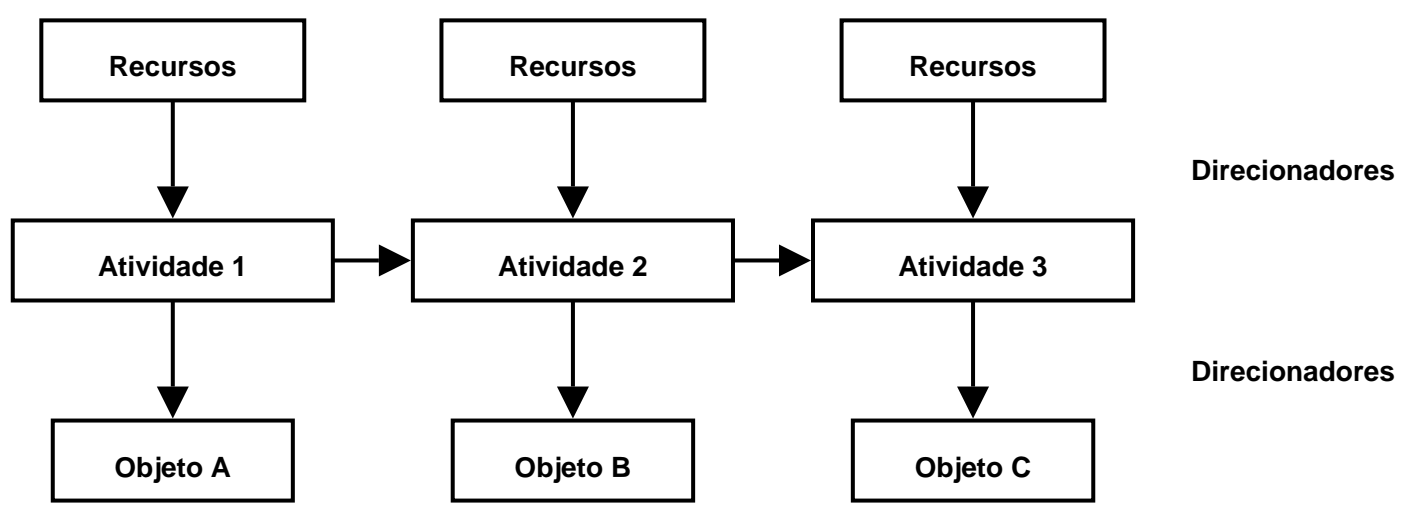

Figura 3.2: Modelo ABC. A figura representa uma seqüência de atividades. Nesta seqüência tem-se seus recursos e objetos de custeios, e para as associações entre recursos e atividades e as associações entre atividades e objetos de custeio, têm-se seus direcionadores.

Enquanto no método tradicional a alocação é feita através de critérios limitados de distribuições (geralmente quantidade produzida/vendida), no ABC existe uma multiplicidade de critérios (denominados de geradores de custos ou cost drivers), sendo um específico à atividade (custo) a que se relaciona (por exemplo: número de notas fiscais emitidas, número de requisições de compras, etc.). $\mathrm{Na}$ tabela 3.1 a seguir, é mostrado um exemplo de como cada método aloca os custos em um Departamento de Manutenção (NAKAGAWA, 2001).

Observe que na tabela 3.1 o modelo baseado em volume mostra a distribuição de custos segundo alguns critérios como salário, depreciação, etc. Isto permite saber quanto, como e para quê os gastos foram feitos. Já o modelo baseado em atividades aloca os custos propriamente nas atividades. Assim, sabe-se o por quê da ocorrência dos gastos (relação causal).

O sistema $\mathrm{ABC}$ parte do princípio que são atividades que consomem recursos e estas atividades dão origem aos produtos, portanto, descobrir o custo do produto é definir o custo das atividades que o compõem.

O que o $\mathrm{ABC}$ traz de novo é o entendimento de que as empresas são formadas por um emaranhado de atividades conectadas umas às outras em uma 
Tabela 3.1: Exemplo de apropriação de custos usando os dois modelos: Baseado em Volume (à esquerda) e o Baseado em Atividades (à direita) (NAKAGAWA, 2001)

\begin{tabular}{lr}
\hline \multicolumn{2}{c}{ Baseado em } \\
\hline Salário & 50.000 \\
Depreciação & 10.000 \\
Suprimentos & 6.000 \\
Impostos & 3.000 \\
Diversos & 1.000 \\
\hline Total & $\mathbf{7 0 . 0 0 0}$ \\
\hline
\end{tabular}

\begin{tabular}{lr}
\hline \multicolumn{2}{c}{ Baseado em Atividades } \\
\hline Organizar manutenção preventiva & 4.000 \\
Executar manutenção preventiva & 30.000 \\
Atender manutenção de emergência & 20.000 \\
Treinar mecânicos & 2.000 \\
Desenvolver dispositivos & 3.000 \\
Manter equipamentos & 1.000 \\
Administrar o Departamento & 10.000 \\
\hline Total & $\mathbf{7 0 . 0 0 0}$ \\
\hline
\end{tabular}

estrutura que é responsável por tudo o que acontece dentro da empresa e de que é na execução dessas atividades que se encontram as explicações de como foram consumidos os recursos que darão origem a um produto. Sendo assim, temos os seguintes pontos novos a serem considerados:

- Os custos no ABC são concentrados nas atividades ou centros de atividades e não em centros de custos, como acontece no custeio tradicional;

- Os direcionadores de custos, utilizados para atribuir os custos das atividades aos produtos, possuem uma relação mais clara com 'por que' o custo ocorreu e para quê, ao contrário do que acontece na metodologia tradicional.

Sabe-se que em um sistema de contabilidade há dois tipos de custos: diretos e indiretos. No ABC, os custos diretos são atribuídos ao produto através das atividades, e os custos indiretos também podem ser atribuídos ao produto, mas usando um número maior de direcionadores e tendo uma relação com o consumo de recursos feitos pelas atividades.

\subsection{Componentes do método ABC}

Os conceitos que delineiam a metodologia ABC são bastante simples. Entre eles, estão os recursos, atividades, direcionadores de custos e objetos de custeio.

\subsubsection{Recursos}

A produção de bens ou serviços (output) pressupõe a existência e a transformação de certos recursos (inputs) através dos processos internos nas organizações. Uma 
das fases na implementação dos sistemas de custeio ABC é a apuração do valor consumido (inputs) pelos departamentos para execução de suas funções. Custos com pessoal, materiais, ocupação, bens móveis e informática, são exemplos de custos que podem ser consumidos pelos departamentos de uma organização e devem ser relacionados às atividades que os consomem.

\subsubsection{Atividades}

Atividade é um processo que combina de forma adequada, pessoas, tecnologias, materiais, métodos e seu ambiente, tendo como objetivo a produção de produtos (NAKAGAWA, 2001). As atividades são para o ABC a base para determinação dos custos, avaliação de desempenho e para o processo de implementação de melhoria contínua. As atividades são tidas como agregadoras de características que são de fundamental importância no gerenciamento dos custos em uma empresa.

As atividades carregam o entendimento comum existente entre os diversos componentes de uma organização.

A informação sobre custos pode ser democratizada por toda a empresa numa terminologia que todos possam entender. As informações que eram de exclusivo entendimento dos contadores e de seus gerentes foram transformadas em uma linguagem comum a todos dentro da empresa.

Associar custos a uma atividade é, de certa forma, simples. Os custos de execução de uma atividade podem ser aparentemente listados (mão-de-obra, custos diretos, etc.) e o que é melhor, podem ser controlados, pois os custos identificados e corretamente alocados a uma atividade podem servir de guia para a criação de medidas de desempenho dessa atividade visando atingir alto grau de eficiência e eficácia na sua execução.

Um dos papéis importantes na identificação das atividades executadas por uma empresa é a análise da necessidade de eliminação de atividades ou da criação de novas atividades (investimentos) que possam melhorar o desempenho futuro da empresa.

\subsubsection{Direcionadores de Custos}

O direcionador de custos é um fato causal que influencia a quantidade de trabalho (e, portanto, de custo) numa atividade.

Os direcionadores de custos são utilizados em duas ocasiões distintas: a pri- 
meira (direcionadores de primeiro estágio), quando se atribuem os custos incorridos em determinado período às atividades e a segunda, quando são atribuídos os custos das atividades aos objetos de custeio (partes de um produto, produto, clientes, etc.).

Os direcionadores de custos devem ser encarados como o estopim dos processos dentro das organizações; entendê-los significa entender por que os processos ocorrem.

Os direcionadores possuem a funcionalidade de relacionar consumo de recursos pelas atividades e atividades pelo produto além de representar como os recursos foram consumidos pelas atividades e o número de vezes que uma atividade foi executada para atender o produto ou o serviço. O acompanhamento dos direcionadores (recursos e atividades) resulta em um mapa de consumo de custos de uma organização (BEZERRA; ROBLES JÚNIOR, 2002).

Os direcionadores de custo podem ser de dois tipos: Direcionadores de Primeiro Estágio (ou Direcionadores de Recursos) e Direcionadores de Segundo Estágio (ou Direcionadores de Atividades) (figura 3.3).

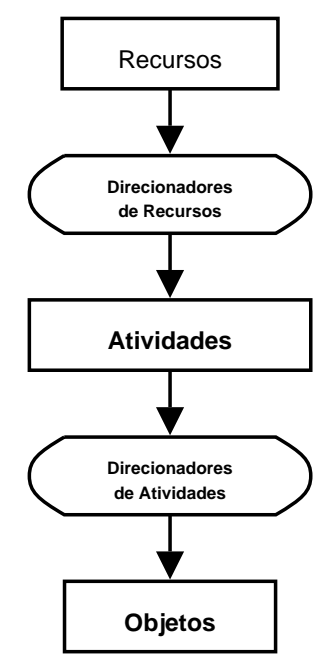

Figura 3.3: Representação dos direcionadores de custo no ABC. Entre os Recursos e as Atividades, tem-se os Direcionadores de Primeiro Estágio e entre as Atividades e o Objeto de Custeio, tem-se os Direcionadores de Segundo Estágio.

\subsubsection{Direcionador de Primeiro Estágio}

Também chamado de Direcionador de Recursos, é quando cada recurso é demandado por um determinado serviço, para uma consecução de atividades ou conjunto delas. Nesse direcionador o valor unitário de recursos é denominado Índice de Custeio de Recursos (ICR). Os ICRs podem ser: 
- ICR de Atividades: Calcula o custo consumido através da medida física representativa da forma como os recursos são consumidos, por ex.: $\mathrm{R} \$$ pessoal/minuto, $\mathrm{R} \$$ ocupação/minuto, etc.

- ICR de Objeto: Calcula o custo por um conjunto de atividades (Objeto) através da medida física de saída do objeto, por ex.: $\mathrm{R} \$$ digitação/documento digitado, $\mathrm{R} \$$ transporte de valores/transação, etc.

Se o ICR de um determinado cargo é $\mathrm{R} \$ 0,65 /$ min serão alocados às atividades $\mathrm{R} \$ 0,65$ para cada minuto de execução de tais atividades que consumirem o tempo deste cargo.

\subsubsection{Direcionador de Segundo Estágio}

Chamado também de direcionador de Atividades, é responsável por calcular o custo das atividades necessárias para a consecução dos objetos. Além disso, calcula o custo dos objetos consumidos por outros objetos.

\subsubsection{Objetos de custeio}

O objeto de custeio é o conjunto de atividades voltadas para um objetivo específico. É o conjunto de atividades representativo de uma transação que comporá as modalidades de produto ou serviço a ser custeado.

O Objeto de Custeio é o ponto final da alocação de custos em um sistema de custeio ABC; é onde os custos das atividades são concentrados. Os objetos de custeio podem ser representados por partes de um produto, pelos produtos, processos, clientes, canais de distribuição. Enfim, tudo aquilo que, de alguma forma, os gerentes acreditem ser interessante conhecer seu custo. Assim, o conceito de objeto de custeio varia de acordo com o que se deseja custear.

O modelo ABC de custeio se faz pelo levantamento de todas as atividades durante a etapa de especificação e estima tempo e recurso consumido para um determinado objeto de custeio.

\subsection{Exemplo didático}

Nesta secção, será mostrado um exemplo didático do uso do ABC. Este exemplo foi tirado de um estudo de caso elaborado por Bezerra e Robles Júnior (2002) e 
de modo a ser somente um exemplo, serão omitidos alguns dados, mostrando-se somente dados relevantes ao exemplo.

Uma empresa prestadora de serviços que efetua análise de crédito para instituições financeiras, possui dois produtos denominados "Análise de crédito para o serviço A" e "Análise de crédito para o serviço B". A empresa trabalha com 15 funcionários. Esta empresa recentemente implantou um sistema ABC.

Foram feitos os levantamentos de atividades e recursos. A tabela 3.2 mostra as atividades contempladas pelo ABC com seus respectivos tempos unitários e direcionadores. A tabela 3.3 demonstra os custos fixos mensais da empresa. A tabela 3.4 indica o valor unitário dos custos variáveis mensais. Note que nas tabelas 3.3 e 3.4 existem indicativos de qual(is) atividade(s) consome(m) o(s) recurso(s), com exceção dos custos de pessoal e de infraestrutura que estão relacionados a todas as atividades. Assim, apenas a atividade A5 consome a depreciação dos equipamentos de informática, pois é a única que utiliza este equipamento. Dessa forma, a atividade A4 receberá o custo direto e variável do Formulário X, a atividade A7 receberá o custo do Formulário Y e finalmente, a atividade A9 receberá o custo direto e variável do Formulário Z.

Tabela 3.2: Atividades, tempo de execução e direcionadores

\begin{tabular}{llll}
\hline Cód. & Atividade & T. Unit. (min) & Direcionador \\
\hline A1 & Receber proposta da operação & 42 & Propostas recebidas \\
A2 & Analisar proposta & 52 & Propostas analisadas \\
A3 & Cadastrar proposta & 15 & Propostas cadastradas \\
A4 & Elaborar parecer técnico & 30 & Pareceres elaborados \\
A5 & Implantar contrato no sistema & 46 & Contratos implantados \\
A6 & Efetuar pagamento da operação & 61 & Pagamentos efetuados \\
A7 & Emitir carnê & 42 & Carnês emitidos \\
A8 & Efetuar baixa das parcelas & 23 & Parcelas baixadas \\
A9 & Liberar alienação fiduciária & 34 & Liberações realizadas \\
\hline
\end{tabular}

Tabela 3.3: Recursos - Custos Fixos Mensais

\begin{tabular}{llc}
\hline Atividade & Grupo & Custo Mensal \\
\hline & Pessoal & $\mathrm{R} \$ 35.200,00$ \\
& Infraestrutura & $\mathrm{R} \$ 30.608,00$ \\
$\mathrm{~A} 5$ & Informática & $\mathrm{R} \$ 14.400,00$ \\
\hline
\end{tabular}

A capacidade prática representa quanto tempo do total disponível para o trabalho os funcionários realmente dedicam para atividades relacionadas ao negócio 
Tabela 3.4: Recursos - Custos Variáveis

\begin{tabular}{llr}
\hline Atividade & Elemento & Custo Unitario \\
\hline A4 & Formulário X & $\mathrm{R} \$ 0,25$ \\
$\mathrm{~A} 7$ & Formulário Y & $\mathrm{R} \$ 0,36$ \\
$\mathrm{~A} 9$ & Formulário Z & $\mathrm{R} \$ 0,60$ \\
\hline
\end{tabular}

da organização. A eq.(3.1) determina a capacidade prática:

$$
C_{p}=I_{c p} \times N_{f} \times T \times D
$$

Onde:

$\boldsymbol{I}_{\boldsymbol{c p}}$ Índice de capacidade prática ${ }^{2}$

$\boldsymbol{N}_{\boldsymbol{f}}$ Número de funcionários

T Carga horária diária

D Número de dias úteis (médio)

Da eq.(3.1) tem-se que a carga horária diária é de 8 horas, o número de dias úteis médios é de 21 dias e o índice de capacidade prática é de $75 \%$, assim, a capacidade prática é de 113.400 minutos/mês.

Como a média de salários da empresa é de $\mathrm{R} \$ 2.346,67$ por funcionário, o custo unitário por minuto desse recurso será seu custo dividido pela capacidade prática de um funcionário ( $\mathrm{R} \$ 2.346,67$ / $7.560 \mathrm{~min})$, que equivale a $\mathrm{R} \$ 0,31$ para cada minuto trabalhado na empresa (assumindo que todos os funcionários possuem carga horária de 8 horas diárias). Portanto, o ICR das ativades relativo aos recursos humanos é de $\mathrm{R} \$ 0,31$.

Para os custos estruturais, o custo unitário da infraestrutura é igual ao consumo de recursos estruturais, dividido pela capacidade prática da empresa. Nesse caso, $\mathrm{R} \$ 30.608,00$ / $113.400 \mathrm{~min} /$ mês, resulta em $\mathrm{R} \$ 0,27$ por minuto/mês trabalhado na empresa, ou seja, o ICR das atividades relativo aos recursos de infraestrutura é de $\mathrm{R} \$ 0,27$.

A mesma situação que ocorre com os custos de infraestrutura, ocorre com os custos de informática. Neste caso, divide-se o custo mensal pelo tempo de

\footnotetext{
${ }^{2}$ este índice é um percentual que desconta o tempo dedicado às atividades pessoais (idas ao médico, licenças, férias, etc.)
} 
execução da atividade A5 e os volumes referente a cada produto (conforme tabela 3.6), que é a única atividade que consome tal recurso. Assim, o custo é $\mathrm{R} \$ 14.400,00 /(46 \min \times(56+50))$ que resulta em $\mathrm{R} \$ 2,95$ sendo este valor, o ICR da atividade A5 relativo à informática.

O cálculo do custo mensal por atividade é feito pela eq.(3.2):

$$
C_{A n}=T_{A n} \times V_{A n} \times C_{u n i t}
$$

Onde:

$\boldsymbol{C}_{\boldsymbol{A} \boldsymbol{n}}$ Custo da atividade $\mathrm{n}$

$\boldsymbol{T}_{\boldsymbol{A} \boldsymbol{n}}$ Tempo unitário da execução da atividade $\mathrm{n}$

$\boldsymbol{V}_{\boldsymbol{A} \boldsymbol{n}}$ Número de vezes que se executa a atividade n no período de um mês

$\boldsymbol{C}_{\text {unit }}$ Custo unitário por minuto dos recursos associados à atividade

O custo total do serviço é dado pela eq.(3.3):

$$
C_{\text {servt }}=\sum_{i=0}^{9} C_{A i_{t}}
$$

Onde:

$\boldsymbol{C}_{\boldsymbol{s e r v}_{\boldsymbol{t}}}$ Custo do serviço t

$\boldsymbol{C}_{\boldsymbol{A} i_{t}}$ Custo da atividade $A_{i}$ para o serviço t

A tabela 3.5 mostra o cálculo do custo unitário total por atividade. Onde as colunas das tabelas representam:

$\boldsymbol{A}_{\boldsymbol{n}}$ Atividade n;

$\boldsymbol{T}$ Tempo de execução da atividade n (min);

$\boldsymbol{C}_{\text {unit }_{\text {pes }}}$ Custo unitário de pessoal (R\$);

$\boldsymbol{C}_{\text {unit }_{i e}}$ Custo unitário de infraestrutura $(\mathrm{R} \$)$;

$\boldsymbol{C}_{\text {unitinf }}$ Custo unitário de informática $(\mathrm{R} \$)$;

$\boldsymbol{C}_{\boldsymbol{f i x o}}$ Custo fixo da atividade n, ou seja, $C_{\text {fixo }}=T \times\left(C_{\text {unit }_{\text {pes }}}+C_{\text {unit }_{\text {ie }}}+C_{\text {unit }_{\text {inf }}}\right)$ $(\mathrm{R} \$)$; 
$\boldsymbol{C}_{\boldsymbol{v} a \boldsymbol{r}}$ Custo variável da atividade n $(\mathrm{R} \$)$;

Total Custo unitário total da atividade n, ou seja Total $=C_{f i x o}+C_{v a r}(\mathrm{R} \$)$;

Tabela 3.5: Cálculo dos custos unitários para cada atividade em relação aos serviços.

\begin{tabular}{rrrrrrrr}
\hline$A_{n}$ & $T$ & $C_{\text {unit }_{\text {pes }}}$ & $C_{\text {unitie }_{i e}}$ & $C_{\text {unit }_{\text {inf }}}$ & $C_{\text {fixo }}$ & $C_{\text {var }}$ & Total \\
\hline A1 & 42 & 0,31 & 0,27 & 0,00 & 24,36 & 0,00 & 24,36 \\
A2 & 52 & 0,31 & 0,27 & 0,00 & 30,16 & 0,00 & 30,16 \\
A3 & 15 & 0,31 & 0,27 & 0,00 & 8,70 & 0,00 & 8,70 \\
A4 & 30 & 0,31 & 0,27 & 0,00 & 17,40 & 0,25 & 17,65 \\
A5 & 46 & 0,31 & 0,27 & 2,95 & 162,38 & 0,00 & 162,38 \\
A6 & 61 & 0,31 & 0,27 & 0,00 & 35,38 & 0,00 & 35,38 \\
A7 & 42 & 0,31 & 0,27 & 0,00 & 24,36 & 0,36 & 24,72 \\
A8 & 23 & 0,31 & 0,27 & 0,00 & 13,34 & 0,00 & 13,34 \\
A9 & 34 & 0,31 & 0,27 & 0,00 & 19,72 & 0,60 & 20,32 \\
\hline
\end{tabular}

Pela tabela 3.6 tem-se o custo mensal do serviço A e do serviço B. Onde as colunas das tabelas representam:

$\boldsymbol{A}_{\boldsymbol{n}}$ Atividade n;

$\boldsymbol{V}$ Volume da atividade n;

$\boldsymbol{C}_{\text {unit }}$ Custo unitário total $(\mathrm{R} \$)$;

$\boldsymbol{C}_{\boldsymbol{m e n s a l}}$ Custo mensal da atividade n $(\mathrm{R} \$)$, ou seja $C_{\text {mensal }}=V \times C_{\text {unit }}$;

Assim, o custo mensal total do processo é de $\mathbf{R} \$ \mathbf{6 7 . 6 4 9 , 1 8}$.

Se for calculado o custo baseado em volume da empresa, tem-se que custo fixo $\left(C_{\text {fixo }}\right)$ é a soma dos custos da tabela 3.3 e o custo variável $\left(C_{v a r}\right)$ é a soma dos custos unitários de cada formulário da tabela 3.4 multiplicados pelos volumes das respectivas atividades que consomem estes recursos nos dois serviços. Assim:

$$
C_{\text {fixo }}=R \$ 35.200,00+R \$ 30.608,00+R \$ 14.400,00=R \$ 80.208,00
$$

$C_{v a r}=R \$ 0,25 \times(56+50)+R \$ 0,36 \times(48+32)+R \$ 0,60 \times(79+90)=R \$ 156,70$ 
Tabela 3.6: Cálculo dos custos mensais para cada atividade em relação ao serviço A e B.

\begin{tabular}{rrrrrr}
\hline & \multicolumn{3}{c}{ Serviço A } & \multicolumn{2}{c}{ Serviço B } \\
\hline$A_{n}$ & $C_{\text {unit }}$ & $V$ & $C_{\text {mensal }}$ & $V$ & $C_{\text {mensal }}$ \\
\hline $\mathrm{A} 1$ & 24,36 & 72 & $1.753,92$ & 120 & $2.923,20$ \\
$\mathrm{~A} 2$ & 30,16 & 72 & $2.171,52$ & 120 & $3.619,20$ \\
$\mathrm{~A} 3$ & 8,70 & 56 & 487,20 & 50 & 435,00 \\
$\mathrm{~A} 4$ & 17,65 & 56 & 988,40 & 50 & 882,50 \\
$\mathrm{~A} 5$ & 162,38 & 56 & $9.093,28$ & 50 & $8.119,00$ \\
$\mathrm{~A} 6$ & 35,38 & 56 & $1.981,28$ & 50 & $1.769,00$ \\
$\mathrm{~A} 7$ & 24,72 & 48 & $1.186,56$ & 32 & 791,04 \\
$\mathrm{~A} 8$ & 13,34 & 1500 & $20.010,00$ & 600 & $8.004,00$ \\
$\mathrm{~A} 9$ & 20,32 & 79 & $1.605,28$ & 90 & $1.828,80$ \\
\hline & & Total & $\mathbf{3 9 2 7 7 , 4 4}$ & Total & $\mathbf{2 8 3 7 1 , 7 4}$ \\
\hline
\end{tabular}

Observe que o custo baseado em volume calculado foi maior que o custo calculado pelo ABC. Observando com mais detalhade o modelo ABC da empresa, verifica-se que esta discrepância ocorre pois, calculando o tempo mensal de execução das atividades (Volumes × Tempos Unitários), tem-se $91.566 \mathrm{~min}$, ou seja, considerando a capacidade prática dos 15 funcionários (113.400 min), há um excesso de 21.834 min em um mês, tendo assim quase 3 funcionários (21.834 / $7.560=2,89$ ) "sobrando" no quadro de pessoal. Neste caso, a simulação dos custos levantados pelo sistema $\mathrm{ABC}$ poderá ser útil para ajustar a quantidade de funcionários (BEZERRA; ROBLES JÚNIOR, 2002). 


\section{Modelagem do Processo de Engenharia de Requisitos}

Antes de fazer a modelagem do ABC para o processo de ER, é importante escolher um método que seja adequado às necessidades da proposta deste trabalho. Os objetivos deste capítulo são escolher um método para o processo de ER no qual será aplicado os conceitos do ABC e justificar a escolha deste.

\subsection{Introdução}

Dada uma grande quantidade de modelos, técnicas e métodos disponíveis, é muito difícil para o engenheiro de requisitos escolher métodos e técnicas apropriados no contexto de um projeto real (JIANG; EBERLEIN; FAR, 2004a). Os métodos tentam contemplar todas as etapas do processo de desenvolvimento da ER: elicitação, análise, especificação e verificação, além de contemplar as atividades referentes ao processo de gerenciamento de requisitos, com maior ou menor detalhamento e para aplicações específicas.

Como o foco principal dos métodos de ER existentes não é a determinação de custos e sim a estruturação de suas etapas, um dos desafios deste trabalho é escolher um método que fornece informações para determinar o custo de cada atividade da maneira adequada aos objetivos do trabalho. Assim, para a escolha do método mais adequado, duas abordagens principais serão feitas:

- O método possui as atividades necessárias para contemplar a etapa de ER com melhor qualidade, ou seja, contemplam as atividades necessárias para se fazer um bom requisito;

- As atividades estão de maneira bem-estruturadas e seu detalhamento está em um nível próprio para o uso do ABC. 


\subsection{Avaliação pela qualidade}

Em relação à análise da qualidade, será escolhido algum modelo, conceito ou padrão que segue algumas práticas referente ao processo de ER. Dentre os modelos existentes foram destacados:

- COncern of Requirement Engineering (CORE): Conceito obtido através da exploração na literatura, sumarização e classificação de todas as questões que envolvem a ER (JIANG; EBERLEIN; FAR, 2004a);

- Padrões do processo de ER: Uma lista de atividades padrões para fazer um processo de ER (GAUSE; WEINBERG, 1989; GASKA; GAUSE, 1998);

- Modelo de maturidade do processo de ER: Modelo do tipo Capability Maturity Model (CMM) com 66 práticas que determinam a qualidade de um processo de ER (SOMMERVILLE; SAWYER, 1997a);

Com objetivo de fornecer uma visão multidisciplinar do processo de ER, os três padrões determinam uma série de práticas em níveis mais altos e mais baixos a serem adotadas para que o processo de ER seja feito da forma mais completa. A tabela 4.1 mostra uma comparação entre os métodos.

Comparando os três padrões, o escolhido será o CORE. O CORE é o resultado de um trabalho de pesquisa que teve como objetivo entrevistar diversos profissionais, perguntando quais conceitos da ER são importantes para que o processo seja feito com a qualidade adequada. Aos conceitos relacionados como principais, foram classificados como major CORE. Assim, esse método pode avaliar as atividades que são importantes ou não e que atendem a um modelo de processo de ER eficaz.

\subsection{Avaliação pela estruturação das atividades}

O gerenciamento de atividades é um meio eficaz, pois incorpora informações das operações de uma organização de uma maneira mais ampla. Os usuários são capazes de extrair e analisar informações relevantes em um nível apropriado de detalhe de acordo com o momento necessário (GEISHECKER, 1996). O conceito de atividades é muito importante não só para o $\mathrm{ABC}$, pois é o ponto chave do custo, mas as atividades também podem ser responsáveis pela melhoria de processos através de medida de desempenho (figura 4.1). As atividedes devem 
Tabela 4.1: Relações entre os conceitos de avaliação do processo de Engenharia de Requisitos (adaptado de Jiang, Eberlein e Far (2004a))

\begin{tabular}{|c|c|c|c|}
\hline & CORE & Padrões & $\begin{array}{l}\text { Modelo de maturi- } \\
\text { dade }\end{array}$ \\
\hline $\begin{array}{l}\text { Suporte para desen- } \\
\text { volvimento do pro- } \\
\text { cesso de ER }\end{array}$ & $\checkmark$ & $\checkmark$ & $\checkmark$ \\
\hline $\begin{array}{l}\text { Suporte para ava- } \\
\text { liação do processo de } \\
\text { ER }\end{array}$ & $\checkmark$ & $\checkmark$ & $\checkmark$ \\
\hline Pontos chaves & $\begin{array}{l}\text { 1.Objetivos mais } \\
\text { específicos para o } \\
\text { processo de ER; } \\
\text { 2.Os fatores im- } \\
\text { portantes que } \\
\text { influencia o pro- } \\
\text { cesso de ER; } \\
\text { 3.Um conjunto de } \\
\text { atividades comum } \\
\text { em um domínio } \\
\text { multidisciplinar. }\end{array}$ & $\begin{array}{l}\text { Uma série de ativi- } \\
\text { dades comum em } \\
\text { um domínio multi- } \\
\text { disciplinar }\end{array}$ & $\begin{array}{l}\text { Uma série de boas } \\
\text { práticas pré defi- } \\
\text { nidas para o pro- } \\
\text { cesso de ER. }\end{array}$ \\
\hline $\begin{array}{l}\text { Escopo da avaliação } \\
\text { do processo de ER }\end{array}$ & O mais completo. & $\begin{array}{l}\text { Focalizado nas } \\
\text { atividades } \\
\text { definição de re- } \\
\text { quisitos, análise e } \\
\text { validação }\end{array}$ & Mais completo \\
\hline $\begin{array}{l}\text { Problemas chaves } \\
\text { no desenvolvimento } \\
\text { e avaliação do } \\
\text { processo de ER }\end{array}$ & $\begin{array}{l}\text { Precisa de refina- } \\
\text { mento. }\end{array}$ & $\begin{array}{l}\text { Modelo refinado e } \\
\text { não completo. }\end{array}$ & $\begin{array}{l}\text { Pré-definido, } \\
\text { conteúdo muito } \\
\text { específico } \\
\text { sem muita } \\
\text { flexibilidade. }\end{array}$ \\
\hline $\begin{array}{l}\text { Aplicabilidade mul- } \\
\text { tidisciplinar }\end{array}$ & $\checkmark$ & $\checkmark$ & $\checkmark$ \\
\hline Flexibilidade & O mais flexível. & Mais flexível. & Flexível. \\
\hline Objetividade & Mais objetivo. & Mais objetivo. & Objetivo. \\
\hline
\end{tabular}

ser estruturadas, pois o conhecimento detalhado do custo de todas as atividades pode ser muito útil à sua gestão e aperfeiçoamento (NAKAGAWA, 2001). Assim, escolher um método de ER adequado é escolher um método que possui suas atividades bem determinadas e estruturadas.

Neste ponto, faz-se necessário conceituar claramente o que seja cada unidade de processamento para o ABC pela hierarquia de conceitos (BRIMSON, 1996):

- Operação: É a menor unidade de trabalho utilizada com o propósito de planejamento ou controle; 


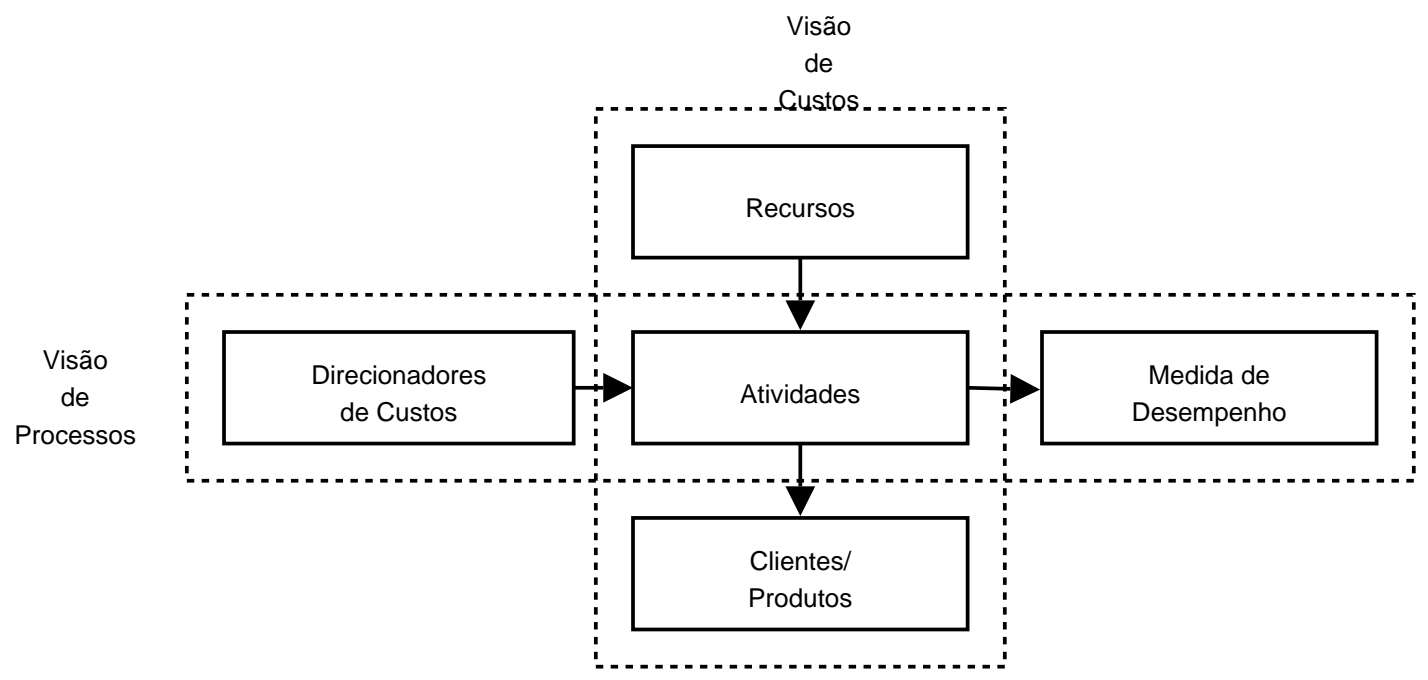

Figura 4.1: Visão Custo $\times$ Processo tendo a atividade como ponto principal. A atividade é o ponto chave para determinação de custos e melhoria de processos

- Tarefa: É a combinação dos elementos de trabalho ou operações que compõem uma atividade. É a maneira como a atividade é realizada;

- Atividade: São processos que consomem recursos substanciais para gerar uma produção. A função principal de uma atividade é converter recursos (material, mão-de-obra e tecnologia) em produção (produtos/serviços);

- Processo: É uma rede de atividades relacionadas e interdependentes ligadas pela produção que permutam;

- Função: É um conjunto de atividades relacionadas a um propósito comum. Apesar da maioria das empresas ser organizada funcionalmente, o espectro total das atividades relacionadas à função é muito mais amplo do que a unidade organizacional que tem a responsabilidade básica pela função.

Alguns métodos fornecem pouca estruturação de atividades e na maioria das vezes, as atividades estão em um nível muito abstrato ou em um nível muito alto (geralmente, em alguns processos de ER, as atividades se resumem a Elicitação, Análise e Especificação) (LOBO; ARTHUR, 2005b). Essa pouca estruturação fornece de maneira incompleta qual o objetivo de cada atividade e com isso, o produto final das mesmas fica muito genérico, sendo muito difícil de determinar o custo do processo de ER. Neste caso, quanto maior é o detalhamento das atividades, mais preciso são as informações das mesmas. Por outro lado, um detalhamento muito grande de atividades para o $\mathrm{ABC}$, chegando a um nível de tarefa, torna o processo muito complexo e portanto, difícil de determinar seus parâmetros e controlá-los. 
Conforme apresentado na secção 2.5 no capítulo 2 , os modelos citados foram:

- PREview;

- Modelo de Processo de ER proposto por Richards (2000);

- Volere;

- Process Framework;

- Triagem;

- RGM;

- x-RGM;

Os critérios para selecionar o método são:

- Nível de detalhe. Os métodos foram classificados em:

- Baixo: O modelo possui as etapas somente em nível dos processos principais da ER (elicitação, análise, especificação, verificação e validação);

- Médio: O modelo possui nível de atividade em algumas etapas do processo de ER, mas não em todas;

- Alto: Todos as etapas do processo de ER está em um nível de atividade;

- Muito Alto: O processo de ER está em um nível de tarefa;

- Cobertura de todos os processos de ER, ou seja, verificação se o método cobre as etapas de elicitação, análise, especificação, verificação e validação no processo de ER;

- Objetividade das atividades. Este critério foi classificado em:

- Baixa: Não há como ter uma medida quantitativa em nenhuma atividade do modelo;

- Média: Somente há como quantificar algumas atividades do modelo;

- Alta: Todas as atividades do modelo podem ser quantificadas.

O comparativo ${ }^{1}$ para escolha do método está apresentado na tabela abaixo (tabela 4.2):

\footnotetext{
${ }^{1}$ Este comparativo teve como base o que foi observado durante a leitura dos materiais relativos aos métodos.
} 
Tabela 4.2: Relações entre os modelos do processo de Engenharia de Requisitos

\begin{tabular}{llll}
\hline & Nível de detalhe & Cobertura & Objetividade \\
\hline PREview & Alto & Todas as etapas & Média \\
Modelo de Processo de ER & Médio & Todas as etapas & Média \\
Volere & Muito Alto & Todas as etapas & Alta \\
Process Framework & Baixo & Todas as etapas & Alta \\
Triagem & Médio & Somente Análise & Média \\
RGM & Médio & Somente Elicitação & Alta \\
x-RGM & Alto & Todas as etapas & Alta \\
\hline
\end{tabular}

\subsection{Método escolhido}

Para escolha do método, usaremos um que tenha um alto nível de detalhe, que cobre todos os processos de ER e que possui as atividades mais objetivas.

Os métodos que satisfazem estes critérios são o Volere e o x-RGM, neste caso, utilizaremos o método Volere, pois este já foi avaliado pelo conceito CORE e foi considerado pelo major CORE como de altíssima qualidade (JIANG; EBERLEIN; FAR, 2004a).

A modelagem de processo Volere é um modelo de ER que cobre todos os processos de ER e pode ser muito útil para um Template ${ }^{2}$ do processo de ER. O processo Volere é um guia passo a passo para reunir os requisitos de um sistema. O modelo desse processo fornece um guia rigoroso para identificar e refinar os requisitos tanto funcionais quanto não-funcionais.

Além disso, as atividades do método Volere são bem estruturadas e com informações completas e detalhadas. Para cada atividade/sub-atividade temos seus participantes e o que resultará ao final das mesmas.

O levantamento de atividades necessárias para desenvolver os requisitos do sistema é o ponto principal para se utilizar o ABC. A partir daí, pode-se levantar os outros elementos para a determinação de custos e analisar as atividades que agregam ou não valor. Como o método Volere está em um nível de tarefa, será necessário agrupar estas tarefas em atividades para poder usar o ABC. No próximo capítulo, o método será detalhado, bem como serão apresentados todos os processos/atividades do Volere de interesse para o ABC.

\footnotetext{
${ }^{2}$ Neste contexto, Template é um diagrama com o objetivo de criar documentos.
} 


\section{Desenvolvimento do Modelo}

O objetivo deste trabalho é determinar o custo de um processo de ER de maneira mais adequada possível. Para isso, utilizaremos como base do custo o método Volere para o processo de ER e com esse método, será feito o cálculo do custo utilizando o modelo ABC.

Para isso, será definido a partir do método Volere, tudo que o sistema ABC de custeio precisa para que se tenha o custo desse método. Neste capítulo serão detalhados os processos, seus objetivos e serão destacadas suas atividades e a seqüência destas para cada processo do método.

\subsection{O método Volere do processo de Engenharia de Requisitos}

Os processos principais de ER consiste em:

- Desenvolvimento de Requisitos;

- Gerenciamento.

Para o método Volere, uma visão do processo da Especificação de Requisitos está sendo representada pela figura 5.1.

Dentro do desenvolvimento de requisitos, o método Volere contempla os seguintes subprocessos do processo de Desenvolvimento (figura 5.2):

- Blastoff;

- Investigação;

- Especificação;

- Portal da Qualidade;

- Prototipagem; 


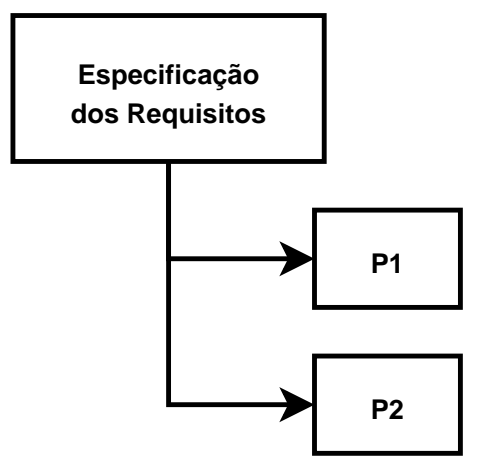

P1: Desenvolvimento dos Requisitos

P2: Gerenciamento

Figura 5.1: Processos do método Volere. A figura mostra dois processos: O desenvolvimento de Requisitos e o Gerenciamento. Neste caso, o gerenciamento foi incluído, pois no Volere não está implícito este processo.

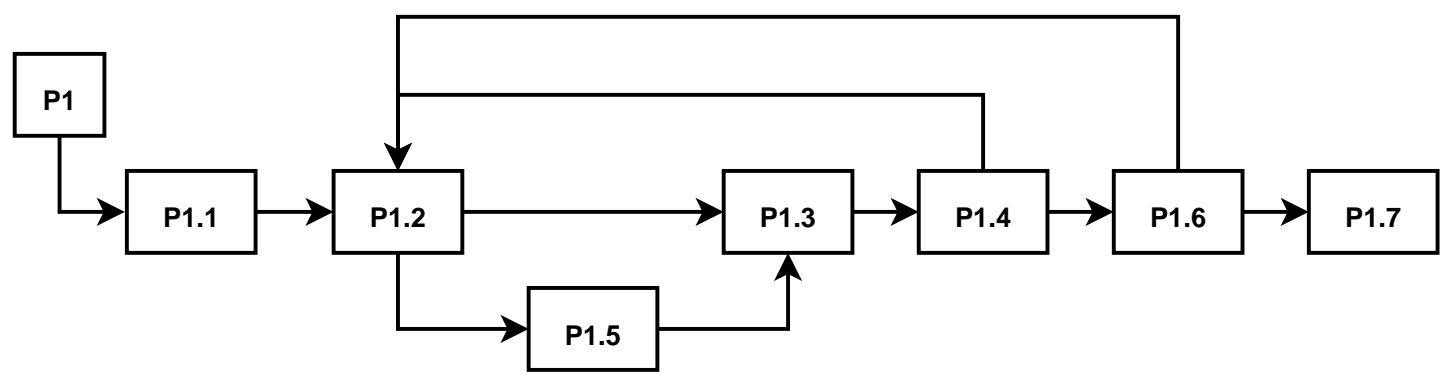
P1.1: Blast off
P1.5: Prototipagem
P1.2: Investigação
P1.6: Repensar os
P1.3: Especificação
P1.7: Post mortem
P1.4: Portal da Qualidade

Figura 5.2: Subprocessos do método Volere. A figura mostra uma visão estruturada dos processos referente ao Desenvolvimento dos Requisitos.

- Repensar os Requisitos;

- Post mortem.

Nos itens a seguir, será detalhado cada processo e suas atividades relevantes.

\subsubsection{Blastoff}

Blastoff vem do inglês que se refere ao processo de ignição de um foguete. O Blastoff tem justamente este propósito, que é preparar tudo que é necessário para o projeto ter início, estar bem fundamentado e ser viável. 
O Blastoff consiste em uma reunião inicial com o objetivo de definir uma série de fundamentos do projeto que serão úteis para qualificá-lo e que serão utilizados como entrada para o levantamento dos requisitos. Estes fundamentos são:

- Propósito do projeto: Algumas frases curtas e mensuráveis do que o produto deve alcançar em relação ao domínio do negócio;

- O cliente: Para quem o produto será construído;

- Os Stakeholders: Quem são as pessoas interessadas no produto;

- Os usuários: Quem irá operar o produto e quais suas qualificações;

- Restrições: Alguma solução de design que deve ser usada e quanto tempo e dinheiro estão disponíveis para o desenvolvimento desta solução;

- Nomes: Quais as terminologias que serão utilizadas no projeto;

- Fatos relevantes e assunções: O que todos os envolvidos no projeto devem saber;

- O escopo do trabalho: Quais são as fronteiras do produto e do projeto;

- A estimativa de custos: quanto esforço ou dinheiro será gasto para que o produto seja possível de fazer;

- Os riscos: Uma pequena análise para revelar os principais riscos do projeto;

Após a análise dos items acima, são determinados se o projeto é viável e se o custo de fazer o produto vale a pena. Além disso, neste processo, o contexto do trabalho é determinado. O contexto do trabalho é um diagrama que situa o projeto em toda a organização, de acordo com o que foi dito por todas as partes envolvidas no projeto.

As atividades que compõem este processo são (a seqüência das atividades do processo de Blastoff está na figura 5.3):

- Preparar para o Encontro de Blastoff: Definir os objetivos do encontro, o arranjo físico e a comunicação com os participantes para a realização do encontro;

- Realizar o encontro: Fazer o levantamento dos fundamentos citados acima; 

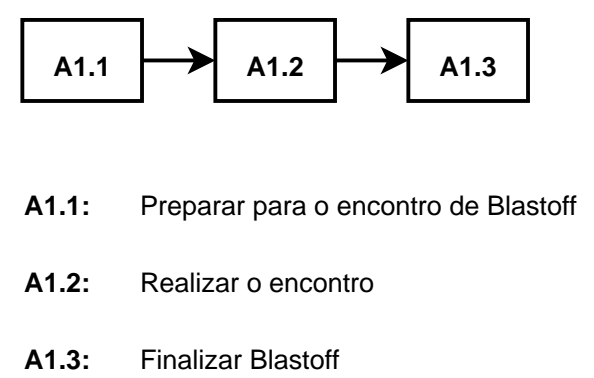

Figura 5.3: Estrutura das atividades do processo de Blastoff

- Finalizar o encontro: Organizar os fundamentos através de um relatório, revisando-o e determinando se o projeto será executado ou não. Este relatório já é o esqueleto da especificação;

\subsubsection{Investigação}

Este processo captura tudo que será parte dos requisitos. Possui como base o processo de Blastoff. O contexto do trabalho, o propósito do produto e as restrições que se aplicam a qualquer solução guiam o analista para saber como estudar o trabalho e como os requisitos serão levantados, enquanto a determinação dos Stakeholders envolvidos no projeto faz com que o analista saiba de quem ele irá levantar as informações referentes aos requisitos do projeto.

Os eventos de negócio são os principais elementos deste processo. O evento de negócio é uma seqüência de atividades que identifica como parte de um trabalho é feito. O analista recebe as informações do contexto do trabalho que foi levantado no processo de Blastoff e determina os eventos de negócio. Para cada evento, é feito uma seqüência de atividades que vem das entrevistas com os envolvidos no projeto.

Os objetivos da Investigação são:

- Estudar o trabalho que atualmente é feito em resposta ao evento de negócio;

- Aprender os desejos e aspirações dos sistemas adjacentes envolvidos nos eventos de negócios;

- Determinar uma melhor resposta que a organização pode fazer para os eventos de negócios;

- Determinar uma maneira do produto contribuir para a resposta desejada;

- Determinar e descrever os requisitos do produto; 
As atividades que compõem este processo são (a seqüência destas atividades está na figura 5.4):

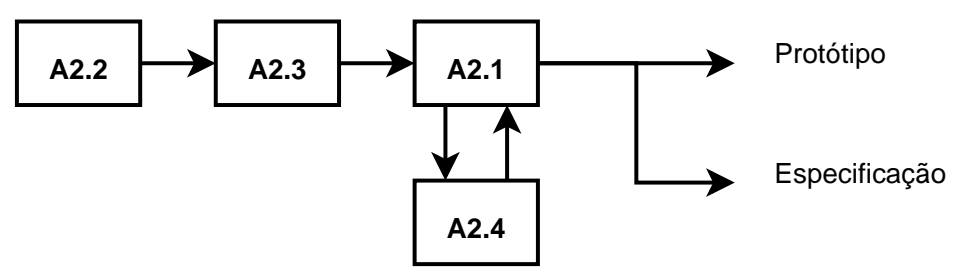
A2.1: $\quad$ Aprender o trabalho
A2.2: Determinar o escopo do produto
A2.3: Fazer o reconhecimento do evento de negócio
A2.4: Perguntar questões de clarificação

Figura 5.4: Estrutura das atividades do processo de Investigação

- Aprender o trabalho: Rever a situação atual do negócio e como o novo projeto será inserido neste contexto, além de aprender tudo que será importante para o projeto através de entrevistas, levantamento de idéias e pesquisas de documentos com o objetivo de levantar os requisitos essenciais;

- Determinar escopo do produto: Analisar os eventos de negócio, estudando os sistemas adjacentes e definindo fronteiras;

- Fazer o reconhecimento de eventos: Coletar o conhecimento de todos os eventos de negócio e determinar técnicas apropriadas de fazer a investigação;

- Perguntar questões de clarificação: Tirar dúvidas com os entrenvistados sobre os eventos de negócios levantados.

No final do processo pode-se ter duas saídas:

- Os eventos de negócio estão claros e podem ser incluídos na especificação (secção 5.1.3);

- Os eventos de negócio não estão claros, sendo necessário a utilização de protótipos para uma avaliação melhor (secção 5.1.5); 


\subsubsection{Especificação}

O processo de Especificação possui o objetivo de se criar uma descrição completa do produto a ser construído.

No processo de Investigação ou Prototipagem, os requisitos encontrados não estão todos bem formulados. Há somente idéias ou intenções para os requisitos. Por outro lado, a especificação de requisitos produzida é a base do contrato para construir o artefato e este deve conter as instruções claras, completas e testadas do que tem que ser construído.

As atividade deste processo são (a seqüência de atividades do processo de especificação está apresentada na figura 5.5):

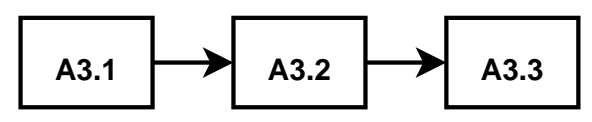
A3.1: Identificar os tipos de requisitos
A3.2: $\quad$ Escrever os critérios de seleção
A3.3: $\quad$ Formalizar os requisitos

Figura 5.5: Estrutura das atividades do processo de Especificação

- Identificar os tipos de requisitos: Identificar todos os tipos de requisitos: potenciais, funcionais, não funcionais, dependentes, conflitantes e compostos;

- Escrever os critérios de seleção: Escrever os critérios funcionais e não funcionais;

- Formalizar os requisitos: Formalizar requisitos e restrições do sistema.

\subsubsection{Portal da Qualidade}

O Portal da Qualidade é um processo em que cada requisito é examinado para determinar se é adequado para incluir na especificação. O objetivo é evitar a inclusão de requisitos incorretos e o mesmo ir para o design e a implementação do produto no qual será muito difícil e caro para encontrar e corrigir.

O processo Portal da Qualidade é compreendido pelas seguintes atividades (a seqüência das atividades desse processo está na figura 5.6): 


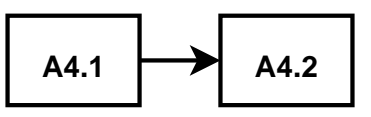

A4.1: Revisar Requisitos

A4.2: Identificar Requisitos supérfluos

Figura 5.6: Estrutura das atividades do processo Portal da Qualidade

- Revisar Requisitos: Revisar os critérios de ajustes, relevância, completude e viabilidade dos requisitos;

- Identificar requisitos supérfluos: Identificar se o requisito é parte importante na especificação ou é somente algo que não faz diferença se tiver ou não;

\subsubsection{Prototipagem}

O propósito da prototipagem é simular aspectos do produto e fazê-lo real o suficiente para ajudar o usuário a pensar sobre os requisitos que poderiam estar perdidos. Durante o processo de Investigação, alguns requisitos não estão claros ou percebe-se que há uma necessidade de fazer alguns experimentos para descobrir requisitos. Assim, constrói-se simulações do possível produto, testando-os com os usuários. A intenção é dar ao usuário a oportunidade de trabalhar com algo real, e assim ter uma idéia melhor do que é necessário para seu trabalho. A descoberta de requisitos no processo de Prototipagem é tratada da mesma maneira que a descoberta dos requisitos no processo de Investigação.

Como a prototipagem é potencialmente mais cara que outros métodos de coleta de requisitos, somente use este processo quando:

- O produto nunca existira antes ou é difícil de visualizá-lo;

- Os usuários não possuem experiência com o tipo do produto, nem com a tecnologia proposta;

- Os usuários fizeram este trabalho por algum tempo e não se lembram exatamente como era feito;

- Os usuários não conseguem articular seus requisitos;

- O analista de requisitos está com problemas de entender o que é requisitado; 
- A exeqüibilidade do requisito está sendo questionada.

A seguir, serão apresentadas as atividades deste processo (uma seqüência representativa destas atividades está na figura 5.7):

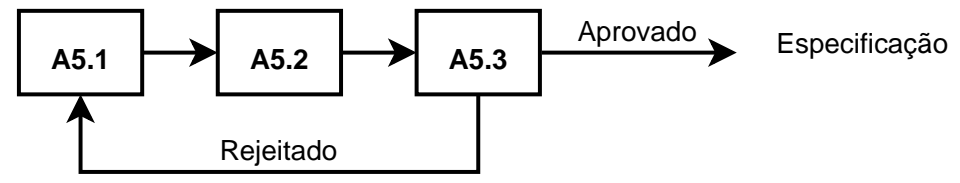

A5.1: Planejar protótipo

A5.2: Construir protótipo

A5.3: Avaliar protótipo

Figura 5.7: Estrutura das atividades do processo de Prototipagem

- Planejar protótipo: Criar protótipos, adaptar ou usar protótipos existentes, decidir se vai utilizar um protótipo de baixa fidelidade (usando lápis, papel e uma pessoa) ou de alta fidelidade (ferramentas específicas);

- Construir protótipo: Desenvolver o protótipo de acordo com que foi definido no item anterior;

- Avaliar protótipo: Testar com o usuário se o protótipo satisfaz o objetivo proposto. Caso negativo, será necessário uma nova iteração;

\subsubsection{Repensar os Requisitos}

O processo de Repensar os Requisitos consiste em fazer uma análise global dos requisitos. O objetivo é revisar a especificação e encontrar requisitos que estão perdidos, conflitantes e/ou ambíguos. Este processo possui os seguintes objetivos:

- Medir novamente o esforço necessário para construir o produto;

- Analisar novamente os riscos envolvidos para completar o projeto;

- Avaliar novamente a decisão de continuar ou interromper o projeto;

Para cumprir os objetivos listados acima, as seguintes atividades são desenvolvidas nesse processo (na figura 5.8 está apresentada a seqüência de atividades referente a este processo): 


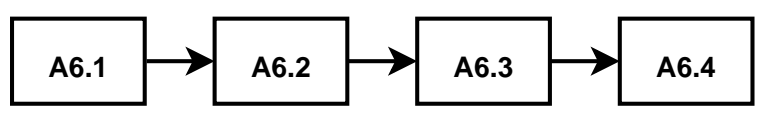

A6.1: Revisar o contexto da especificação

A6.2: Avaliar os riscos de requisitos

A6.3: Estimar esforços

A6.4: Publicar a especificação revisada

Figura 5.8: Estrutura das atividades do processo de Repensar os Requisitos

- Revisar o contexto da especificação: Identificar requisitos perdidos, conflitantes e ambíguos;

- Avaliar os riscos de requisitos: Avaliar novamente os riscos do produto;

- Estimar esforços: Estimar novamente esforços;

- Publicar a especificação revisada: Refazer a especificação com o contexto revisado.

\subsubsection{Post Mortem}

O processo de Post mortem possui o objetivo de unir informações a respeito de todo o levantamento do projeto. O processo consiste em entrevistar todas as pessoas envolvidas na etapa de requisitos, buscando comentários sobre pontos fortes, pontos fracos, possíveis melhorias a idéias para os próximos levantamentos de requisitos.

As atividades desse processo são (representada pela figura 5.9):

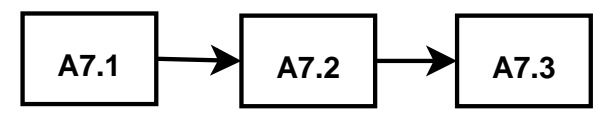

A7.1: $\quad$ Buscar entradas para revisão

A7.2: $\quad$ Fazer o Post mortem

A7.3: $\quad$ Construir os filtros de requisitos

Figura 5.9: Estrutura das atividades do processo de Post mortem 
- Buscar entradas para revisão: Buscar através de encontros individuais e em grupo tudo que foi relevante para o processo de levantamento e especificação de requisitos;

- Fazer o Post mortem: Fazer um relatório com as informações levantadas na atividade citada acima;

- Construir os filtros de requisitos: Preparar um documento que servirá de base para futuros levantamentos de requisitos.

No próximo capítulo será feito uso desses processos/atividades determinados neste capítulo para um estudo de caso. Serão identificados os parâmetros para o $\mathrm{ABC}$ e seus atributos, direcionadores e recursos. 


\section{Estudo de Caso}

\subsection{Introdução}

O objetivo deste capítulo é mostrar através de um estudo de caso, como o modelo proposto no capítulo 5 poderá ser desenvolvido. Esse estudo de caso consistirá em um exemplo de um projeto real de uma empresa, destacando a etapa de ER. A partir desse exemplo, será feito um comparativo entre o que o método apresentado nos dirá sobre o custo neste caso e o que a empresa estimou de custo para cumprir esta etapa.

Nas secções a seguir, serão apresentados os materiais e métodos utilizados, o escopo do projeto, o tratamento das informações recebidas e o resumo de cada atividade com seus parâmetros para o ABC.

\subsection{Materiais e Métodos}

Os materiais e métodos empregados estão listados a seguir:

1. Busca de informações em sistema específico;

2. Busca de informações sobre o projeto;

3. Tratamento dos dados levantados em relação à:

(a) Atividades;

(b) Recursos ${ }^{1}$;

4. Classificação dos dados em relação ao modelo ABC e o método Volere.

Nos próximos itens, serão detalhados os passos citados acima.

\footnotetext{
${ }^{1}$ Recursos neste caso se refere somente a recursos humanos
} 


\subsubsection{Busca de Informações sobre o projeto}

Inicialmente, foram levantadas algumas informações de escopo e objetivos em relação ao projeto. Estas informações foram obtidas na proposta do projeto que foi enviada ao cliente.

\subsubsection{Busca de Informações em sistema específico}

As informações foram obtidas do sistema GePro. Devido ao grande número de projetos, a empresa sentiu a necessidade de criar esta ferramenta para controle dos projetos. Esse controle permitiu o detalhamento das atividades dentro de um projeto e também a distribuição por tempo nos projetos. Com isso, permitiu-se incluir apontamentos, comissões e estatísticas de projetos e dessa forma ter maior controle de prazos e identificar qual atividade do projeto tomou mais tempo.

Inicialmente este sistema só controlava os projetos, no qual os colaboradores incluia suas atividades desenvolvidas e o coodenador validava as atividades e verificava o andamento dos projetos. Mas atualmente, o sistema permite além de controlar os projetos no ponto de vista de processos, permite controlar o projeto pelo ponto de vista financeiro, no qual o sistema recebeu o nome de SiGE (Sistema de informações GErenciais) tendo o GePro como um módulo.

O SiGE (mais especificamente, o GePro) é totalmente baseado na Web, cada tipo de usuário (colaborador, coordenador, recursos humanos, etc.), tem acesso a certas partes do sistema e o programa fica encarregado de organizar estas informações e mostrá-las de acordo com a necessidade e com as limitações de cada tipo de usuário.

Os dados relativos ao total de horas gastas por atividade e os recursos envolvidos no projeto puderam ser obtidos diteramente pelo sistema. Como a finalidade do sistema é obter dados financeiros do projeto (como horas totais utilizadas por pessoa, comparando com o que foi planejado), informações sobre horas gastas por recurso em cada atividade, foram obtidas através de consultas com a Base de Dados deste sistema.

Os dados obtidos foram:

- Relação tempo por atividade;

- Recursos e horas gastas por recursos (pessoal) em cada atividade;

Os resultados desta consulta foram todas as atividades determinadas para 
execução do projeto e as horas gastas por pessoal nestas atividades.

Tendo os requisitos como escopo do presente trabalho, foram separadas as atividades relacionadas aos requisitos das outras atividades relativas ao projeto.

\subsubsection{Tratamento dos dados levantados}

Como o desenvolvimento do processo de ER para o estudo de caso que será analisado não foi feito pelo método Volere, foi necessário adaptar as etapas do projeto para esse método, de acordo com escopo do projeto e os relatórios de atividades. Além disso, os únicos parâmetros que se tinha no estudo de caso eram as atividades em um nível macro e o tempo gasto para as mesmas. Assim, foi necessário distribuir os tempos gastos nas as atividades contidas no projeto que puderam ser classificadas como requisitos e especificação nas atividades apresentadas pelo Volere. Esta etapa contou com a ajuda dos gerentes e dos colaboradores do projeto.

Após decompor as atividades, foi necessário adaptar a participação de cada recurso com as atividades do método Volere. Isto também foi feito através de entrevistas com os gerentes do projeto.

Como última etapa, foi determinado para cada atividade do método Volere, o tempo total estimado, a participação percentual de cada recurso e os direcionadores de custo.

\subsection{Sobre a Empresa a ser estudada}

A empresa analisada trata-se de uma pequena empresa prestadora de serviços de consultoria referente a custos, processos, e há algum tempo, está desenvolvendo sistemas relativos às esses temas. Possui bancos como principais clientes.

A empresa não possui um processo de ER (os gerentes consideram este processo como ad hoc), mas os gerentes sabem da importância de se fazer os requisitos para evitar problemas futuros. A grande dificuldade é fazer alguns clientes entender a importância de se cumprir a etapa de requisitos no início do projeto. 


\subsection{Sobre o processo de contratação de um pro- jeto}

Na empresa estudada, a etapa de pré-projeto é a etapa inicial de contratação de um projeto. Ela é iniciada pela demanda que pode partir tanto do cliente quanto da empresa. Após esta demanda, é feito um pré-levantamento que consiste em obter uma noção da dimensão do projeto (quantas pessoas dentro do lado cliente estarão envolvidas, quantas áreas, qual o tamanho de cada área), nesta etapa, tem-se uma estimativa bem grosseira do tempo para execução de tal projeto. A seguir, é elaborada uma proposta e preparada uma apresentação. Na elaboração da proposta, é estudada a possibilidade de incluir uma etapa de especificação ou não. Este estudo de inclusão da etapa de especificação, segundo um gerente de projeto da empresa, consiste em determinar as oportunidades que o projeto trará e se a dimensão do projeto requer um especificação ou não. Finalmente, é feita uma reunião de apresentação do projeto para aprovação.

Caso o projeto seja aprovado, uma proposta mais detalhada será feita, nesta proposta, é determinado o preço do projeto e pode ou não ser incluído nesse preço o custo de tudo que foi feito anteriormente (a empresa, pode tomar esta decisão pelos mesmos motivos citados na decisão da inclusão da especificação). Na empresa estudada, a determinação do preço do projeto é dada pela quantidade de horas contratada pelo cliente multiplicado pelo custo de cada recurso humano utilizado (este já inclui o custo referente aos overheads do recurso), acrescido uma margem de lucro.

Caso o projeto não seja aprovado, a empresa arca com o custo do pré-projeto e este é contabilizado nos custos gerenciais da empresa.

\subsection{O projeto}

Buscando ampliar as visões e entendimentos dos processos de negócios do Banco "A", melhorar a integração entre a cultura de processos e a cultura de custos e minimizar o esforço para levantamento e tratamento de dados, surgiu a necessidade de ter disponível uma ferramenta para apoio na tradução dos modelos de processos para o modelo ABC (de acordo com a figura 6.1).

Este projeto tem como objeto a prestação de serviços de Consultoria, Desenvolvimento e Implementação de Interface entre a ferramenta de modelagem de 


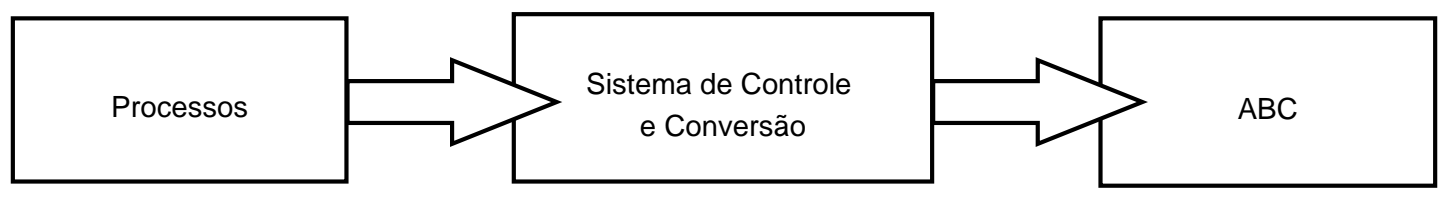

Figura 6.1: Proposta de solução do projeto. A proposta de solução é de uma ferramenta que consiga extrair as informações de processos, trate estes dados e transfira para o sistema de cálculo do ABC.

processos $\left(\mathrm{ARIS}^{2}\right)$ e o sistema de ABC do Banco "A", baseado na Metodologia de Documentação Corporativa de Processos para o Departamento de Organização e Métodos do Banco "A".

O objetivo principal é disponibilizar uma solução tecnológica para a interface entre o software de processos e o software de ABC, que permita a exportação dos dados dos objetos levantados em processos para o software de custos.

Atualmente os dados provenientes do software de Processos, em formato bruto, não podem ser importados diretamente para o software de cálculo de custeio. É necessário o tratamento das informações, visando sua adequação para o custeio. Atualmente, os dados validados provenientes da ferramenta denominada DOCEASIER recebem este tratamento em ambiente Microsoft ${ }^{\circledR}$ Excell $^{3}$ e Microsoft ${ }^{\circledR}$ Access $^{4}$. As seguintes etapas são executadas:

- Montagem dos objetos de custos e seus relacionamentos;

- Distribuição dos objetos de suporte;

- Tratamento da Agência Padrão;

- Associação de dados estatísticos aos objetos.

A implementação da nova metodologia de processos, através do software de Processos, levará aos seguintes impactos no tratamento de dados para o ABC:

- O novo modelo de processos exigirá alterações nos tratamentos executados (citados acima). O processamento dos dados, que hoje está preparado para as informações do DOCEASIER, deverá ser adequado para a nova estrutura de dados gerada pelo software de Processos;

- Será necessária uma revisão da modelagem no software de cálculo do ABC, devido à alteração conceitual das informações de origem.

\footnotetext{
${ }^{2}$ Copyright $@$ CIDS Scheer AG

${ }^{3}$ Copyright (C)Microsoft Corporation

${ }^{4}$ Copyright (C)Microsoft Corporation
} 
- O ABC necessita da totalidade dos produtos do Banco "A" modelados no software de Processos, a fim de ser possível o cálculo dos custos da nova árvore de produtos. A implementação parcial, no software de cálculo do ABC, não é possível.

É importante ressaltar que a integração não será realizada diretamente para o software de custos, pois existem alguns fatores o qual será necessário a interação do usuário para devida interpretação para após incluir no sistema de custeio.

O Sistema a ser desenvolvido irá simplificar sobremaneira este processo, embora não irá automatizá-lo por completo, mas gerando as informações necessárias para o tratamento no sistema de custeio.

Como principais benefícios esperados do presente Projeto, podemos destacar:

- Integração e uniformização dos dados levantados em processos com os dados do ABC.

- Automatização de toda conversão necessária para a tradução do modelo de processos para o modelo de custos ABC;

- Simplificação e Racionalização do tempo e dos procedimentos de levantamentos de processos para diferentes necessidades do Banco "A";

- Visão dos Processos de Negócios e Serviços e suas respectivas Cadeia de Valor;

- Elaboração de base única de informações de processos integrada, para atender as necessidades como ISO, ABC, ABM, controles internos, análise e modelagem de Processos;

- Documentação e manutenção dos processos e atividades das Dependências da Organização de forma descentralizada;

\subsection{Informações obtidas}

\subsubsection{Recursos}

A tabela 6.1 mostra os recursos participantes do projeto. Estes foram divididos em três grupos:

- Gerentes: denominado GE; 
- Consultores de Sistemas: denominado CS;

- Analistas de Sistemas: denominado AS;

Para a etapa de requisitos, nem todos os recursos foram utilizados, os outros recursos, foram utilizados somente em etapas posteriores ao projeto ou foram fazendo parte da equipe do projeto após a especificação estar pronta.

Tabela 6.1: Informações de Recursos obtidos no sistema GePro

\begin{tabular}{lll}
\hline Gerentes (GE) & Consultores (CS) & Analistas (AS) \\
\hline GE01* & CS01* & AS01* \\
GE02* & CSO2* $^{*}$ & AS02* \\
& CS03* & AS03 \\
& CS04* & AS04* \\
& & AS05 \\
& & AS06* \\
& & AS07 \\
\hline
\end{tabular}

${ }^{*}$ Recursos que foram utilizados na etapa de requisitos

O custo de cada recurso, ${ }^{5}$ está na tabela à seguir (tabela 6.2). Neste custo está excluso a margem de lucro de cada recurso.

Tabela 6.2: Informações de custo de Recursos

\begin{tabular}{lr}
\hline Recurso & Custo(por hora) \\
\hline GE & $\$ 40,00$ \\
CS & $\$ 30,00$ \\
AS & $\$ 25,00$ \\
\hline
\end{tabular}

\subsubsection{Atividades e Horas}

As atividades obtidas estão na tabela 6.3. A coluna denominada classificação não foi obtida no sistema, mas sim informada pelos gerentes do projeto.

Separando as atividades relativas aos requisitos e especificações, obteve-se a tabela 6.4, no qual, as atividades consistem em:

\footnotetext{
${ }^{5}$ Este custo é fictício e é somente para determinação do custo do processo de ER deste trabalho
} 
Tabela 6.3: Informações de Atividades obtidas no sistema GePro

\begin{tabular}{lll}
\hline Atividade & Horas & Classificação \\
\hline DISCUTIR CRITÉRIOS & 694 & Requisitos \\
ESPECIFICAR SISTEMAS & 345 & Requisitos \\
ESTUDO DO MODELO E DO ARIS & 225 & Requisitos \\
DESENVOLVIMENTO INTERFACE - VB & 1357 & Implementação \\
SCRIPTS - VALIDAÇÃO E GERAÇÃO DO GUCP & 436 & Implementação \\
DOCUMENTACAO DO SISTEMA & 48 & Testes \\
ACOMPANHAMENTO DE PERFORMANCE DO SIS- & 24 & Testes \\
TEMA & & \\
\hline
\end{tabular}

- Discutir criérios: Esta é a principal atividade que se refere a elicitação, análise, verificação e validação de requisitos. Ela consiste em verificar juntamente com o cliente o que adotar de premissas, onde e como obter as informações, entrevistar os usuários para identificar necessidades, apresentar a especificação para verificação e validação do cliente. No projeto estudado, esta atividade também recebeu as horas referente ao pré-projeto;

- Especificar sistemas: Formalizar o que foi levantado na discussão dos critérios;

- Estudo do modelo e do ARIS: Esta atividade consiste em desenvolver protótipos para saber como a ferramenta se comporta para cumprir os objetivos do projeto.

Tabela 6.4: Informações de Atividades referentes aos requisitos e especificações

\begin{tabular}{llll}
\hline Código & Atividade & Horas & Horas(\%) \\
\hline 1 & DISCUTIR CRITÉRIOS & 694 & $54,89 \%$ \\
2 & ESPECIFICAR SISTEMAS & 345 & $27,31 \%$ \\
3 & ESTUDO DO MODELO E DO ARIS & 225 & $17,80 \%$ \\
\hline \multicolumn{3}{l}{ Total } & 1264 \\
\hline
\end{tabular}

Assim, foi feita a distribuição das atividades da tabela 6.4 nos processos e atividades para o método Volere. A partir da distribuição, foi feita uma estimativa de quanto tempo (em percentagem) foi gasto nas atividades e após isso, esta estimativa foi adaptada para que se obtenha os tempos em horas. Esta estimativa foi feita através de entrevistas com os gerentes deste projeto e o resultado encontra-se na tabela 6.5. 
Tabela 6.5: Distribuição das atividades do método Volere tomando como base as atividades descritas na tabela 6.4

\begin{tabular}{lllr}
\hline Processo & Atividade & Etapa & \% Atribuída \\
\hline \multirow{3}{*}{ BLASTOFF } & Preparar para o encontro de Blastoff & 1 & $1 \%$ \\
& Realizar o encontro & 1 & $3 \%$ \\
& Finalizar o Blastoff & 1 & $1 \%$ \\
\hline \multirow{3}{*}{ INVESTIGAÇÃO } & Aprender o trabalho & 3 & $20 \%$ \\
& Determinar o escopo do produto & 1 & $30 \%$ \\
& Reconhecer os eventos de negócio & 1 & $30 \%$ \\
& Perguntar questões de clarificação & 1 & $5 \%$ \\
\hline \multirow{3}{*}{ ESPECIFICAÇÃO } & Identificar os tipos de requisitos & 2 & $15 \%$ \\
& Escrever critérios de seleção & 2 & $10 \%$ \\
& Formalizar os requisitos & 2 & $60 \%$ \\
\hline PORTAL DA & Revisar Requisitos & 1 & $5 \%$ \\
QUALIDADE & Identificar requisitos supérfluos & 1 & $5 \%$ \\
\hline \multirow{3}{*}{ PROTOTIPAGEM } & Planejar protótipo & 3 & $15 \%$ \\
& Construir protótipo & 3 & $50 \%$ \\
& Avaliar protótipo & 3 & $15 \%$ \\
\hline \multirow{2}{*}{ REPENSAR OS } & Revisar o contexto da especificação & 2 & $5 \%$ \\
REQUISITOS & Avaliar os riscos de requisitos & 1 & $10 \%$ \\
& Estimar esforços & 2 & $5 \%$ \\
& Publicar a especificação revisada & 2 & $5 \%$ \\
\hline \multirow{3}{*}{ POST MORTEM } & Buscar entradas para revisão & 1 & $3 \%$ \\
& Fazer o Post mortem & 1 & $5 \%$ \\
& Construir os filtros de requisitos & 1 & $2 \%$ \\
\hline
\end{tabular}

\subsubsection{Recursos e Atividades}

Neste ponto, a análise do estudo de caso seguiu dois caminhos:

- Foram analisados os dados reais do desenvolvimento da etapa de requisitos (que foi denominado "Realizado");

- A partir dos dados de participação dos recursos nas atividades do realizado, foram analisados os dados, se no projeto fossem utilizados os recursos no tempo planejado (denominado "Planejado");

\subsubsection{Análise do Realizado}

A distribuição das horas gastas pelos recursos nas atividades, foram feitas de duas maneiras: 
1. Pela participação dos recursos em cada atividade levantada pelo sistema de Gerenciamento de Projetos (tabela 6.6);

2. Pela participação de cada recurso nas atividades levantadas pelo mesmo sistema (tabela 6.7);

Tabela 6.6: Distribuição dos recursos em cada atividades referente aos requisitos, obtida através do GePro. Esta distribuição mostra a participação de cada recurso para cumprimento de cada atividade que foi realizada durante o projeto.

\begin{tabular}{|c|c|c|c|c|}
\hline Cod & Atividade & Rec. & Horas & $\operatorname{Horas}(\%)$ \\
\hline \multirow[t]{11}{*}{1} & DISCUTIR CRITÉRIOS & & & \\
\hline & & GE01 & 44 & $6,34 \%$ \\
\hline & & GE02 & 179 & $25,79 \%$ \\
\hline & & CS01 & 25 & $3,60 \%$ \\
\hline & & CS02 & 280 & $40,35 \%$ \\
\hline & & CS03 & 4 & $0,58 \%$ \\
\hline & & CS04 & 64 & $9,22 \%$ \\
\hline & & AS01 & 64 & $9,22 \%$ \\
\hline & & AS02 & 0 & $0,00 \%$ \\
\hline & & $\mathrm{AS} 04$ & 34 & $4,90 \%$ \\
\hline & & AS06 & 0 & $0,00 \%$ \\
\hline \multirow[t]{11}{*}{2} & ESPECIFICAR SISTEMAS & & & \\
\hline & & GE01 & 0 & $0,00 \%$ \\
\hline & & GE02 & 0 & $0,00 \%$ \\
\hline & & CS01 & 93 & $26,96 \%$ \\
\hline & & CS02 & 0 & $0,00 \%$ \\
\hline & & CS03 & 72 & $20,87 \%$ \\
\hline & & CS04 & 0 & $0,00 \%$ \\
\hline & & AS01 & 0 & $0,00 \%$ \\
\hline & & $\mathrm{AS} 02$ & 140 & $40,58 \%$ \\
\hline & & AS04 & 0 & $0,00 \%$ \\
\hline & & AS06 & 40 & $11,59 \%$ \\
\hline \multirow[t]{11}{*}{3} & ESTUDO DO MODELO E DO ARIS & & & \\
\hline & & GE01 & 0 & $0,00 \%$ \\
\hline & & GE02 & 0 & $0,00 \%$ \\
\hline & & CS01 & 64 & $28,44 \%$ \\
\hline & & CS02 & 0 & $0,00 \%$ \\
\hline & & CS03 & 0 & $0,00 \%$ \\
\hline & & CS04 & 1 & $0,44 \%$ \\
\hline & & AS01 & 72 & $32,00 \%$ \\
\hline & & AS02 & 8 & $3,56 \%$ \\
\hline & & AS04 & 24 & $10,67 \%$ \\
\hline & & AS06 & 56 & $24,89 \%$ \\
\hline
\end{tabular}

Finalmente, foi feita uma tabela com informações de Tempo, Recursos e Direcionadores para cada processo/ atividade do método Volere. Os dados de re- 
Tabela 6.7: Distribuição de cada recurso nas atividades referente aos requisitos obtida através do GePro. A tabela mostra a participação de cada recurso para o cumprimento de todas as atividades realizadas.

\begin{tabular}{lrrr}
\hline Cod & Atividade 1 & Atividade 2 & Atividade 3 \\
\hline GE01 & $100,00 \%$ & $0,00 \%$ & $0,00 \%$ \\
GE02 & $100,00 \%$ & $0,00 \%$ & $0,00 \%$ \\
CS01 & $13,74 \%$ & $51,10 \%$ & $35,16 \%$ \\
CS02 & $100,00 \%$ & $0,00 \%$ & $0,00 \%$ \\
CS03 & $5,26 \%$ & $94,74 \%$ & $0,00 \%$ \\
CS04 & $98,46 \%$ & $0,00 \%$ & $1,54 \%$ \\
AS01 & $47,06 \%$ & $0,00 \%$ & $52,94 \%$ \\
AS02 & $0,00 \%$ & $94,59 \%$ & $5,41 \%$ \\
AS04 & $58,62 \%$ & $0,00 \%$ & $41,38 \%$ \\
AS06 & $0,00 \%$ & $41,67 \%$ & $58,33 \%$ \\
\hline
\end{tabular}

cursos, foram obtidos adaptando as percentagens da participação dos recursos nas atividades descritas na tabela 6.6 nos dados da distribuição de percentagens (com os devidos ajustes) das atividades do Volere da tabela 6.6. A tabela está no Apêndice A.

\subsubsection{Análise do Planejado}

Da mesma forma que foi conduzida a distribuição das atividades determinadas no projeto para o método Volere e a distribuição dos recursos participantes da etapa de requisitos do que foi realizado, também foram feitas essas determinações referente ao que foi planejado inicialmente. Na proposta do projeto, foram sugeridas duas atividades: uma de Levantamento e outra de Especificação nas quais foram estimados 20 dias úteis para cumprimento destas.

Neste caso, a proposta previa a mesma quantidade de recursos do que foi realizado. Tanto para os Consultores quanto para os Analistas, foi determinado que esses recuros estariam em tempo integral na realização do projeto (ou seja, 8 horas diárias, 160 horas totais referente à etapa de Levantamento e Especificação), e os gerentes estariam em tempo parcial (4 horas diárias, 80 horas totais).

Assim, para determinar o custo referente ao que foi planejado, teve-se como base a distribuição dos recursos em todas as atividades realizadas referente aos requisitos levantados pelo sistema GePro, de acordo com a tabela 6.7. Esta talela serviu de base para distribuir as horas planejadas nas atividades do método Volere. Da mesma forma que se obteve a tabela 6.6 obteve-se uma tabela equivalente do que foi planejado (tabela 6.8). A tabela de levantamento de Tempo, 
Recursos e Direcionadores para cada atividade do método Volere encontra-se no Apêndice B.

Tabela 6.8: Distribuição dos recursos em cada atividades referente ao que foi planejado, tendo como base a percentagem da participação de cada recurso nas atividade referente aos requisitos (de acordo com a tabela 6.7). Esta distribuição mostra a participação de cada recurso para cumprimento das atividades realizadas mas utilizando-se das atividades que foram realizada durante o projeto.

\begin{tabular}{|c|c|c|c|c|}
\hline Cod & Atividade & Rec. & Horas & $\operatorname{Horas}(\%)$ \\
\hline \multirow[t]{11}{*}{1} & DISCUTIR CRITÉRIOS & & & \\
\hline & & GE01 & 80 & $11,82 \%$ \\
\hline & & GE02 & 80 & $11,82 \%$ \\
\hline & & CS01 & 22 & $3,25 \%$ \\
\hline & & CS02 & 160 & $23,63 \%$ \\
\hline & & CS03 & 8 & $1,24 \%$ \\
\hline & & $\mathrm{CS} 04$ & 158 & $23,27 \%$ \\
\hline & & AS01 & 75 & $11,12 \%$ \\
\hline & & AS02 & 0 & $0,00 \%$ \\
\hline & & $\mathrm{AS} 04$ & 94 & $13,85 \%$ \\
\hline & & AS06 & 0 & $0,00 \%$ \\
\hline \multirow[t]{11}{*}{2} & ESPECIFICAR SISTEMAS & & & \\
\hline & & GE01 & 0 & $0,00 \%$ \\
\hline & & GE02 & 0 & $0,00 \%$ \\
\hline & & CS01 & 82 & $18,18 \%$ \\
\hline & & $\mathrm{CS} 02$ & 0 & $0,00 \%$ \\
\hline & & CS03 & 152 & $33,70 \%$ \\
\hline & & CS04 & 0 & $0,00 \%$ \\
\hline & & AS01 & 0 & $0,00 \%$ \\
\hline & & $\mathrm{AS} 02$ & 150 & $33,26 \%$ \\
\hline & & AS04 & 0 & $0,00 \%$ \\
\hline & & AS06 & 67 & $14,86 \%$ \\
\hline \multirow[t]{11}{*}{3} & ESTUDO DO MODELO E DO ARIS & & & \\
\hline & & GE01 & 0 & $0,00 \%$ \\
\hline & & GE02 & 0 & $0,00 \%$ \\
\hline & & $\mathrm{CS} 01$ & 56 & $17,95 \%$ \\
\hline & & $\mathrm{CS} 02$ & 0 & $0,00 \%$ \\
\hline & & $\mathrm{CSO3}$ & 0 & $0,00 \%$ \\
\hline & & CS04 & 2 & $0,64 \%$ \\
\hline & & AS01 & 85 & $27,24 \%$ \\
\hline & & $\mathrm{AS} 02$ & 10 & $3,21 \%$ \\
\hline & & $\mathrm{AS} 04$ & 66 & $21,15 \%$ \\
\hline & & AS06 & 93 & $29,81 \%$ \\
\hline
\end{tabular}

Com o modelo pronto, é interessante ter uma ferramenta para agilizar o cálculo do custo do processo. Essa ferramenta foi desenvolvida em uma planilha do Microsoft ${ }^{\circledR}$ Excell 2000. Nesta ferramenta, serão determinados os recursos, os 
direcionadores, o tempo desenvolvido em cada atividade e o volume, além de ser distribuído os esforços de cada recurso nas atividades.

\subsection{Ferramenta de Cálculo de custo}

A ferramenta criada, consiste em um protótipo para o cálculo do custo do processo de ER. Esta tem o objetivo de automatizar o cálculo do custo, dado os recursos, os direcionadores, o tempo de cada atividade, o volume e a percentagem de cada recurso nas atividades.

A ferramenta consiste em quatro planilhas:

1. Recursos;

2. Direcionadores;

3. Atividades;

4. Atividades - Detalhes;

A planilha Recursos é responsável por incluir os recursos humanos (pessoal), os recursos de informática e os recursos de infraestrutura. Esta planilha está na figura 6.2 com o preenchimento dos recursos pertencente ao estudo de caso. Nesta planilha deve-se inserir os seguintes dados:

- Código: Código para representar o recurso;

- Descrição: Uma descrição breve do recurso;

- Custo: O custo por hora do recurso;

A planilha Direcionadores é responsável por conter os direcionadores de custeio para o ABC. A planilha Direcionadores devidamente preenchida com os dados deste estudo de caso está na figura 6.3. Nesta planilha deve-se incluir os seguintes campos:

- Código: O código do direcionador;

- Descrição: Uma descrição do direcionador;

Há também a planilha em que se insere os dados das atividades do projeto. Esta planilha é denominada Atividades. A planilha Atividades é responsável por 
maneiras:

- Pelo tempo total da atividade considerando todos os recursos. Neste caso, a distribuição dos recursos nas atividades deve somar 100\%;

- Pelo tempo gasto por recurso na atividade. Neste caso, deve-se fazer uma distribuição percentual de cada recurso na planilha Atividade Detalhe variando até $100 \%$ (que significa uma participação na atividade em tempo integral);

- Recursos: Indica quais recursos participam do projeto.

- Direcionador: Indica qual é o direcionador de custo desta atividade;

- Volume: Volume da atividade de acordo com o direcionador escolhido. Para o ABC, o volume pode ser por dedicação (neste caso, o volume é unitário) ou por repetição (neste caso, deve-se determinar quantas vezes a atividade é executada por processo);

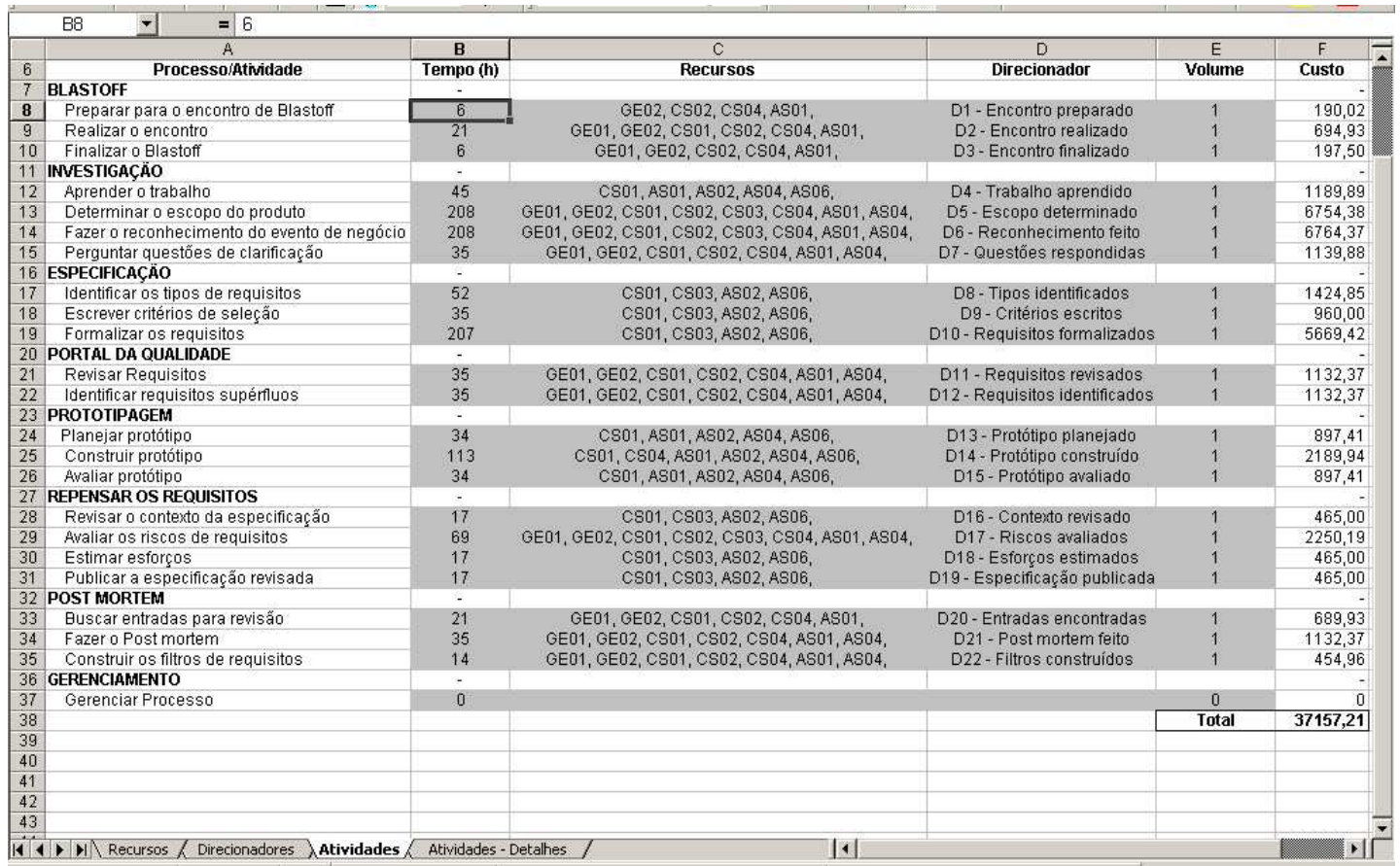

Figura 6.4: Planilha de Atividades. Esta é a principal planilha do protótipo. Nesta incluem-se os recursos criados na planilha Recursos, os direcionadores da planilha Direcionadores, além de incluir o tempo e o volume. Além disso, nesta planilha é fornecido o custo de cada atividade e o custo total.

Para incluir recursos e direcionadores, na atividade referente, dê um duplo clique na coluna Recursos ou Direcionador, respectivamente. Ao clicar duas vezes na coluna de Recursos, a janela representada na figura 6.5 aparecerá, neste caso, 
pode-se incluir um ou mais recursos, relacionando aqueles que participarão da atividade (na coluna da esquerda da janela) e clicando no botão ">" para incluir. Da mesma forma, para excluir um ou mais recursos, selecione aqueles da coluna da direita da janela que deseja remover e clique no botão " $<$ ". Pode-se clicar no botão "Fechar" para fechar a janela. Ao clicar duas vezes na coluna Direcionador da planilha Atividades, a janela representada pela figura 6.6 aparecerá. Para incluir um direcionador, selecione aquele que deseja incluir na atividade e clique em "Inserir".

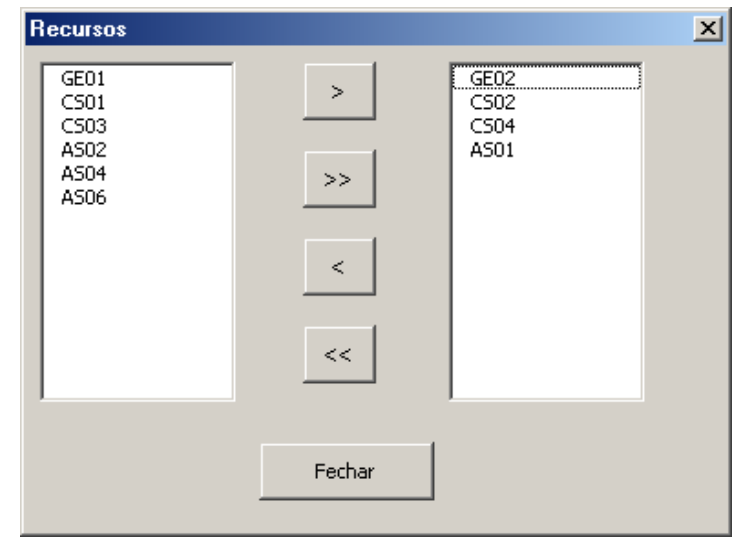

Figura 6.5: Janela de inclusão/ exclusão de recursos.

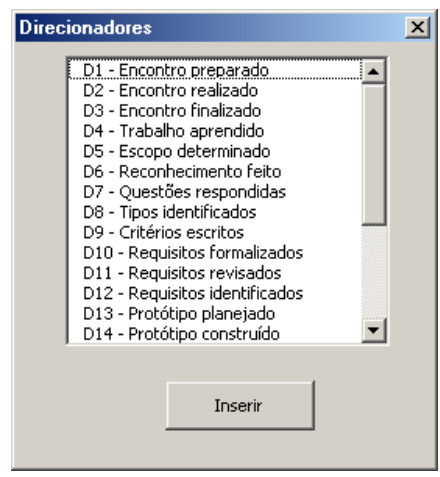

Figura 6.6: Janela de inclusão de direcionadores.

A planilha Atividades - Detalhes é responsável por distribuir a participação dos recursos na atividade. A planilha, preenchida com os dados do estudo de caso, está na figura 6.7. Conforme dito acima, de acordo com o que foi a estimativa de tempo, a distribuição varia. Quando se adiciona um novo recuros, este aparecerá nesta planilha com a participação de 100\%. Assim, para ajustar, basta inserir a percentagem de participação na coluna à direira do código do recurso na atividade em questão.

Esta ferramenta é uma maneira de calcular mais rapidamente o custo do processo. Ela será usada para calcular os custos do realizado e do planejado referente ao estudo de caso. No próximo capítulo, serão apresentados os resultados obtidos e uma discussão de tudo que foi considerado no estudo de caso. 


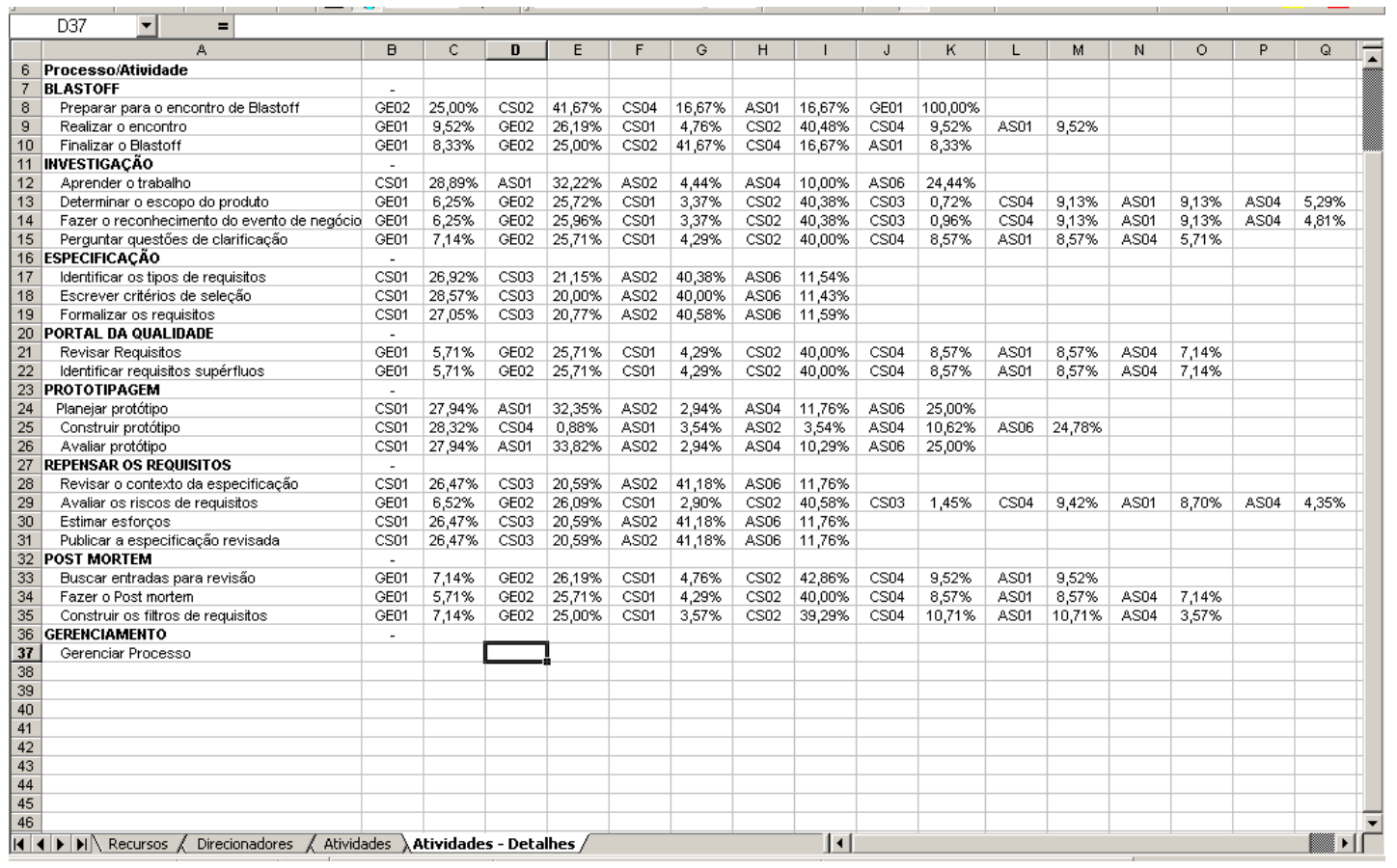

Figura 6.7: Planilha de detalhamento de recursos. Nesta planilha, faz-se a distribuição da participação dos recursos em cada atividade do método Volere. 


\section{$7 \quad$ Resultados e Discussão}

No capítulo anterior, foram feitos os levantamentos da participação dos recursos nas atividades. O objetivo deste capítulo é apresentar o cálculo desenvolvido para o custo do processo de ER juntamente com a discussão destes resultados e as considerações sobre tudo que foi levantado.

Este capítulo visa discutir o estudo de caso a respeito dos seguintes aspectos:

- Análise do custo referente aos requisitos compararando com o que seria planejado (de acordo com o que foi levantado no capítulo 6);

- Análise sobre atividades extras que não foram registradas mas possuem impacto na etapa de requisitos;

- Análise de riscos do projeto e como este pode impactar no custo da etapa de requisitos;

- Identificação de alguns pontos importantes que poderia ser considerado no estudo de caso;

Após estas discussões, este capítulo terá também um objetivo de fazer uma estimativa, usando esta abordagem, de um novo projeto que está em fase de negociação e como a abordagem poderá auxiliar o gerente a determinar um custo para a etapa de requisitos.

Finalmente, serão apresentadas algumas limitações da abordagem deste trabalho.

\subsection{Análise do custo da etapa de requisitos}

O cálculo foi feito através da ferramenta descrita no capítulo anterior, utilizando os dados que estão no Apêndice A. Os resultados, encontram-se na tabela 7.1.

Observe que na tabela 7.1, a etapa de requisitos do projeto custou $\mathrm{R} \$ 37.157,21$ e pelos dados que se encontram no Apêndice A, foram gastos 1264 horas. Como 
Tabela 7.1: Resultado do cálculo do custo realizado das atividades usando o método Volere. Nesta tabela estão os custos referentes a cada atividade do método

Volere para o que foi realizado no estudo de caso.

\begin{tabular}{|c|c|c|}
\hline Processo & Atividade & Custo $(\mathrm{R} \$)$ \\
\hline \multirow{3}{*}{$B L A S T O F F$} & Preparar para o encontro de Blastoff & 190,02 \\
\hline & Realizar o encontro & 694,93 \\
\hline & Finalizar o Blastoff & 197,50 \\
\hline \multirow{4}{*}{ INVESTIGAÇÃO } & Aprender o trabalho & 1189,89 \\
\hline & Determinar o escopo do produto & 6754,38 \\
\hline & Reconhecer os eventos de negócio & 6764,37 \\
\hline & Perguntar questões de clarificação & 1139,88 \\
\hline \multirow{3}{*}{ ESPECIFICAÇÃO } & Identificar os tipos de requisitos & 1424,85 \\
\hline & Escrever critérios de seleção & 960,00 \\
\hline & Formalizar os requisitos & 5669,42 \\
\hline PORTAL DA & Revisar Requisitos & 1132,37 \\
\hline QUALIDADE & Identificar requisitos supérfluos & 1132,37 \\
\hline \multirow{3}{*}{ PROTOTIPAGEM } & Planejar protótipo & 897,41 \\
\hline & Construir protótipo & 2189,94 \\
\hline & Avaliar protótipo & 897,41 \\
\hline \multirow{4}{*}{$\begin{array}{l}\text { REPENSAR OS } \\
\text { REQUISITOS }\end{array}$} & Revisar o contexto da especificação & 465,00 \\
\hline & Avaliar os riscos de requisitos & 2250,19 \\
\hline & Estimar esforços & 465,00 \\
\hline & Publicar a especificação revisada & 465,00 \\
\hline \multirow{4}{*}{ POST MORTEM } & Buscar entradas para revisão & 689,93 \\
\hline & Fazer o Post mortem & 1132,37 \\
\hline & Construir os filtros de requisitos & 454,96 \\
\hline & Total & 37157,21 \\
\hline
\end{tabular}

a quantidade de horas planejadas (de acordo com os dados no Apêndice B) foi de 1440. Teoricamente, a empresa poderia prever um lucro adicional de 13,92\% ((1440 - 1264)/1264), ou seja, um lucro adicional de $\mathrm{R} \$ 5.712,28$.

Entretanto, não foi isso que aconteceu. Analisando a participação em horas planejadas dos recursos (tabela 6.8), eram previstas a utilização de 160 horas de cada Analista e Consultor e 80 horas de cada Gerente, mas pela participação dos recursos, em horas, do que foi realizado, observa-se uma distribuição irregular dos recursos, ou seja alguns trabalharam mais horas do que foi previsto, enquanto outros trabalharam menos. Assim, fazendo uma projeção da quantidade de horas que cada um deveria ter trabalhado pela percentagem que realmente cada um trabalhou em relação às atividades levantadas (resultando a tabela 6.8), através do levantamento contido no Apêndice B e do cálculo feito pela ferramenta, obtevese a tabela 7.2 . 
Tabela 7.2: Resultado do cálculo do custo planejado das atividades usando o método Volere. Nesta tabela estão os custos referentes a cada atividade do método Volere para o que foi planejado no estudo de caso.

\begin{tabular}{llr}
\hline Processo & Atividade & Custo (R\$) \\
\hline \multirow{3}{*}{ BLASTOFF } & Preparar para o encontro de Blastoff & 159,25 \\
& Realizar o encontro & 582,63 \\
& Finalizar o Blastoff & 194,27 \\
\hline \multirow{2}{*}{ INVESTIGAÇÃOO } & Aprender o trabalho & 1184,98 \\
& Determinar o escopo do produto & 5742,36 \\
& Reconhecer os eventos de negócio & 5742,36 \\
& Perguntar questões de clarificação & 963,82 \\
\hline \multirow{2}{*}{ ESPECIFICAÇÃOO } & Identificar os tipos de requisitos & 1880,03 \\
& Escrever critérios de seleção & 1232,12 \\
& Formalizar os requisitos & 7452,68 \\
\hline PORTAL DA & Revisar Requisitos & 962,59 \\
QUALIDADE & Identificar requisitos supérfluos & 962,59 \\
\hline \multirow{3}{*}{ PROTOTIPAGEM } & Planejar protótipo & 893,60 \\
& Construir protótipo & 2969,88 \\
& Avaliar protótipo & 893,60 \\
\hline \multirow{2}{*}{ REPENSAR OS } & Revisar o contexto da especificação & 632,93 \\
REQUISITOS & Avaliar os riscos de requisitos & 1970,27 \\
& Estimar esforços & 632,93 \\
& Publicar a especificação revisada & 602,91 \\
\hline \multirow{2}{*}{ POST MORTEM } & Buscar entradas para revisão & 555,05 \\
& Fazer o Post mortem & 962,59 \\
& Construir os filtros de requisitos & 393,42 \\
\hline & Total & $\mathbf{3 7 5 6 6 , 8 4}$ \\
\hline
\end{tabular}

Pela tabela 7.2 , pode-se observar que o custo planejado seria de $\mathrm{R} \$ 37.566,84$, dessa forma, comparando com a tabela 7.1, o lucro adicional foi de apenas $\mathrm{R} \$ 409,63$. Assim, o lucro adicional que a empresa previa para a etapa de requisitos, de fato não houve. Isto permite considerar que uma análise mais apurada dos recursos pelo $\mathrm{ABC}$ foi determinante para saber se realmente a operação foi lucrativa ou não (COOPER; KAPLAN, 1992).

\subsection{Custos implícitos ao projeto}

A presente abordagem visou determimar o custo do levantamento de requisitos e especificação, entretanto, alguma atividades que, apesar de não estarem computadas diretamente no projeto, poderiam causar impacto na verificação do lucro real do projeto. A atividade de gerenciamento não foi incluída no estudo, pois esta 
estava diluída nas atividades levantadas, assim neste estudo de caso, a atividade de gerenciamento está com custo zero.

Outro custo implícito ao projeto é o tempo de espera entre a aprovação e o início do projeto que às vezes é necessário. Este tempo de espera é devido tanto à necessidade do cliente em iniciar o projeto no tempo oportuno quanto à burocracia existentes em grandes clientes, pois o mesmo tem que passar por um departamento de compras para aprovação (assim, o projeto ainda corre o risco de não ser aprovado por este departamento). Neste caso, a empresa estudada, pode decidir se vai incluir estas horas no projeto.

\subsection{Análise do impacto da fase de requisitos}

Observe, que, conforme presente na secção 6.4 e na seção 7.2, foram identificados os seguintes riscos que a empresa pode assumir:

- O projeto não ser aprovado, mesmo sendo aprovado previamente pelo cliente, mas rejeitado por algum outro departamento;

- Não fazer a especificação por considerar que o projeto é pequeno ou que o cliente poderá questionar a importância ou não de uma etapa de requisitos;

- A etapa de pré-projeto não ser incorporada às atividades referente ao projeto;

Não é o objetivo deste trabalho avaliar os riscos do projeto. Somente foi feita esta identificação para verificar que o aumento do custo seguido pela redução do lucro do projeto depende de muitos fatores que são específicos às situações enfrentadas e que cabe à empresa assumir ou não os riscos.

Um problema identificado no projeto é que o mesmo foi feito em conjunto com o projeto de levantamento de processos no Banco "A". A metodologia de processos do Banco "A" estava em fase inicial de amadurecimento. Sendo assim, somente foi utilizado este sistema após todos os processos de todos os departamentos serem levantados. Para testar a funcionalidade do sistema, o Banco "A" forneceu um modelo, que um dos colaboradores do projeto, classificou-o como "Muito simplificado", ou seja, não era adequado à realidade do Banco "A" e assim, poderia não funcionar de acordo com os desejos do cliente. O sistema foi entregue antes da data prevista, e ao final do levantamento dos processos, o sistema mostrou algumas limitações em relação à metodologia do Banco "A" a 
respeito de processos, além de, após a entrega do sistema, alguns critérios referentes à metodologia de processos do Banco "A" foram mudados (devido ao amadurecimento natural da metodologia no Banco "A"). Isto gerou um segundo projeto, no qual foi como um retrabalho deste analisado no estudo de caso.

Podemos concluir que neste caso, este projeto foi um primeiro incremento de um projeto maior, pois após este, houve mais um outro projeto com o mesmo objetivo do analisado neste estudo de caso, mas desta vez, com as implementações evolutivas da metodologia de processos do Banco "A". Neste caso, tanto o cliente quanto a empresa, mesmo ao final do projeto, não tinham conhecimento do artefato que foi construído, apesar de ter havido um processo de requisitos e assim, o mesmo não foi devidamente formulado para as necessidades da empresa (MELI, 1999).

\subsection{Novo projeto}

Nesta secção, será usada esta abordagem para estimar o custo de um projeto em sua fase inicial.

\subsubsection{O projeto}

O Banco "B", possui um planejamento orçamentário anual, respeitando-se as revisões efetuadas. Após o fechamento do orçamento, são realizadas as consultas sobre as verbas orçadas e os possíveis remanejamentos de verbas entre contas orçamentárias da mesma área ou entre áreas. Estes remanejamentos só podem ocorrer dentro do mesmo tipo de orçamento (despesa ou investimento).

Para a elaboração e acompanhamento do valor orçado e do realizado será utilizado um software de controle orçamentário chamado Hyperion ${ }^{1}$. Porém, falta uma ferramenta para integrar as consultas de verbas entre as áreas envolvidas e enviálas ao Hyperion ${ }^{\circledR}$. Para atender a demanda do Departamento de Controladoria e Gestão de Informação e dos departamentos usuários do orçamento, a empresa apresenta, uma solução para o Controle de Consulta de Verba Orçamentária, procurando atender as necessidades de integração com o Hyperion ${ }^{\circledR}$.

\subsubsection{Estimativas}

Neste projeto, na fase de requisitos, serão usados três recursos:

\footnotetext{
${ }^{1}$ Copyright (C)Hyperion Solutions Corporation.
} 
- Um Gerente (GE01) (custo de $\mathrm{R} \$ 40,00$ por hora) que trabalhará em tempo parcial. Este gerente participará principalmente das etapas iniciais e finais do projeto, além de disponibilizar metade do tempo alocado neste projeto para atividade de gerenciamento;

- Um Analista de Negócio (AN01) (custo de R\$25,00 por hora) que estará nesta etapa de requisitos em tempo integral. O Analista de Negócio será responsável por fazer todas as entrevistas com o cliente e identificar todos os requisitos necessários.

- Um analista de sistemas (AS01) (custo de $\mathrm{R} \$ 25,00$ por hora) que será responsável, em tempo integral, em fazer a especificação dos requisitos levantados pelo Analista de Negócio, além de, caso seja necessário, construir algum protótipo para melhor entendimento de alguns requisitos entre o cliente e a empresa que fará o sistema;

Fazendo uma estimativa de tempo para cada atividade do Volere, tem-se a tabela presente no Apêndice C. Assim, calculando o custo pela tabela contida no Apêndice $\mathrm{C}$ e usando o protótipo descrito no capítulo 6 , secção 6.7, foi criada a tabela 7.3 .

No caso apresentado na tabela 7.3 foi calculado um custo de $\mathrm{R} \$ 7.200,00$ para levantar, analisar, verificar, validar, especificar e gerenciar os requisitos do sistema.

\subsection{Considerações sobre o estudo de caso}

Nas secções abaixo serão feitas algumas considerações a respeito do estudo de caso. Estas considerações incluem os critérios adotados para o estudo de caso e limitações desta abordagem.

\subsubsection{Critérios}

Abaixo, serão discutidos os critérios a respeito dos recursos utilizados, dos direcionadores criados, das atividades levantadas e da busca de informações feitas para o levantamento do ABC no estudo de caso. 
Tabela 7.3: Resultado do cálculo do custo do novo projeto das atividades usando o método Volere. Nesta tabela estão os custos referentes a cada atividade do método Volere para o que foi planejado em um novo projeto.

\begin{tabular}{llr}
\hline Processo & Atividade & Custo (R\$) \\
\hline \multirow{3}{*}{ BLASTOFF } & Preparar para o encontro de Blastoff & 325,00 \\
& Realizar o encontro & 390,00 \\
& Finalizar o Blastoff & 325,00 \\
\hline \multirow{4}{*}{ INVESTIGAÇÃOO } & Aprender o trabalho & 500,00 \\
& Determinar o escopo do produto & 400,00 \\
& Reconhecer os eventos de negócio & 600,00 \\
& Perguntar questões de clarificação & 300,00 \\
\hline \multirow{3}{*}{ ESPECIFICAÇÃO } & Identificar os tipos de requisitos & 150,00 \\
& Escrever critérios de seleção & 100,00 \\
& Formalizar os requisitos & 700,00 \\
\hline PORTAL DA & Revisar Requisitos & 200,00 \\
QUALIDADE & Identificar requisitos supérfluos & 300,00 \\
\hline \multirow{3}{*}{ PROTOTIPAGEM } & Planejar protótipo & 100,00 \\
& Construir protótipo & 550,00 \\
& Avaliar protótipo & 100,00 \\
\hline \multirow{2}{*}{ REPENSAR OS } & Revisar o contexto da especificação & 200,00 \\
REQUISITOS & Avaliar os riscos de requisitos & 230,00 \\
& Estimar esforços & 460,00 \\
& Publicar a especificação revisada & 400,00 \\
\hline \multirow{2}{*}{ POST MORTEM } & Buscar entradas para revisão & 160,00 \\
& Fazer o Post mortem & 460,00 \\
& Construir os filtros de requisitos & 250,00 \\
\hline \multirow{2}{*}{ GERENCIAMENTO } & Gerenciar Processo & 1200,00 \\
\hline & Total & $\mathbf{7 2 0 0 , 0 0}$ \\
\hline
\end{tabular}

\subsubsection{Recursos}

No sistema de gerenciamento de Projetos, somente são incluídos recursos humanos, e no custo de cada recurso (determinado na tabela 6.1), já estão adicionados o custo de infraestrutura e encargos. Mas para o cálculo, poderiam ser utilizados outros recursos como:

- Informática (depreciação dos equipamentos);

- Infraestrutura (separar do custo de recursos humanos);

Nos casos citados acima, basta determinar o custo por hora de utilização destes recursos e incluir na planilha Recursos da ferramenta criada. 


\subsubsection{Direcionadores}

No estudo de caso, os direcionadores eram compostos pelo cumprimento das atividades do processo (ou seja, o volume foi determinado por dedicação). Poderia também usar outros direcionadores como, por exemplo, na atividade "Fazer o reconhecimento do evento de negócio", o direcionador poderia ser "Eventos de Negócios". Neste caso, seria necessário saber quantos eventos de negócios serão levantados. Outro exemplo está na atividade "Revisar Requisitos" que um direcionador também adequado poderia ser os requisitos que serão levantados, mas também era necessário saber a quantidade de requisitos.

\subsubsection{Capacidade Prática}

Ao contrário do exemplo didático presente no capítulo 3, no estudo de caso, não foram feitas considerações a respeito da capacidade prática, pois o sistema de gerenciamento de projeto da empresa não fornecia as datas de início e de fim das atividades do projeto, sendo assim, não foi possível calcular o excesso de capacidade.

\subsubsection{Busca de Informações}

Alguns recursos não apontavam as atividades de maneira correta, ou seja, os apontamentos nem sempre estavam de acordo com a atividade que foi executada, podendo ter gerado alguma discrepância em relação ao custo calculado.

\subsection{Limitações da abordagem deste trabalho}

\subsubsection{Aplicabilidade}

Devido a grande quantidade de atividades para fazer a etapa de requisitos, esta proposta, para o método Volere é adequada a projetos médios a grandes. Para usar em projetos menores, seria necessário suprir ou agrupar algumas atividades do método.

\subsubsection{Estimativa de Tempo}

Esta abordagem não substitui a experiência do gerente de requisitos a respeito da estimativa de tempo. Ela é somente um meio para direcionar esta estimativa. 
Assim, cabe ao responsável por fazer uma estimativa, considerar as seguintes possibilidades:

- Reutilizando dados de projetos realizados previamente, buscando alguma similaridade entre eles;

- Através de métricas que permitam a avaliação do tempo a ser gasto;

Em relação às métricas, estas podem estar relacionadas direta ou indiretamente a alguns fatores referentes à complexidade. Neste caso, alguns fatores citados por Parsons-Hann e Liu (2005) como tipos de stakeholders, habilidade do analista de requisitos e outros fatores como departamentos envolvidos, impacto do artefato podem ser úteis para uma estimativa mais precisa do tempo. 


\section{Conclusões e trabalhos futuros}

\section{1 conclusões}

A abordagem usando o sistema ABC para estimar o custo do processo de ER, permite incluir várias inferências:

- Trata-se de uma abordagem nova e pouco explorada na literatura.

- A abordagem sugere um sistema fexível em que as atividades podem ser realizadas de forma distintas, bem como elas podem ser atualizadas tecnologicamente, organizacionalmente e funcionalmente.

- A estimativa de tempo não é mais feita sem critérios e sim pela seqüência de atividades do método, tornando a estimativa mais apurada e controlável.

- Uma análise do ABC permitiu comparar, no estudo de caso, com mais detalhe, o custo previsto e o custo realizado, e assim indicar uma super ou sub utilização dos recursos.

- Nesta abordagem, o ABC mostrou ser um sistema de custeio que permite uma multiplicidade de critérios a respeito dos direcionadores de custos e recursos

- Não basta ter um método, se existem muitos fatores subjetivos que possam afetá-lo. Esta abordagem não consegue direcionar estes fatores.

- Esta abordagem pode ser aplicada a qualquer método de ER que possua suas atividades estruturadas.

- A ferramenta desenvolvida permite fazer um estudo de custo da etapa de requisitos, podendo ser ajustado conforme o prazo do projeto. 


\subsection{Trabalhos Futuros}

Como trabalhos futuros, estão incluídos:

- A criação de métricas para determinar a complexidade do processo de ER e assim, fornecer uma base de apoio para fazer a estimativa de tempo.

- A proposta de inclusão ou acoplamento desta abordagem em ferramentas de requisitos existentes (como por exemplo, usar a planilha criada como saída de um planejamento de projetos utilizando o Microsoft ${ }^{\circledR}$ Project $^{1}$.

- Na abordagem proposta, foi direcionado o uso do método Volere para usar o ABC, mas seria possível desenvolver uma metodologia para usar o ABC em qualquer processo de ER.

- A criação de uma ferramenta de simulação para o ABC de acordo com as atividades do processo de ER.

\footnotetext{
${ }^{1}$ Copyright (C)Microsoft Corporation
} 


\section{Referências}

ÅKERUD, D.; RENDLO, H.; HENRICSSON, F.; BARRIO, J. An industry case study - Teleca. Ronneby: Blekinge Institute of Technology, 2003. (Case Studies Series). Disponível em: $<$ http://idenet.bth.se/servlet/download/element/36351/Case_Studies_2003.pdf $>$. Acesso em: 18 abr. 2007.

ALCÁZAR, E. G.; MONZÓN, A. A process framework for requirements analysis and specification. In: ICRE '00: Proceedings of the 4th International Conference on Requirements Engineering (ICRE'00). [S.l.]: IEEE Computer Society, Washington, DC, USA, 2000. p. 27.

ARTHUR, D.; GRÖNER, K. An operational model for structuring the requirements generation process. Requir. Eng., Springer-Verlag New York, Inc., Secaucus, NJ, USA, v. 10, n. 1, p. 45-62, 2005.

AXELSSON, M.; GUSTAFSSON, J.; KERVALL, F.; SONESSON, J. ARequirements Engineering Industry Case Study Alpha. Ronneby: Blekinge Institute of Technology, 2003. (Case Studies Series). Disponível em: $<$ http://idenet.bth.se/servlet/download/element/36351/Case_Studies_2003.pdf $>$. Acesso em: 18 abr. 2007.

BASILI, V. R.; TURNER, A. J. Iterative enhancement - a practical technique for software development. IEEE Transactions on Software Engineering, IEEE Computer Society Press, Los Alamitos, CA, USA, v. 1, n. 1, p. 390-396, 1975.

BECK, K. Embracing change with extreme programming. Computer, IEEE Computer Society Press, Los Alamitos, CA, USA, v. 32, n. 10, p. 70-77, 1999.

BEN-ARIEH, D.; QIAN, L. Activity-based cost management for design and development stage. International Journal of Production Economics, v. 83, n. 2, p. 169-183, 2003.

BENNINGTON, H. D. Production of large computer programs. In: Proc. ONR Symposium on Advanced Programming Methods for Digital Computers. [S.l.: s.n.], 1956. p. 15-27. Também disponível em Annals of the History of Computing, v. 5, n. 4, p. 350-361, 1983.

BEZERRA, F. A.; ROBLES JÚNIOR, A. Gestão de custos através do sistema de custeio ABC utilizando simulação. In: IX Congresso Brasileiro de Custos. São Paulo: [s.n.], 2002.

BOEHM, B. A spiral model of software development and enhancement. SIGSOFT Softw. Eng. Notes, ACM Press, New York, NY, USA, v. 11, n. 4, p. 14-24, 1986.

BOEHM, B. W. Software Engineering Economics. Englewood Cliffs, N.J.: Prentice-Hall, 1981. 
BORDEN, J. P. Review of literature on activity based costing. Journal of Cost Management for the manufacturing Industry, p. 4, 1990.

BRIMSON, J. A. Contabilidade por atividades. São Paulo: Editora Atlas, 1996.

BROEHL, A.-P.; DROESCHEL, W. Das V-Modell: Der Standard fuer die Softwareentwicklung mit Praxisleitfaden. 2nd. ed. München: Oldenbourg Verlag, 1995.

BUBENKO, J.; ROLLAND, C.; LOUCOPOULOS, P.; DEANTONELLIS, V. Facilitating 'fuzzy to formal' requirements modelling. In: IEEE 1st Conference on Requirements Engineering, ICRE'94. [S.1.]: IEEE Computer Society, 1994. p. $154-158$.

BUBENKO, J. A. Challenges in requirements engineering. In: $R E$ '95: Proceedings of the Second IEEE International Symposium on Requirements Engineering. [S.l.]: IEEE Computer Society, Washington, DC, USA, 1995. p. 160.

CAGWIN, D.; BOUWMAN, M. J. The association between activity-based costing and improvement in financial performance. Management Accounting Research, v. 13, n. 1, p. 39, 2002.

CARR, J. J. Requirements engineering and management:the key to designing quality complex systems. The TQMMagazine, v. 12, n. 6, p. 400, 2000.

CARTER, R. A.; ANTÓN, A. I.; WILliAMS, L.; DAGNINO, A. Evolving beyond requirements creep: A risk-based evolutionary prototyping model. In: RE '01: Proceedings of the Fifth IEEE International Symposium on Requirements Engineering (RE '01). [S.l.]: IEEE Computer Society, Washington, DC, USA, 2001. p. 94.

CHATZOGLOU, P. D.; MACAULAY, L. A. Requirements capture and analysis: A survey of current practice. Requir. Eng., v. 1, n. 2, 1996.

COOPER, R.; KAPLAN, R. S. Activity-based systems: Measuring the costs of resource usage. Accounting Horizons, v. 6, n. 3, p. 1-12, 1992.

CORBIN, D. S. Team requirements definition: Looking for a mouse and finding an elephant. Journal of Systems Management, ACM Press, New York, NY, USA, v. 42, n. 5, p. 28-30, 1991.

COSTELLO, R. J.; LIU, D.-B. Metrics for requirements engineering. J. Syst. Softw., Elsevier Science Inc., New York, NY, USA, v. 29, n. 1, p. 39-63, 1995.

DAVIS, A.; OVERMYER, S.; JORDAN, K.; CARUSO, J.; DANDASHI, F.; DINH, A.; KINCAID, G.; LEDEBOER, G.; REYNOLDS, P.; SITARAM, P.; TA, A.; THEOFANOS, M. Identifying and measuring quality in a software requirements specification. In: First International Proceedings of Software Metrics Symposium. Baltimore, MD, USA: [s.n.], 1993. p. 141-152.

DAVIS, A. M. The art of requirements triage. Computer, IEEE Computer Society Press, Los Alamitos, CA, USA, v. 36, n. 3, p. 42-49, 2003. 
DAVIS, A. M.; HICKEY, A. M. Requirements researchers: Do we practice what we preach? Requirements Engineering, Springer, London, UK, v. 7, n. 2, p. 107-111, 2002.

DRIVER, M. Activity-based costing: a tool for adaptive and generative organizational learning? The learning organization, v. 8, n. 3, p. 94-105, 2001.

EMAM, K. E.; MADHAVJI, N. H. A field study of requirements engineering practices in information systems development. In: $R E$ '95: Proceedings of the Second IEEE International Symposium on Requirements Engineering. [S.l.]: IEEE Computer Society, Washington, DC, USA, 1995. p. 68.

FINKELSTEIN, A.; KRAMER, J.; NUSEIBEH, B.; GOEDICKE, M. Viewpoints: a framework for integrating multiple perspectives in system development. International Journal of Software Engineering and Knowledge Engineering, World Scientific Publishing, v. 2, n. 1, p. 31-58, 1992.

FREEMAN, T. Transforming cost management into a strategic weapon. Journal of Cost Management, v. 12, n. 6, p. 13-26, 1998.

GASKA, M. T.; GAUSE, D. C. An approach for cross-discipline requirements engineering process patterns. In: ICRE '98: Proceedings of the 3rd International Conference on Requirements Engineering. Colorado Springs, CO: IEEE Computer Society, Washington, DC, USA, 1998. p. 182-190.

GAUSE, D. C.; WEINBERG, G. M. Exploring Requirements: Quality Before Design. New York, NY, USA: Dorset House Publishing Co., Inc., 1989.

GEISHECKER, M. L. New technologies support ABC. Management Accounting, Montvale, v. 77, n. 9, p. 42-46, 1996.

GOMAA, H.; SCOTT, D. B. Prototyping as a tool in the specification of user requirements. In: ICSE '81: Proceedings of the 5th international conference on Software engineering. San Diego, California, United States: IEEE Press, Piscataway, NJ, USA, 1981. p. 333-342.

GREENSPAN, S. J.; MYLOPOULOS, J.; BORGIDA, A. Capturing more world knowledge in the requirements specification. In: ICSE '82: Proceedings of the 6th international conference on Software engineering. Tokyo, Japan: IEEE Computer Society Press, Los Alamitos, CA, USA, 1982. p. 225-234.

GUPTA, M.; GALLOWAY, K. Activity-based costing/management and its implications for operations management. Technovation, Amsterdam, v. 23, n. 2, p. $131-138,2003$.

HELBERG, C.; GALletly, J. E.; BICHENO, J. R. Simulating activity-based costing. Industrial Management + Data Systems, Wembley, v. 94, n. 9, p. 3-9, 1994.

HICKEY, A. M.; DAVIS, A. M. Elicitation technique selection: How do experts do it? In: RE '03: Proceedings of the 11th IEEE International Conference on Requirements Engineering. Washington, DC, USA: IEEE Computer Society, 2003. p. 169. 
HOFMANN, H. F.; LEHNER, F. Requirements engineering as a success factor in software projects. IEEE Software, IEEE Computer Society, Los Alamitos, CA, USA, v. 18, n. 4, p. 58-66, 2001.

HOOPER, J. W.; HSIA, P. Scenario-based prototyping for requirements identification. In: Proceedings of the workshop on Rapid prototyping. Columbia, Maryland: ACM Press, New York, NY, USA, 1982. p. 88-93.

HOUDEK, F.; POHL, K. Analyzing requirements engineering processes: A case study. In: DEXA '00: Proceedings of the 11th International Workshop on Database and Expert Systems Applications. [S.1.]: IEEE Computer Society, Washington, DC, USA, 2000. p. 983.

HSIA, P.; DAVIS, A.; KUNG, D. Status report: requirements engineering. Software, IEEE, IEEE Computer Society Press, Los Alamitos, CA, USA, v. 10, n. 6 , p. $75-79,1993$.

IEEE. Std 1233a-1998: IEEE guide for developing system requirements specifications. Los Alamitos, CA, USA, 1998.

IEEE. Std 830-1998: IEEE recommended practice for software requirements specification. Los Alamitos, CA, USA, 1998.

JIANG, L.; EBERLEIN, A.; FAR, B. H. Evaluating the requirements engineering process using major concerns. In: Proceedings of the IASTED International Conference on Software Engineering (SE2004) as part of the Twenty-Second IASTED International Multi-Conference on Applied Informatics. Innsbruck, Austria: [s.n.], 2004.

JIANG, L.; EBERLEIN, A.; FAR, B. H. A methodology for requirements engineering process development. ecbs, IEEE Computer Society, Los Alamitos, CA, USA, v. 00, p. 263, 2004.

KAINDL, H. A practical approach to combining requirements definition and object-oriented analysis. Ann. Softw. Eng., J. C. Baltzer AG, Science Publishers, Red Bank, NJ, USA, v. 3, p. 319-343, 1997.

KAINDL, H.; BRINKKEMPER, S.; JR, J. A. B.; FARBEY, B.; GREENSPAN, S. J.; HEITMEYER, C. L.; LEITE, J. C. S. do P.; MEAD, N. R.; MYLOPOULOS, J.; SIDDIQI, J. Requirements engineering and technology transfer: Obstacles, incentives and improvement agenda. Requirements Engineering, Springer, London, UK, v. 7, n. 3, p. 113-123, 2002.

KARLSSON, J.; RYAN, K. A cost-value approach for prioritizing requirements. IEEE Software, IEEE Computer Society Press, Los Alamitos, CA, USA, v. 14, n. 5, p. 67-74, 1997.

KASSER, J.; WILLIAMS, V. What do you mean you can't tell me if my project is in trouble? In: First European Conference on Software Metrics (FESMA 98). Antwerp, Belgium: [s.n.], 1998.

KINSELLA, S. Activity based costing: Does it warrant inclusion in a guide to the project management body of knowledge (PMBOK guide)? Project Management Journal, v. 33, n. 2, p. 49-56, 2002. 
KOTONYA, G.; SOMMERVILLE, I. Requirements engineering with viewpoints. Software Engineering Journal, IEEE Computer Society, v. 11, n. 1, p. 5-18, 1996.

KRUCHTEN, P. The Rational Unified Process: An Introduction. Boston, MA, USA: Addison-Wesley Longman Publishing Co., Inc., 2003.

KRUMWIEDE, K. R. The implementation stages of activity-based costing and the impact of contextual and organizational factors. Journal of Management Accounting Research, Sarasota, v. 10, p. 239-278, 1998.

KUDIKYALA, U. K.; ALLEN, E. B.; VAUGHN, R. B. Measuring consensus during verification and validation of requirements. In: Proceedings Supplement: 10th IEEE International Software Metrics Symposium. Chicago, USA: IEEE Computer Society Press, Los Alamitos, CA, USA, 2004.

LARMAN, C.; BASILI, V. R. Iterative and incremental development: A brief history. Computer, IEEE Computer Society Press, Los Alamitos, CA, USA, v. 36, n. 6 , p. $47-56,2003$.

LAVAZZA, L.; VALETTO, G. Requirements-based estimation of change costs. Empirical Software. Engineering., Kluwer Academic Publishers, Hingham, MA, USA, v. 5, n. 3, p. 229-243, 2000.

LEITE, J. C. S. P. Viewpoints analysis: a case study. ACM Software Engineering Notes, ACM Press, New York, NY, USA, v. 14, n. 3, p. 111-119, 1989.

LERE, J. C. Activity-based costing: a powerful tool for pricing. The Journal of Business and Industrial Marketing, MCB UP Ltd, v. 15, n. 1, p. 23-33, 2000.

LETZA, S. R.; GADD, K. Should activity-based costing be considered as the costing method of choice for total quality organizations? The TQM Magazine, v. 6 , n. 5 , p. 57-64, 1994.

LOBO, L.; ARTHUR, J. D. Local and global analysis: Complementary activities for increasing the effectiveness of requirements verification and validation. ArXiv Computer Science e-prints, 2005.

LOBO, L.; ARTHUR, J. D. An objectives-driven process for selecting methods to support requirements engineering activities. ArXiv Computer Science e-prints, 2005.

MACHERIDIS, N. The Specific Costing Problems of Project Form - How those can be managed with activity based costing. Lundi: Institute of Economic Research, Lundi University, 2004. (Working Paper Series n. 2004/2).

MARTIN, S.; AURUM, A.; JEFFERY, R.; PAECH, B. Requirements engineering process models in practice. In: Seventh Australian workshop on Requirements Engineering: AWRE 02. Melbourne, Austalia: [s.n.], 2002. p. 141-155.

MCGOWAN, A. S. Perceived benefits of ABCM implementation. Accounting Horizons, Sarasota, v. 12, n. 1, p. 31-50, 1998. 
MCGOWAN, A. S.; KLAMMER, T. P. Satisfaction with activity-based cost management implementation. Journal of Management Accounting Research, Sarasota, v. 9, p. 217-238, 1997.

MEAD, N. R. Why is it so difficult to introduce requirements engineering research results into mainstream requirements engineering practice? In: 4th International Conference on Requirements Engineering. [S.l.]: IEEE Computer Society Press, Los Alamitos, CA, USA, 2000. p. 75-76.

MELI, R. Risks, requirements, and estimation of a software project. In: Proceedings of the 10th European Software Control and Metrics Conference (ESCOM-SCOPE 99). [S.l.: s.n.], 1999.

MOLL, J. H. van; JACOBS, J. C.; FREIMUT, B.; TRIENEKENS, J. J. M. The importance of life cycle modeling to defect detection and prevention. In: STEP '02: Proceedings of the 10th International Workshop on Software Technology and Engineering Practice. [S.l.]: IEEE Computer Society, Washington, DC, USA, 2002. p. 144.

MOORTHY, S. Manage your requirements, manage your project. In: REProMan '05: Workshop on the Interplay of Requirements Engineering and Project Management. Paris, France: [s.n.], 2005.

MORRIS, P.; MASERA, M.; WILIKENS, M. Requirements engineering and industrial uptake. In: Third International Conference on Requirements Engineering. Colorado Springs, CO, USA: IEEE Computer Society Press, Los Alamitos, CA, USA, 1998. p. 130-137.

MOTTA, S. de A.; PAMPLONA, E. de O. Integração entre os sistemas de custeio baseado em atividades (ABC) e custo da qualidade. In: VI Congresso Brasileiro de Custos. São Paulo, SP: [s.n.], 1999.

MOYNIHAN, T. Requirements-uncertainty: Should it be a latent, aggregate or profit construct? aswec, IEEE Computer Society, Los Alamitos, CA, USA, v. 00, p. 181, 2000.

MULLERY, G. P. CORE - A method for controlled requirement specification. In: ICSE 'r9: Proceedings of the 4th international conference on Software engineering. Munich, Germany: IEEE Press, Piscataway, NJ, USA, 1979. p. 126-135.

NAKAGAWA, M. Gestão Estratégica de Custos. São Paulo: Editora Atlas, 1991.

NAKAGAWA, M. $A B C$ : Custeio baseado em atividades. São Paulo: Editora Atlas, 2001.

NGUYEN, L.; SWATMAN, P. A. Managing the requirements engineering process. Journal Requirements Engineering, Springer, London, v. 8, n. 1, p. 55-68, 1998.

NORD, R. L.; SONI, D. Experience with global analysis: A practical method for analyzing factors that influence software architectures. In: Second International SofTware Requirements to Architectures Workshop (STRAW'03). Portland, OR, USA: IEEE Computer Society, 2003. p. 34-40. 
OOI, G.; SOH, C.; LEE, P. M. An activity based costing approach to systems development and implementation. In: ICIS '98: Proceedings of the international conference on Information systems. Atlanta, GA, USA: Association for Information Systems, 1998. p. 341-345.

PARSONS-HANN, H.; LIU, K. Measuring requirements complexity to increase the probability of project success. In: $\operatorname{ICEIS~(3).~[S.l.:~s.n.],~2005.~p.~434-438.~}$

PFAHL, D.; LEBSANFT, K. Using simulation to analyse the impact of software requirement volatility on project performance. Information and Software Technology, Elsevier Science, v. 42, n. 14, p. 1001-1008, 2000.

PMI. A Guide To The Project Management Body Of Knowledge (PMBOK Guides). [S.l.]: Project Management Institute, 2000.

POHL, K. The three dimensions of requirements engineering: a framework and its applications. In: CAISE '93: Selected papers from the fifth international conference on Advanced information systems engineering. Paris-Sorbonne, France: Pergamon Press Inc., Elmsford, NY, USA, 1994. p. 243-258.

PRESSMAN, R. S. Software Engineering: A Practitioner's Approach. Sixth edition. NY: McGraw-Hill, 2005.

RAZ, T.; ELNATHAN, D. Activity based costing for projects. International Journal of Project Management, v. 17, n. 1, p. 61-68, 1999.

RICHARDS, D. A process model for requirements elicitation. In: Proceedings of The 11th Australasian Conference on Information Systems. Brisbane, Australia: [s.n.], 2000. p. 6-8.

RISING, L.; JANOFF, N. S. The scrum software development process for small teams. IEEE Software, IEEE Computer Society, Los Alamitos, CA, USA, v. 17, n. 4 , p. 26-32, 2000.

ROBERTSON, J.; ROBERTSON, S. Requirements management: A Cinderella story. Requirements Engineering, Springer, London, UK, v. 5, n. 2, p. 134-136, 2000 .

ROBERTSON, S.; ROBERTSON, J. Mastering the requirements process. New York, NY, USA: ACM Press/Addison-Wesley Publishing Co., 1999.

ROSS, D.; SCHOMAN, K. E. J. Structured analysis for requirements definition. IEEE Transactions on Software Engineering, IEEE Computer Society Press, Los Alamitos, CA, USA, v. 3, n. 1, p. 6-15, 1977.

ROWEN, R. B. Software project management under incomplete and ambiguous specifications. IEEE Transactions on Engineering Management, IEEE Computer Society Press, Los Alamitos, CA, USA, v. 37, n. 1, p. 10-21, 1990.

ROYCE, W. W. Managing the development of large software systems: Concepts and techniques. In: 1970 WESCON Technical Papers. Los Angeles: Western Electronic Show and Convention, 1970. v. 14, p. 1-9. Reimpresso em Proceedings of the Ninth International Conference on Software Engineering, Pittsburgh, PA, USA, ACM Press, 1989, p.328-338. 
RUMBAUGH, J.; JACOBSON, I.; BOOCH, G. (Ed.). The Unified Modeling Language reference manual. Essex, UK, UK: Addison-Wesley Longman Ltd., 1999.

RZEPKA, W. E.; OHNO, Y. Requirements engineering environments: Software tools for modeling user needs - guest editors' introduction. IEEE Computer, v. 18, n. 4 , p. $9-12,1985$.

SAWYER, P.; SOMMERVILLE, I.; VILLER, S. PREview: Tackling the Real Concerns of Requirements Engineering. Lancaster: Cooperative Systems Engineering Group, Lancaster University, 1996. (Technical Report CSEG/5/1996).

SCARLETT, B. In defence of management accounting applications. Management Accounting, v. 74, n. 1, p. 46-48, 2004.

SCHWABER, K. Scrum development process. In: OOPSLA'95 Workshop on Business Object Design and Implementation. [S.l.]: Springer-Verlag, 1995.

SHIELDS, M. D. An empirical analysis of firms' implementation experiences with activity-based costing. Journal of Management Accounting Research, Sarasota, v. 7, p. 148, 1995.

SILVA, J. R.; SANTOS, E. A. Applying petri nets to requirements validation. In: IFAC Symposium on Information Control Problems in Manufacturing: INCOM'04. Salvador, BA, Brazil: [s.n.], 2004.

SIVZATTIAN, S.; NUSEIBEH, B. Linking the selection of requirements to market value: A portfolio-based approach. In: Proc. 'th Int'l Requirements Eng.: Foundation for Software Quality (REFSQ 01). [S.l.: s.n.], 2001. p. 202-213.

SOMMERVILLE, I.; SAWYER, P. Requirements Engineering: A Good Practice Guide. New York, NY, USA: John Wiley \& Sons, Inc., 1997.

SOMMERVILLE, I.; SAWYER, P. Viewpoints: Principles, problems and a practical approach to requirements engineering. Annals of Software Engineering, v. 3, p. 101-130, 1997.

SOMMERVILLE, I.; SAWYER, P.; VILLER, S. Viewpoints for requirements elicitation: A practical approach. In: ICRE '98: Proceedings of the 3rd International Conference on Requirements Engineering. Washington, DC, USA: IEEE Computer Society, 1998. p. 74-81.

SPEDDING, T. A.; SUN, G. Q. Application of discrete event simulation to the activity based costing of manufacturing systems. International Journal of Production Economics, v. 58, n. 3, p. 289-301, 1999.

STANDISH GROUP. The CHAOS report. [S.l.], 1994.

SWENSON, D. The benefits of activity-based cost management to the manufacturing industry. Journal of Management Accounting Research, Sarasota, v. 7, p. 167, 1995. 
TORNBERG, K.; JAMSEN, M.; PARANKO, J. Activity-based costing and process modeling for cost-conscious product design: A case study in a manufacturing company. International Journal of Production Economics, v. 79, n. 2, p. 75-82, 2002.

TURNEY, P. B. B.; STRATTON, A. J. Using ABC to support continuous improvement. Management Accounting, v. 74, n. 3, p. 46-51, 1992.

WILLIAMS, D.; KENNEDY, M. Towards a model of decision-making for systems requirements engineering process management. In: Proceedings of the Eighteenth International System Dynamics Conference. Bergen, Norway: [s.n.], 2000 .

WILLIAMS, D. W.; HALL, T.; KENNEDY, M. A framework for improving the requirements engineering process management. Software Quality Journal, v. 8, n. 2, p. 133-147, 1999. 


\section{Apêndice A - Levantamento dos parâmetros do $\mathrm{ABC}$ das atividades do Volere (Realizado)}

\begin{tabular}{|c|c|}
\hline & Blastoff \\
\hline Atividade: & Preparar para o encontro de Blastoff \\
\hline Tempo(h): & 6 \\
\hline \multirow[t]{4}{*}{ Recursos: } & GE02 - 25,00\% \\
\hline & CS02 - 41,67\% \\
\hline & $\mathrm{CS} 04-16,67 \%$ \\
\hline & AS01 - 16,67\% \\
\hline Direcionador: & Encontro preparado \\
\hline Atividade: & Realizar o encontro \\
\hline Tempo(h): & 21 \\
\hline \multirow[t]{6}{*}{ Recursos: } & GE01 - 9,52\% \\
\hline & GE02 - 26,19\% \\
\hline & $\mathrm{CS} 01-4,76 \%$ \\
\hline & CS02 - 40,48\% \\
\hline & $\mathrm{CS} 04-9,52 \%$ \\
\hline & $\mathrm{AS} 01-9,52 \%$ \\
\hline Direcionador: & Encontro realizado \\
\hline Atividade: & Finalizar o Blastoff \\
\hline Tempo(h): & 6 \\
\hline \multirow[t]{3}{*}{ Recursos: } & GE01 - 8,33\% \\
\hline & GE02 - 25,00\% \\
\hline & $\mathrm{CS} 02-41,67 \%$ \\
\hline
\end{tabular}


continuação

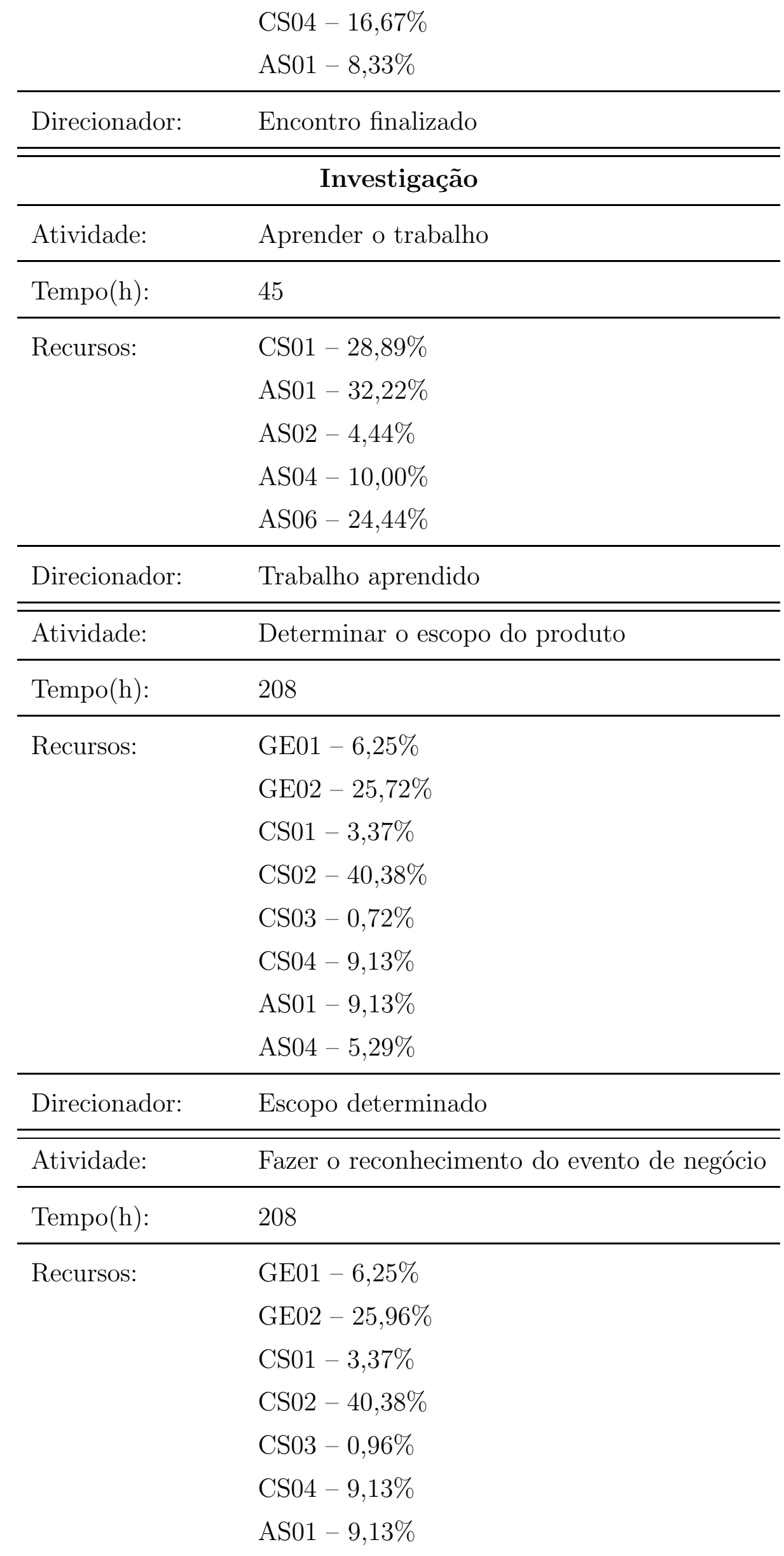


continuação

\begin{tabular}{ll} 
& AS04 - 4,81\% \\
\hline Direcionador: & Reconhecimento feito \\
\hline \hline Atividade: & Perguntar questões de clarificação \\
\hline Tempo(h): & 35 \\
\hline Recursos: & GE01 - 7,14\% \\
& GE02 - 25,71\% \\
& CS01 - 4,29\% \\
& CS02 - 40,00\% \\
& CS04 - 8,57\% \\
& AS01 - 8,57\% \\
& AS04 $-5,71 \%$ \\
\hline
\end{tabular}

Direcionador: Questões respondidas

Especificação

\begin{tabular}{ll}
\hline Atividade: & Identificar os tipos de requisitos \\
\hline Tempo(h): & 52 \\
\hline Recursos: & CS01 - 26,92\% \\
& CS03 - 21,15\% \\
& AS02 - 40,38\% \\
& AS06 - 11,54\% \\
\hline Direcionador: & Tipos identificados \\
\hline \hline Atividade: & Escrever critérios de seleção \\
\hline Tempo(h): & 35 \\
\hline Recursos: & CS01 - 28,57\% \\
& CS03 - 20,00\% \\
& AS02 - 40,00\% \\
& AS06 - 11,43\% \\
\hline Tempo(h): & Critérios escritos \\
\hline \hline Recursos: & Formalizar os requisitos \\
\hline Atividade: & CS03 - 20,77\% \\
\hline
\end{tabular}


continuação

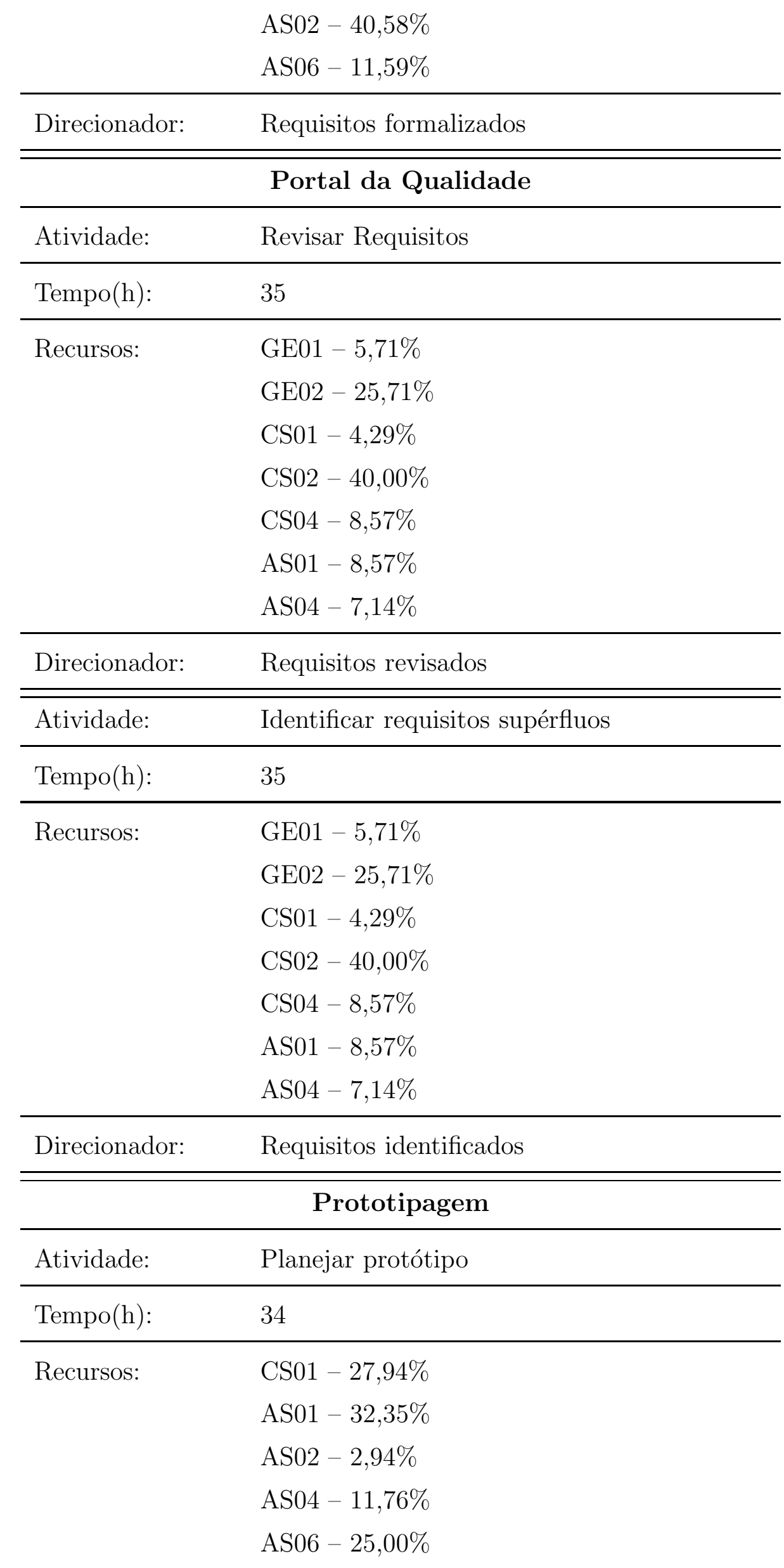


continuação

\begin{tabular}{ll}
\hline Direcionador: & Protótipo planejado \\
\hline \hline Atividade: & Construir protótipo \\
\hline Tempo(h): & 113 \\
\hline Recursos: & CS01 - 28,32\% \\
& CS04 - 0,88\% \\
& AS01 - 31,86\% \\
& AS02 - 3,54\% \\
& AS04 - 10,62\% \\
& AS06 - 24,78\% \\
\hline Direcionador: & Protótipo construído \\
\hline \hline Atividade: & Avaliar protótipo \\
\hline Tempo(h): & 34 \\
\hline Recursos: & CS01 - 27,94\% \\
& AS01 - 33,82\% \\
& AS02 - 2,94\% \\
& AS04 - 10,29\% \\
& AS06 - 25,00\% \\
\hline \hline
\end{tabular}

\section{Repensar os Requisitos}

\begin{tabular}{ll}
\hline Atividade: & Revisar o contexto da especificação \\
\hline Tempo(h): & 17 \\
\hline Recursos: & CS01 $-26,47 \%$ \\
& CS03 $-20,59 \%$ \\
& AS02 - 41,18\% \\
& AS06 $-11,76 \%$ \\
\hline Direcionador: & Contexto revisado \\
\hline \hline Atividade: & Avaliar os riscos de requisitos \\
\hline Tempo(h): & 69 \\
\hline Recursos: & GE01 $-6,52 \%$ \\
& GE02 $-26,09 \%$ \\
& CS01 $-2,90 \%$
\end{tabular}


continuação

\begin{tabular}{ll} 
& CS02 - 40,58\% \\
& CS03 - 1,45\% \\
& AS01 - 8,70\% \\
& AS04 - 4,35\% \\
\hline Direcionador: & Riscos avaliados \\
\hline \hline Atividade: & Estimar esforços \\
\hline Tempo(h): & 17 \\
\hline Recursos: & CS01 - 26,47\% \\
& CS03 - 20,59\% \\
AS02 - 41,18\% & AS06 - 11,76\% \\
\hline Direcionador: & Esforços estimados \\
\hline \hline Atividade: & Publicar a especificação revisada \\
\hline Tempo(h): & 17 \\
\hline Recursos: & CS01 - 26,47\% \\
\hline \hline Direcionador: & Especificação publicada $-20,59 \%$ \\
\hline & AS02 - 41,18\% \\
\hline
\end{tabular}

Post mortem

\begin{tabular}{ll}
\hline Atividade: & Buscar entradas para revisão \\
\hline Tempo(h): & 21 \\
\hline Recursos: & GE01 $-7,14 \%$ \\
& GE02 $-26,19 \%$ \\
& CS01 $-4,76 \%$ \\
& CS02 $-42,86 \%$ \\
& CS04 $-9,52 \%$ \\
& AS01 $-9,52 \%$ \\
\hline Direcionador: & Entradas encontradas \\
\hline \hline Atividade: & Fazer o Post mortem \\
\hline Tempo(h): & 35 \\
\end{tabular}


continuação

\begin{tabular}{|c|c|}
\hline \multirow[t]{7}{*}{ Recursos: } & GE01 - 5,71\% \\
\hline & GE02 - 25,71\% \\
\hline & CS01 - 4,29\% \\
\hline & $\mathrm{CS} 02-40,00 \%$ \\
\hline & $\mathrm{CS} 04-8,57 \%$ \\
\hline & $\mathrm{AS} 01-8,57 \%$ \\
\hline & $\mathrm{AS} 04-7,14 \%$ \\
\hline Direcionador: & Post mortem feito \\
\hline Atividade: & Construir os filtros de requisitos \\
\hline Tempo(h): & 14 \\
\hline \multirow[t]{7}{*}{ Recursos: } & GE01 - 7,14\% \\
\hline & GE02 - 25,00\% \\
\hline & $\mathrm{CS} 01-3,57 \%$ \\
\hline & $\mathrm{CS} 02-39,29 \%$ \\
\hline & $\mathrm{CS} 04-10,71 \%$ \\
\hline & AS01 - 10,71\% \\
\hline & $\mathrm{AS} 04-3,57 \%$ \\
\hline Direcionador: & Filtros construídos \\
\hline Total de Horas: & 1264 \\
\hline
\end{tabular}




\section{Apêndice B - Levantamento dos parâmetros do $\mathrm{ABC}$ das atividades do Volere (Planejado)}

\begin{tabular}{|c|c|}
\hline & Blastoff \\
\hline Atividade: & Preparar para o encontro de Blastoff \\
\hline Tempo(h): & 7 \\
\hline \multirow[t]{6}{*}{ Recursos: } & GE01 - 14,29\% \\
\hline & GE02 - 7,14\% \\
\hline & $\mathrm{CS} 02-21,43 \%$ \\
\hline & $\mathrm{CS} 04-14,29 \%$ \\
\hline & AS01 - 14,29\% \\
\hline & $\mathrm{AS} 04-13,85 \%$ \\
\hline Direcionador: & Encontro preparado \\
\hline Atividade: & Realizar o encontro \\
\hline Tempo(h): & 21 \\
\hline \multirow[t]{8}{*}{ Recursos: } & GE01 - 9,52\% \\
\hline & GE02 - 11,90\% \\
\hline & CS01 - 2,38\% \\
\hline & $\mathrm{CS} 02-23,81 \%$ \\
\hline & $\mathrm{CS} 03-2,38 \%$ \\
\hline & $\mathrm{CS} 04-23,81 \%$ \\
\hline & AS01 - 11,90\% \\
\hline & $\mathrm{AS} 04-13,85 \%$ \\
\hline Direcionador: & Encontro realizado \\
\hline Atividade: & Finalizar o Blastoff \\
\hline
\end{tabular}


continuação

\begin{tabular}{ll} 
Tempo(h): & 7 \\
\hline Recursos: & GE01 $-14,29 \%$ \\
& GE02 $-14,29 \%$ \\
& CS02 $-21,43 \%$ \\
& CS04 $-21,43 \%$ \\
& AS01 - 14,29\% \\
& AS04 $-13,85 \%$ \\
\hline Direcionador: & Encontro finalizado \\
\hline \hline
\end{tabular}

\section{Investigação}

\begin{tabular}{ll}
\hline Atividade: & Aprender o trabalho \\
\hline Tempo(h): & 62 \\
\hline Recursos: & CS01-17,74\% \\
& CS04 $-0,81 \%$ \\
& AS01 - 27,42\% \\
& AS02 - 3,23\% \\
& AS04 $-21,15 \%$ \\
& AS06 $-29,81 \%$ \\
\hline
\end{tabular}

Direcionador: Trabalho aprendido

\begin{tabular}{ll}
\hline \hline Atividade: & Determinar o escopo do produto \\
\hline Tempo(h): & 203 \\
\hline Recursos: & GE01 $-11,82 \%$ \\
& GE02 $-11,82 \%$ \\
& CS01 $-3,20 \%$ \\
& CS02 $-23,65 \%$ \\
& CS03 $-1,23 \%$ \\
& CS04 $-23,15 \%$ \\
& AS01 $-11,08 \%$ \\
& AS04 $-13,85 \%$ \\
\hline Direcionador: & Escopo determinado \\
\hline \hline Atividade: & Fazer o reconhecimento do evento de negócio \\
\hline Tempo(h): & 203 \\
\hline
\end{tabular}


continuação

\begin{tabular}{|c|c|}
\hline \multirow[t]{8}{*}{ Recursos: } & GE01 - 11,82\% \\
\hline & GE02 - 11,82\% \\
\hline & CS01 - 3,20\% \\
\hline & $\mathrm{CS} 02-23,65 \%$ \\
\hline & CS03-1,23\% \\
\hline & CS04 - 23,15\% \\
\hline & AS01 - 11,33\% \\
\hline & AS04-13,85\% \\
\hline Direcionador: & Reconhecimento feito \\
\hline Atividade: & Perguntar questões de clarificação \\
\hline Tempo(h): & 34 \\
\hline \multirow[t]{8}{*}{ Recursos: } & GE01-11,76\% \\
\hline & GE02 - 11,76\% \\
\hline & CS01 - 2,94\% \\
\hline & $\mathrm{CS} 02-23,53 \%$ \\
\hline & $\mathrm{CS} 03-1,47 \%$ \\
\hline & $\mathrm{CS} 04-23,53 \%$ \\
\hline & AS01 - 11,76\% \\
\hline & $\mathrm{AS} 04-13,85 \%$ \\
\hline Direcionador: & Questões respondidas \\
\hline
\end{tabular}

\section{Especificação}

\begin{tabular}{ll}
\hline Atividade: & Identificar os tipos de requisitos \\
\hline Tempo(h): & 68 \\
\hline Recursos: & CS01 $-18,38 \%$ \\
& CS03 - 33,82\% \\
& AS02 - 33,09\% \\
& AS06 - 14,86\% \\
\hline Direcionador: & Tipos identificados \\
\hline \hline Atividade: & Escrever critérios de seleção \\
\hline Tempo(h): & 45 \\
\hline Recursos: & CS01 - 17,78\% \\
& CS03 - 33,33\%
\end{tabular}


continuação

\begin{tabular}{|c|c|}
\hline & $\begin{array}{l}\text { AS02 - 33,33\% } \\
\text { AS06 - 14,86\% }\end{array}$ \\
\hline Direcionador: & Critérios escritos \\
\hline Atividade: & Formalizar os requisitos \\
\hline Tempo(h): & 270 \\
\hline \multirow[t]{4}{*}{ Recursos: } & CS01 - 18,15\% \\
\hline & $\mathrm{CS} 03-33,70 \%$ \\
\hline & AS02-33,33\% \\
\hline & AS06 - 14,86\% \\
\hline \multirow[t]{2}{*}{ Direcionador: } & Requisitos formalizados \\
\hline & Portal da Qualidade \\
\hline Atividade: & Revisar Requisitos \\
\hline Tempo(h): & 34 \\
\hline \multirow[t]{8}{*}{ Recursos: } & GE01 - 11,76\% \\
\hline & GE02 - 11,76\% \\
\hline & CS01 - 2,94\% \\
\hline & $\mathrm{CS} 02-23,53 \%$ \\
\hline & $\mathrm{CS} 03-1,47 \%$ \\
\hline & $\mathrm{CS} 04-23,53 \%$ \\
\hline & AS01 - 11,76\% \\
\hline & $\mathrm{AS} 04-13,85 \%$ \\
\hline Direcionador: & Requisitos revisados \\
\hline Atividade: & Identificar requisitos supérfluos \\
\hline Tempo(h): & 34 \\
\hline \multirow[t]{8}{*}{ Recursos: } & GE01 - 11,76\% \\
\hline & GE02 - 11,76\% \\
\hline & CS01 - 2,94\% \\
\hline & $\mathrm{CS} 02-23,53 \%$ \\
\hline & $\mathrm{CS} 03-1,47 \%$ \\
\hline & $\mathrm{CS} 04-23,53 \%$ \\
\hline & AS01 - 11,76\% \\
\hline & AS04 - 13,85\% \\
\hline
\end{tabular}


continuação

\begin{tabular}{|c|c|}
\hline Direcionador: & Requisitos identificados \\
\hline & Prototipagem \\
\hline Atividade: & Planejar protótipo \\
\hline Tempo(h): & 46 \\
\hline \multirow[t]{6}{*}{ Recursos: } & CS01 - 18,48\% \\
\hline & CS04 - 1,09\% \\
\hline & AS01 - 27,17\% \\
\hline & $\mathrm{AS} 02-3,26 \%$ \\
\hline & AS04 - 21,15\% \\
\hline & AS06 - 29,81\% \\
\hline Direcionador: & Protótipo planejado \\
\hline Atividade: & Construir protótipo \\
\hline Tempo(h): & 155 \\
\hline \multirow[t]{6}{*}{ Recursos: } & $\mathrm{CS} 01-18,06 \%$ \\
\hline & $\mathrm{CS} 04-0,65 \%$ \\
\hline & AS01 - 27,10\% \\
\hline & $\mathrm{AS} 02-3,23 \%$ \\
\hline & $\mathrm{AS} 04-21,15 \%$ \\
\hline & AS06 - 29,81\% \\
\hline Direcionador: & Protótipo construído \\
\hline Atividade: & Avaliar protótipo \\
\hline Tempo(h): & 46 \\
\hline \multirow[t]{6}{*}{ Recursos: } & CS01 - 18,48\% \\
\hline & $\mathrm{CS} 04-1,09 \%$ \\
\hline & AS01 - 27,17\% \\
\hline & $\mathrm{AS} 02-3,26 \%$ \\
\hline & AS04 - 21,15\% \\
\hline & AS06 - 29,81\% \\
\hline Direcionador: & Protótipo avaliado \\
\hline
\end{tabular}

\section{Repensar os Requisitos}

Atividade: Revisar o contexto da especificação 
continuação

\begin{tabular}{|c|c|}
\hline Tempo(h): & 23 \\
\hline \multirow[t]{4}{*}{ Recursos: } & CS01 - 17,39\% \\
\hline & $\mathrm{CS} 03-37,78 \%$ \\
\hline & $\mathrm{AS} 02-32,61 \%$ \\
\hline & AS06 - 14,86\% \\
\hline Direcionador: & Contexto revisado \\
\hline Atividade: & Avaliar os riscos de requisitos \\
\hline Tempo(h): & 68 \\
\hline \multirow[t]{8}{*}{ Recursos: } & GE01 - 11,76\% \\
\hline & GE02 - 11,76\% \\
\hline & $\mathrm{CS} 01-5,88 \%$ \\
\hline & $\mathrm{CS} 02-23,53 \%$ \\
\hline & $\mathrm{CS} 03-0,74 \%$ \\
\hline & $\mathrm{CS} 04-23,53 \%$ \\
\hline & $\mathrm{AS} 01-8,82 \%$ \\
\hline & AS04 - 13,85\% \\
\hline Direcionador: & Riscos avaliados \\
\hline Atividade: & Estimar esforços \\
\hline Tempo(h): & 23 \\
\hline \multirow[t]{4}{*}{ Recursos: } & CS01 - 17,39\% \\
\hline & $\mathrm{CS} 03-34,78 \%$ \\
\hline & AS02 - 23,61\% \\
\hline & $\mathrm{AS} 06-14,86 \%$ \\
\hline Direcionador: & Esforços estimados \\
\hline Atividade: & Publicar a especificação revisada \\
\hline Tempo(h): & 23 \\
\hline \multirow[t]{4}{*}{ Recursos: } & CS01 - 17,39\% \\
\hline & $\mathrm{CS} 03-30,43 \%$ \\
\hline & AS02 - 32,61\% \\
\hline & AS06 - 14,86\% \\
\hline Direcionador: & Especificação publicada \\
\hline
\end{tabular}


continuação

\section{Post mortem}

\begin{tabular}{|c|c|}
\hline Atividade: & Buscar entradas para revisão \\
\hline Tempo(h): & 20 \\
\hline \multirow[t]{7}{*}{ Recursos: } & GE01 - 12,50\% \\
\hline & GE02 - 12,50\% \\
\hline & $\mathrm{CS} 01-2,50 \%$ \\
\hline & $\mathrm{CS} 02-22,50 \%$ \\
\hline & $\mathrm{CS} 04-22,50 \%$ \\
\hline & $\mathrm{AS} 01-12,50 \%$ \\
\hline & $\mathrm{AS} 04-13,85 \%$ \\
\hline Direcionador: & Entradas encontradas \\
\hline Atividade: & Fazer o Post mortem \\
\hline Tempo(h): & 34 \\
\hline \multirow[t]{8}{*}{ Recursos: } & GE01 - 11,76\% \\
\hline & GE02 - 11,76\% \\
\hline & $\mathrm{CS} 01-2,94 \%$ \\
\hline & $\mathrm{CS} 02-23,53 \%$ \\
\hline & $\mathrm{CS} 03-1,47 \%$ \\
\hline & $\mathrm{CS} 04-23,53 \%$ \\
\hline & AS01 - 11,76\% \\
\hline & $\mathrm{AS} 04-13,85 \%$ \\
\hline Direcionador: & Post mortem feito \\
\hline Atividade: & Construir os filtros de requisitos \\
\hline Tempo(h): & 14 \\
\hline \multirow[t]{7}{*}{ Recursos: } & GE01 - 10,71\% \\
\hline & GE02 - 10,71\% \\
\hline & $\mathrm{CS} 01-3,57 \%$ \\
\hline & $\mathrm{CS} 02-25,00 \%$ \\
\hline & $\mathrm{CS} 04-25,00 \%$ \\
\hline & AS01 - 10,71\% \\
\hline & $\mathrm{AS} 04-13,85 \%$ \\
\hline Direcionador: & Filtros construídos \\
\hline
\end{tabular}


Apêndice B - Levantamento dos parâmetros do ABC das atividades do Volere (Planejado) 142

continuação

Total de Horas: 1440 


\section{Apêndice C - Levantamento dos parâmetros do $\mathrm{ABC}$ das atividades do Volere (Novo projeto)}

\begin{tabular}{|c|c|}
\hline \multicolumn{2}{|r|}{ Blastoff } \\
\hline Atividade: & Preparar para o encontro de Blastoff \\
\hline Tempo(h): & 10 \\
\hline \multirow[t]{2}{*}{ Recursos: } & GE01 - 50,00\% \\
\hline & AN01 - 50,00\% \\
\hline Direcionador: & Encontro preparado \\
\hline Atividade: & Realizar o encontro \\
\hline Tempo(h): & 12 \\
\hline \multirow[t]{2}{*}{ Recursos: } & GE01 - 50,00\% \\
\hline & AN01 - 50,00\% \\
\hline Direcionador: & Encontro realizado \\
\hline Atividade: & Finalizar o Blastoff \\
\hline Tempo(h): & 10 \\
\hline \multirow[t]{2}{*}{ Recursos: } & GE01 - 50,00\% \\
\hline & AN01 - 50,00\% \\
\hline Direcionador: & Encontro finalizado \\
\hline \multicolumn{2}{|r|}{ Investigação } \\
\hline Atividade: & Aprender o trabalho \\
\hline Tempo(h): & 20 \\
\hline Recursos: & AN01 - 50,00\% \\
\hline
\end{tabular}




\begin{tabular}{ll} 
& AS01 $-50,00 \%$ \\
\hline Direcionador: & Trabalho aprendido \\
\hline \hline Atividade: & Determinar o escopo do produto \\
\hline Tempo(h): & 16 \\
\hline Recursos: & AN01 - 75,00\% \\
\hline Direcionador: & Escopo determinado $-25,00 \%$ \\
\hline \hline Atividade: & Fazer o reconhecimento do evento de negócio \\
\hline Tempo(h): & 24 \\
\hline Recursos: & AN01 - 100,00\% \\
\hline Direcionador: & Reconhecimento feito \\
\hline \hline Atividade: & Perguntar questões de clarificação \\
\hline Tempo(h): & 12 \\
\hline Recursos: & AN01 - 100,00\% \\
\hline Direcionador: & Questões respondidas \\
\hline \hline
\end{tabular}

\section{Especificação}

\begin{tabular}{ll}
\hline Atividade: & Identificar os tipos de requisitos \\
\hline Tempo(h): & 6 \\
\hline Recursos: & AN01 - 16,67\% \\
& AS01 - 83,33\% \\
\hline Direcionador: & Tipos identificados \\
\hline \hline Atividade: & Escrever critérios de seleção \\
\hline Tempo(h): & 4 \\
\hline Recursos: & AN01 - 25,00\% \\
\hline Direcionador: & AS01 - $75,00 \%$ \\
\hline \hline Atividade: & Formalizar os requisitos \\
\hline Tempo(h): & 28 \\
\hline
\end{tabular}


continuação

\begin{tabular}{|c|c|}
\hline Recursos: & AS01 - 100,00\% \\
\hline Direcionador: & Requisitos formalizados \\
\hline & Portal da Qualidade \\
\hline Atividade: & Revisar Requisitos \\
\hline Tempo(h): & 8 \\
\hline Recursos: & AN01 - 50,00\% \\
\hline & AS01 - 50,00\% \\
\hline Direcionador: & Requisitos revisados \\
\hline Atividade: & Identificar requisitos supérfluos \\
\hline Tempo(h): & 12 \\
\hline Recursos: & AN01 - 50,00\% \\
\hline & AS01 - 50,00\% \\
\hline Direcionador: & Requisitos identificados \\
\hline & Prototipagem \\
\hline Atividade: & Planejar protótipo \\
\hline Tempo(h): & 4 \\
\hline Recursos: & AN01 - 25,00\% \\
\hline & AS01 - 75,00\% \\
\hline Direcionador: & Protótipo planejado \\
\hline Atividade: & Construir protótipo \\
\hline Tempo(h): & 22 \\
\hline Recursos: & AS01 - 100,00\% \\
\hline Direcionador: & Protótipo construído \\
\hline Atividade: & Avaliar protótipo \\
\hline Tempo(h): & 4 \\
\hline Recursos: & AN01 - 25,00\% \\
\hline & $\mathrm{AS} 01-75,00 \%$ \\
\hline Direcionador: & Protótipo avaliado \\
\hline
\end{tabular}


continuação

\section{Repensar os Requisitos}

\begin{tabular}{ll}
\hline Atividade: & Revisar o contexto da especificação \\
\hline Tempo(h): & 8 \\
\hline Recursos: & AN01 - 25,00\% \\
& AS01 - 75,00\% \\
\hline Direcionador: & Contexto revisado \\
\hline \hline Atividade: & Avaliar os riscos de requisitos \\
\hline Tempo(h): & 8 \\
\hline Recursos: & GE01 - 25,00\% \\
& AN01 - 37,50\% \\
\hline Direcionador: & Riscos avaliados $-37,50 \%$ \\
\hline \hline Atividade: & Estimar esforços \\
\hline Tempo(h): & 16 \\
\hline Recursos: & GE01 - 25,00\% \\
\hline Direcionador: & Esforços estimados $-37,50 \%$ \\
\hline \hline
\end{tabular}

\begin{tabular}{ll}
\hline \hline Atividade: & Publicar a especificação revisada \\
\hline Tempo(h): & 16 \\
\hline Recursos: & AN01 - $25,00 \%$ \\
& AS01 - 75,00\% \\
\hline Direcionador: & Especificação publicada \\
\hline \hline Atividade: & Pust mortem \\
\hline Tempo(h): & 4 \\
\hline Recursos: & GE01 - 100,00\% \\
\hline Direcionadradas para revisão & Entradas encontradas \\
\hline \hline Atividade: & Fazer o Post mortem \\
\hline
\end{tabular}


continuação

\begin{tabular}{ll} 
Tempo(h): & 16 \\
\hline Recursos: & GE01 $-25,00 \%$ \\
& AN01 $-75,00 \%$ \\
\hline Direcionador: & Post mortem feito \\
\hline \hline Atividade: & Construir os filtros de requisitos \\
\hline Tempo(h): & 10 \\
\hline Recursos: & AN01 - 50,00\% \\
\hline Direcionador: & Filtros construídos $-50,00 \%$ \\
\hline \hline Atividade: & Gerenciar Processo \\
\hline Tempo(h): & 30 \\
\hline Recursos: & GE01 - 100,00\% \\
\hline Direcionador: & Processo Gerenciado \\
\hline \hline Total de Horas: & $\mathbf{3 0 0}$ \\
\hline
\end{tabular}

